Prepared in cooperation with the Bureau of Land Management

Protocol for Route Restoration in California's Desert Renewable Energy Conservation Plan Area

Techniques and Methods 2-A17

- U.S. Department of the Interior

U.S. Geological Survey. 
Cover: Recovering road restoration site in the west Mojave Desert during a year of above average rainfall, resulting in abundant annual vegetation. The site is located near the Ridgecrest Field Office, Desert District, California Bureau of Land Management. Photograph taken by Lesley DeFalco, U.S. Geological Survey, April 5, 2005. 


\section{Protocol for Route Restoration in California's Desert Renewable Energy Conservation Plan Area}

By Todd C. Esque, Ka-Voka R. Jackson, Alexandrea M. Rice, Jeffery K. Childers, Caroline S. Woods, Amy Fesnock-Parker, Andrew C. Johnson, Lauren J. Price, Kristin E. Forgrave, Sara J. Scoles-Sciulla, and Lesley A. DeFalco

Prepared in cooperation with the Bureau of Land Management

Techniques and Methods 2-A17 


\section{U.S. Geological Survey, Reston, Virginia: 2021}

For more information on the USGS - the Federal source for science about the Earth, its natural and living resources, natural hazards, and the environment—visit https://www.usgs.gov or call 1-888-ASK-USGS.

For an overview of USGS information products, including maps, imagery, and publications, visit https://store.usgs.gov/.

Any use of trade, firm, or product names is for descriptive purposes only and does not imply endorsement by the U.S. Government.

Although this information product, for the most part, is in the public domain, it also may contain copyrighted materials as noted in the text. Permission to reproduce copyrighted items must be secured from the copyright owner.

Suggested citation:

Esque, T.C., Jackson, K.R., Rice, A.M., Childers, J.K., Woods, C.S., Fesnock-Parker, A., Johnson, A.C., Price, L.J., Forgrave, K.E., Scoles-Sciulla, S.J., and DeFalco, L.A., 2021, Protocol for route restoration in California's desert renewable energy conservation plan area: U.S. Geological Survey Techniques and Methods 2-A17, 60 p., https://doi.org/10.3133/tm2A17.

ISSN 2328-7055 (online) 


\section{Acknowledgments}

We thank Peg Margolias and Russell A. Scofield of the United States Department of the Interior, Bureau of Land Management, California, for contributing to the design and reviewing the protocol. We also thank the restoration practitioners at District offices and field stations across the Bureau of Land Management in California for their participation in questionnaires and workshops that guided our work on the protocol. We appreciate the review and shared ideas from the United States Department of the Interior, Bureau of Land Management-National Operations Center, Assessment, Inventory, and Monitoring team, including Aleta Nafus, Sarah Burnett, and Emily Kachergis. 



\section{Contents}

Acknowledgments ……...................................................................................................................

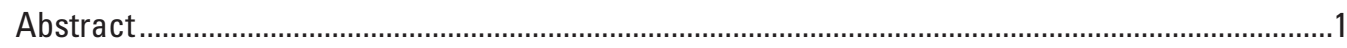

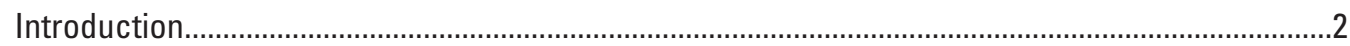

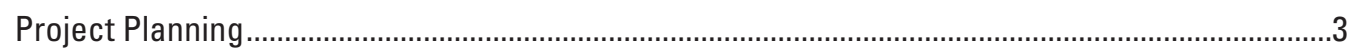

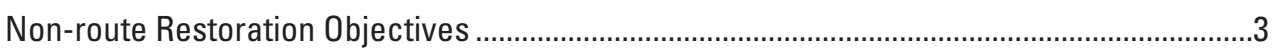

Monitoring Design ..........................................................................................................

Paired Restoration Plots and Reference Plots ……..............................................................

Monitoring Frequency.........................................................................................................

Project Timeline..............................................................................................................

Data Management—Data Input, Quality Assurance, Quality Control, Archiving,

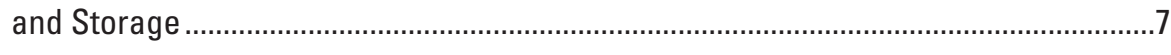

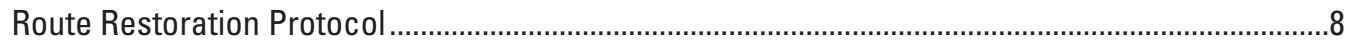

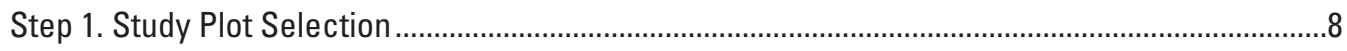

Step 1. A. Identify Target Polygon .....................................................................................

Step 1. B. Identify All Roadheads .........................................................................................

Step 1. C. Identify a Paired Reference Plot ………………………………………............

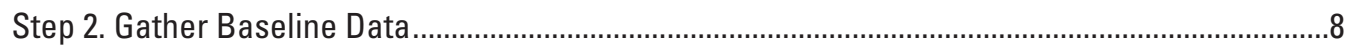

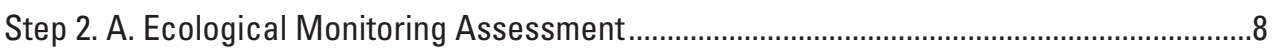

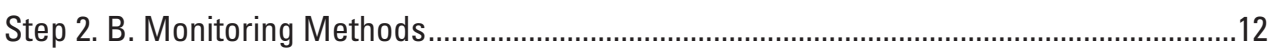

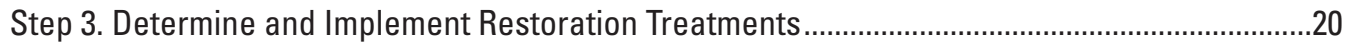

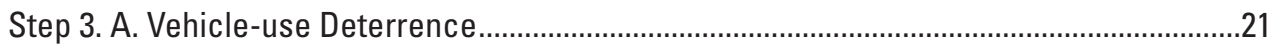

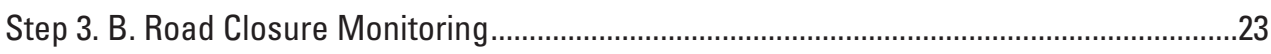

Step 3. C. Ecological Restoration Treatments ......................................................................24

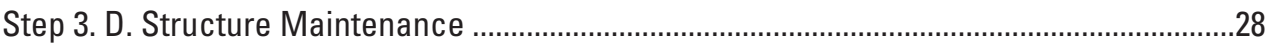

Step 4. Measure and Evaluate Treatment Effectiveness ...........................................................28

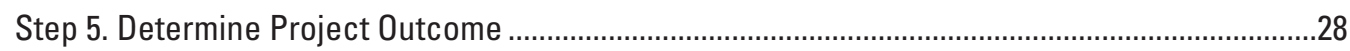

Step 5. A. Aerial Imagery Evaluation ................................................................................2

Step 5. B. Ecological Function Evaluation Guidelines ………….........................................2

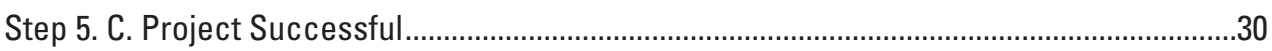

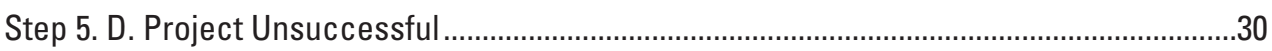

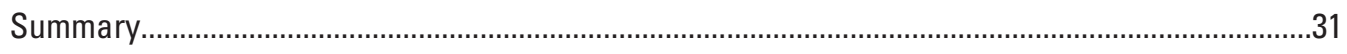

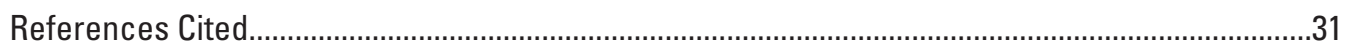

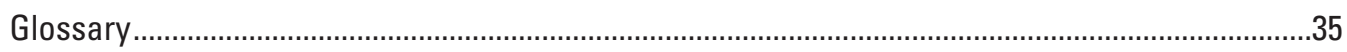

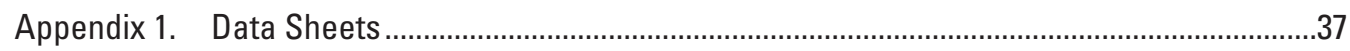

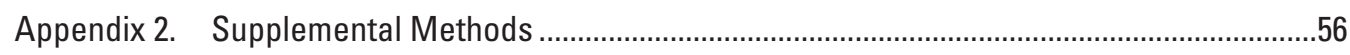




\section{Figures}

1. Photograph showing an example of the roadhead position at the junction of an

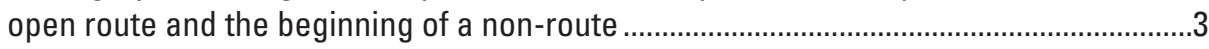

2. Map showing monitoring design.

3. Photographs showing examples of photo board and monitoring site condition photographs recorded on a route restoration plot.

4. Photograph showing the line-point-intercept transects that start at the closed route/non-route roadhead, are centered on the most-disturbed tread, and maintain that functional position, in-line with the non-route curvature.

5. Photograph showing an employee properly aligning a pin-flag to the transect line while conducting the line-point intercept method

6. Photographs showing an example of a belt transect on a single-track disturbance centered on the tread and perpendicular to the line-point-intercept transect and centered on the most damaged tread of a double track road, with the quadrat tape extending from one tread toward the median of the road

7. Image showing canopy gap that is performed by recording the beginning and end of where a plant intercepts or touches the line along the transect and covers more than 50 percent of 3 centimeters consecutively......

8. Photographs showing the process of adding roughly 25 grams of soil to the palm of your hand and then adding water to break down soil aggregates and manipulate the soil to determine clay content .........................................16

9. Diagram showing manual soil texture determination........................................................17

10. Photograph showing bulk density pit excavation method.............................................18

11. Photograph showing a small soil fragment roughly the same size as the tip of the scoop.

12. Photograph showing the soil stability test kit..............................................................

13. Photograph showing dead branches and other native plant material ...........................21

14. Photograph showing the rock scatter restoration method used to disguise

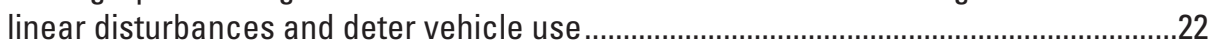

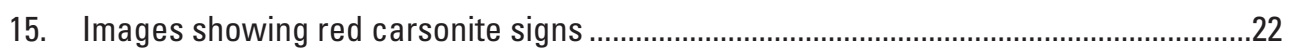

16. Photographs showing barriers such as wooden gates and boulders can be used to prevent vehicle access to restricted areas - possibly in combination

17. Photographs showing harvester ants burrowing in compacted roadbed and trailing to collect seed and a wind scorpion burrowing into the tread of a compacted roadbed

18. Images showing comparison of National Agriculture Imagery Program imagery of a roadhead for a treated and closed non-route in comparison with an open route at the 1:10,000 scale and a field photograph from the roadhead of the same closed and open routes 


\section{Tables}

1. Ecosystem indicators and monitoring methods for restoration of non-routes ..................6

2. Timeline for route restoration ........................................................................................

3. Descriptions for assigning a visibility classification to a plot .............................................10

4. Descriptions for assigning the erosion classification to a plot .........................................11

5. Surface substrate grain size classifications.......................................................................13

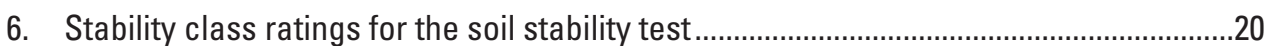

7. Restoration Action Decision Tree ....................................................................................20

8. Erosion Control Decision Tree ..........................................................................................20

9. Use these restoration outcome criteria to determine if a polygon meets the criteria to be considered successfully restored or on a positive trajectory toward success.

\section{Conversion Factors}

International System of Units to U.S. customary units

\begin{tabular}{lcl}
\hline \multicolumn{1}{c}{ Multiply } & By & \multicolumn{1}{c}{ To obtain } \\
\hline centimeter $(\mathrm{cm})$ & 0.3937 & inch (in.) \\
millimeter $(\mathrm{mm})$ & 0.03937 & inch (in.) \\
meter $(\mathrm{m})$ & 3.281 & foot $(\mathrm{ft})$ \\
meter $(\mathrm{m})$ & 1.094 & yard $(\mathrm{yd})$ \\
\hline & Area & \\
\hline square meter $\left(\mathrm{m}^{2}\right)$ & 0.0002471 & acre \\
square meter $\left(\mathrm{m}^{2}\right)$ & 10.76 & square foot $\left(\mathrm{ft}^{2}\right)$ \\
\hline & Volume & \\
\hline liter $(\mathrm{L})$ & 33.81402 & ounce, fluid (fl. oz) \\
liter $(\mathrm{L})$ & 2.113 & pint (pt) \\
liter $(\mathrm{L})$ & 1.057 & quart $(\mathrm{qt})$ \\
liter $(\mathrm{L})$ & 0.2642 & gallon $(\mathrm{gal})$ \\
cubic centimeter $\left(\mathrm{cm}^{3}\right)$ & 0.06102 & cubic inch (in $\left.{ }^{3}\right)$ \\
liter $(\mathrm{L})$ & 61.02 & cubic inch (in $\left.{ }^{3}\right)$ \\
\hline & Mass & \\
\hline gram $(\mathrm{g})$ & 0.03527 & ounce, avoirdupois $(\mathrm{oz})$ \\
\hline & Density & \\
\hline gram per cubic centimeter $\left(\mathrm{g} / \mathrm{cm}^{3}\right)$ & 62.4220 & pound per cubic foot $\left(\mathrm{lb} / \mathrm{ft}^{3}\right)$ \\
\hline
\end{tabular}

Temperature in degrees Celsius $\left({ }^{\circ} \mathrm{C}\right)$ may be converted to degrees Fahrenheit $\left({ }^{\circ} \mathrm{F}\right)$ as follows:

$$
{ }^{\circ} \mathrm{F}=\left(1.8 \times{ }^{\circ} \mathrm{C}\right)+32 .
$$




\section{Abbreviations}

$\begin{array}{ll}\text { AIM } & \text { Assessment, Inventory, and Monitoring Strategy } \\ \text { BLM } & \text { Bureau of Land Management } \\ \text { BSC } & \text { biological soil crust } \\ \text { DRECP } & \text { Desert Renewable Energy Conservation Plan } \\ \text { FO } & \text { Field Office } \\ \text { GIS } & \text { geographic information system } \\ \text { LOS } & \text { line of sight } \\ \text { LPI } & \text { line-point intercept } \\ \text { LUPA } & \text { Land Use Plan Amendment } \\ \text { NAIP } & \text { National Agriculture Imagery Program } \\ \text { OHV } & \text { off-highway vehicle } \\ \text { OA/QC } & \text { quality assurance/quality control } \\ \text { SDARTT } & \text { Surface Disturbance Analysis Reclamation Tracking Tool } \\ \text { USGS } & \text { U.S. Geological Survey } \\ \text { VM } & \text { vertical mulch }\end{array}$




\title{
Protocol for Route Restoration in California's Desert Renewable Energy Conservation Plan Area
}

\author{
By Todd C. Esque ${ }^{1}$, Ka-Voka R. Jackson 1,2, Alexandrea M. Rice ${ }^{3,1}$, Jeffery K. Childers ${ }^{4}$, Caroline S. Woods ${ }^{5}$, \\ Amy Fesnock-Parker ${ }^{6}$, Andrew C. Johnsonn ${ }^{7}$ Lauren J. Price ${ }^{8}$, Kristin E. Forgrave ${ }^{1}$, Sara J. Scoles-Sciulla ${ }^{1}$, and \\ Lesley A. DeFalco ${ }^{1}$
}

\begin{abstract}
In the deserts of the Southwestern United States, increased off-highway vehicle use can lead to widespread vehicular damage to desert ecosystems. As the popularity and intensity of vehicle use on public lands continues, the Bureau of Land Management (BLM) is challenged to manage the routes used by recreationists while minimizing activity beyond designated routes and mitigating environmental impacts. Ecosystem function and habitat quality can be degraded by vehicle activities, especially when the activities are occurring outside authorized routes or authorized open areas. Restoration mitigates damage to soils and vegetation;
\end{abstract}

${ }^{1}$ U.S. Geological Survey, Western Ecological Research Center, 160 N. Stephanie St., Henderson, NV 89074.

${ }^{2}$ Restoration Projects Manager, Middle Fork Willamette Watershed Council, ka-voka@middleforkwillamette.org.

${ }^{3}$ Department of Natural Resources, 226 Mann Dr, Ithaca, NY 14853 , Cornell University, Ithaca, New York, USA.

${ }^{4}$ Associate Field Manager, Resources and Administration Branch Chief, Barstow Field Office, Department of the Interior, Region 8 \& 10, 2601 Barstow Road, Barstow, CA 92311.

5Planning \& Environmental Coordinator, Bureau of Land Management, Ridgecrest Field Office, California Desert District, Department of the Interior, Region 8 \& 10, 300 S. Richmond Rd., Ridgecrest, CA 93555.

${ }^{6}$ Wildlife and Listed Species Lead, California State Office, Bureau of Land Management.

${ }^{7}$ Geographer, USDI Bureau of Land Management, Eagle Lake Field Office, 2550 Riverside Drive, Susanville, CA 96130.

${ }^{8}$ National Operations Center, Bureau of Land Management, Denver Federal Center, Building 50, Denver, Colorado 80225-0047. however, methods vary across the desert, results appear to be inconsistent, and standardized monitoring plans do not exist. The Desert Renewable Energy Conservation Plan Land Use Plan Amendment to the California Desert Conservation Area Land Use Plan identified the need for, and directed implementation of, standardized monitoring of restoration, which includes minimizing surface disturbance to agency prescribed levels in areas of critical environmental concern and on California Desert National Conservation Lands. To assist the BLM in implementing the Desert Renewable Energy Conservation Plan Land Use Plan Amendment, we define ecological restoration as the process of halting or minimizing future degradation while simultaneously assisting the recovery of ecosystem function and community composition in relation to intact reference sites. The monitoring strategies provided in this protocol are used to restore degraded ecosystems after use of non-routes has ceased (non-designated routes or vehicle-caused linear disturbances) by applying techniques to improve edaphic properties, hydrologic function, and biotic community composition. This protocol also provides criteria that can be used to distinguish the status of non-routes and land parcels as "restored" or "disturbed." This protocol was developed by the U.S. Geological Survey, in collaboration with BLM restoration practitioners, to identify standard restoration methods and establish criteria to determine when restoration is achieved. This protocol also develops new methods to increase restoration rates and successes on public lands in the southern California deserts. BLM's long-term implementation plan for the evaluation of road restoration described in this report is to transition toward managing the work, including developing the workforce and long-term storage and management of the data during the next several years. This report is intended to be regularly updated as the program develops. 


\section{Introduction}

The Bureau of Land Management (BLM) administers almost 11 million acres of public land in the California Desert District of southern California. Off-highway vehicle (OHV) use has increased in recent years, and advances in vehicle technology allow the public to access and travel on more terrain than ever before. However, vehicle-related activities cause damage to desert ecosystems and disrupt natural recovery processes that typically require decades to centuries without management intervention (Belnap and Warren, 2002; Webb, 2002). Vehicle use across landscapes can fragment habitats and severely damage vegetation, reduce biodiversity, destabilize or erode soil surfaces, and alter hydrological processes (Bury and others, 1977; Webb and Wilshire, 1983; Ouren and others, 2007). Land management agencies seek ecological restoration procedures that halt or minimize future degradation while simultaneously assisting the recovery of ecosystem function and plant community composition in relation to intact reference sites.

The BLM's Desert Renewable Energy Conservation Plan (DRECP) Land Use Plan Amendment (LUPA) streamlines procedures for renewable energy development within development focus areas (DFAs), while conserving natural and cultural resources and providing recreational opportunities to the public on BLM land (DRECP, BLM, 2016). The DRECP designates 3,956,000 acres as California Desert National Conservation Lands ${ }^{9}$, and the LUPA provides a cap of 1 percent as the upper limit of disturbance allowed within each unit of these conservation lands.

Restoration planning and implementation of management actions required to achieve the "restored" status for public lands according to the DRECP LUPA amendment receive public scrutiny from development interests that are required to invest in public lands because of their actions (for example, planning minimization or mitigation) and by other groups supporting additional management actions to protect public lands and resources (for example, comments from user groups in the DRECP, BLM, 2016). The DRECP obligates the BLM to provide standards for implementing and monitoring restoration methods and to define the criteria by which land parcels will be deemed "restored." To accomplish that goal, the U.S. Geological Survey (USGS) and BLM adapted a definition of restoration and developed a protocol for actions to gauge restoration success. The definition for ecological restoration for route restoration is "the process of halting or minimizing future degradation from use as a route while simultaneously assisting the recovery of ecosystem function and community composition in relation to reference sites" (adapted from Society for Ecological Restoration International, 2004).

This protocol is designed to establish standardized ecological monitoring of road restoration sites using practical and efficacious methods. For consistency with long term BLM management goals, workflows, and protocols, we have incorporated methods from the national Assessment, Inventory, and Monitoring (AIM) Program to the greatest extent possible. These methods include technical methods, data collection, and datasheets that match the workflow and design used by the BLM to archive the data for future use (BLM, 2020). Other parts of the protocol described herein were developed through consultations with BLM restoration practitioners, members of the Society for Ecological Restoration-Southwest Chapter, public information events, other Interior and Defense bureaus, academics, and non-governmental organizations, including The Defenders of Wildlife, Transition Habitat Conservancy, and Mojave Desert Land Trust.

This protocol has three primary goals:

1. Guide implementation and evaluation of ecological restoration practices to restore non-designated routes and decommissioned routes removed from public use (hereafter collectively referred to as "non-routes") in the DRECP LUPA area.

2. Inform compliance with the DRECP LUPA amendment, which requires at least one of two criteria are met for a land parcel (polygon) to be deemed restored (see Ecological Function Evaluation Guidelines):

a. Ground disturbance from prior vehicle activity is no longer visible at 1:10,000 scale, using best available aerial imagery, or

b. Ecosystem function measured along non-route disturbances is improved.

3. Identify ecological recovery metrics that determine when non-routes meet successfully restored ecological function criteria.

4. Collect data consistent with the BLM Assessment Inventory and Monitoring (AIM) Strategy (Toevs and others, 2011) core methods wherever possible. Elements of the protocol that are not currently consistent with core methods and data flow are intended for incorporation into ancillary parts of the AIM Program to accommodate BLM (California) data storage/accessibility needs.

\footnotetext{
${ }^{9}$ Designated pursuant to Public Law 111-11 and managed as a part of the Bureau of Land Management's Natural Landscape Conservation System (NLCS).
} 
The guidelines within this protocol address ecological restoration and monitoring practices for linear disturbances made by vehicle activity on public lands administered by the California Desert District and Bishop Field Offices (within the Central California District). However, this protocol provides evidence-based criteria for determining restoration success for DRECP purposes as well as conservation of wilderness, cultural resources, and natural resources, and can be adaptively managed as needed. To deem a restoration project successful, standardized and repeatable methods of restoration implementation and monitoring address key ecosystem functions, such as edaphic properties, hydrologic function, and biotic communities in association with linear features. For our purposes of targeting linear non-route disturbances, large denuded areas (such as, OHV staging areas, mines, or camping areas) will not be considered in this protocol. Other restoration targets, such as mines and decommissioned rights of way, are also outside the scope of this protocol.

\section{Project Planning}

Ecological restoration of non-routes is unique in that these disturbances are distinctly linear and occur in particularly harsh desert environments in the California Desert District. Therefore, this non-route restoration protocol entails meticulous planning of the project structure from the development of timeline to the frequency of monitoring. These aspects are detailed in this section.

\section{Non-route Restoration Objectives}

Specific implementation and ecological monitoring objectives must be met to consider non-routes restored in accordance with these guidelines. First, we suggest that management actions implemented to treat linear disturbances caused by vehicles meet two objectives:

1. Eliminate further disturbance by discouraging vehicle travel on non-routes, and

2. Decrease non-route visibility along the line-of-sight (LOS, the distance a linear disturbance is visible on the ground from the access point of the non-route); or, if not feasible because of terrain characteristics, then reduce visibility at the immediate roadhead (where the non-route meets an open route) and extending along the non-route for greater than $77 \mathrm{~m}$ in length to accommodate ecological monitoring needs (fig. 1).

When vehicle use on restored non-routes has ceased, as determined through closure monitoring, additional objectives from ecological monitoring must be met for an area to meet the definition of "restored." These objectives include:
3. Visibility of the disturbed non-route is obscured at $1: 10,000$ scale using the best available aerial imagery, or

4. Ecosystem function (native vegetation, soil characteristics, hydrologic function) of non-routes improves to the level of the reference sites (as detailed in the "Monitoring Frequency" section).

\section{Monitoring Design}

Each BLM Field Office (FO) has unique recreation areas that experience various levels of human activity and vehicle use; therefore, we adopted land parcels called "polygons" (Ron Gartland, formerly BLM) to standardize and compare restoration outcomes across FOs. Polygons are bounded by legal open routes or, when necessary, by the boundaries of BLM and non-BLM land and roads. The network of non-routes within the polygons is the focus for restoration.

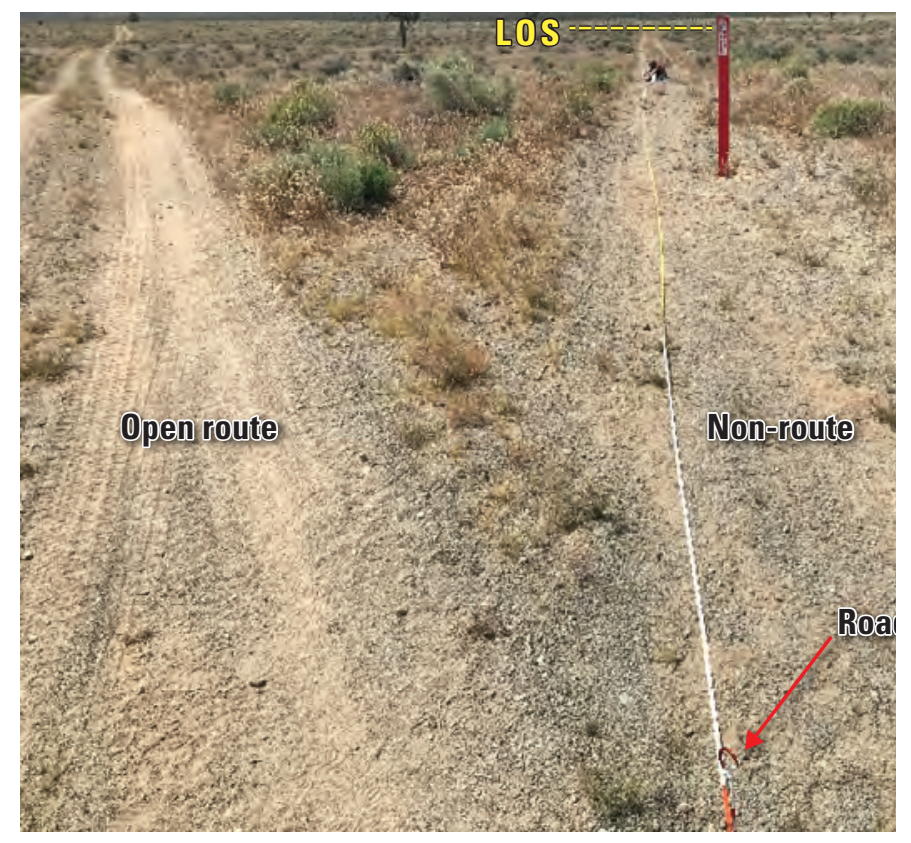

Figure 1. An example of the roadhead position at the junction of an open route (left-designated for travel by a brown carsonite route sign or the lack of a red closure sign) and the beginning of a non-route (closed to travel-designated by a red carsonite closure sign).The line-of-sight (LOS—horizontal dashed line-in yellow at the top of the figure) is the soil and vegetation disturbance on the non-route that is discernable from the vantage point of the roadhead. Photograph taken by the Western Ecological Research Center Road Restoration Team, U.S. Geological Survey, spring 2020. 
Polygons contain six or more non-routes for restoration monitoring without any legal or open access routes. Each polygon contains several restoration sites that are individually identified and within each site is a restoration plot and its paired reference plot. Restoration non-routes can be identified for work because they are visible at a 1:10,000 scale by using remotely sensed imagery (BLM, 2016). Restoration and reference plots must be greater than 77 meters (m) in length to accommodate monitoring transects and restoration activities.

Restoration success depends, first, on implementing treatments that prevent access to all non-routes within each polygon. Because the polygon is the unit for determining restoration status of land parcels, 100 percent of roadheads within a polygon must be recovered to meet the definition of a successful restoration. Limiting access preserves the integrity of the restoration treatments as a whole and promotes the natural recovery of the polygon interior. Each treated polygon initiates a 'defensible space' (Caroline Woods, BLM, oral commun., 2020; fig. 2) where roadheads have been treated around the perimeter as a minimum, but this space expands when adjacent polygons are stabilized by the cessation of vehicle incursions and likewise ecologically restored. The addition of polygons increases the area-to-perimeter ratio of the defensible space and preserves the restoration in progress.

\section{Paired Restoration Plots and Reference Plots}

Each restoration plot within a polygon will be paired with a reference plot located within $50 \mathrm{~m}$, which must be void of vehicle incursions. However, if plots free of vehicle incursions do not exist, reference plots may contain recovered incursions. Each reference plot is at least $77 \mathrm{~m}$ long, which is equal in length to restoration plots and accommodates monitoring measurements. A reference plot may be paired with multiple restoration plots under certain circumstances such as when appropriate reference areas are unavailable. However, this alternative is best avoided when possible because it can reduce statistical rigor in the experimental analyses.

The paired reference plot will be monitored concurrently with the treated restoration plot because reference plot characteristics can shift with external influences, such as weather events or new disturbance; however, the plot design accounts for regional changes by requiring the reference plot to be within $50 \mathrm{~m}$ of the restoration plot; thus decreasing the chances of occurrence on a soil ped of a different type.

\section{Monitoring Frequency}

Detecting change at sites where restoration actions occur is fundamental to understanding the degree of success and to determining when a polygon can be considered "restored" under the DRECP LUPA, and it is important to document initial condition and the post-treatment condition at standardized intervals (table 1). Important indicators of ecological recovery fall into three categories: (1) soil, (2) hydrologic, and (3) biotic indicators. Some indicators are monitored across all project sites and are termed Core Indicators based on BLM's Assessment, Inventory, and Monitoring Program (AIM; Herrick and others, 2017). Other ancillary indicators that may not be prescribed for every restoration site are monitored according to site visibility and consultation with the Restoration Action Decision Tree (see the "Monitoring Frequency" section; table 1).

There are two types of post-treatment monitoring: (1) implementation and (2) ecological. Implementation monitoring occurs within the first 3 years of installing treatments to monitor public closure (in other words, no vehicle activity), treatment integrity (structures still intact, such as vertical mulch), and initial recovery trajectories. Ecological monitoring focuses on the recovery of ecosystem function, such as soil processes (arrested wind erosion, accumulation of organics), hydrological processes (decreased velocity of surface flows, increased infiltration), and biological processes (seed bank development, plant growth, increased animal visitation; DeFalco and Scoles-Sciulla, 2013). Thus, ecological monitoring occurs over longer periods.

Recommended monitoring methods and frequencies for ecosystem indicators are separated into the biotic, soil, and hydrologic categories (table 1); however, some monitoring methods may be used to gather data for more than one indicator (for example, line-point intercept). Some methods have been adopted from the AIM protocol and others are modified or introduced de novo with appropriate justification for use. However, these data may not be comparable to other AIM plot data due to the nature of the non-route disturbances and plot setup. Notably, plot species richness is only sampled on the non-route plot (sampling area $=154$ square meters $\left[\mathrm{m}^{2}\right]$ ), whereas AIM protocol samples an entire circular plot (sampling area $=2,827.4 \mathrm{~m}^{2}$ ).

An ecological monitoring plan is important because arid lands can take years, decades, or even centuries to recover from disturbance, even with assisted recovery through active restoration in the absence of subsequent vehicular encroachment. Ecological monitoring in a polygon is performed seasonally in the first 3 years to capture annual plant cover and richness. Subsequent ecological monitoring occurs annually or biennially, preferably during the spring and fall months because intense desert summer heat and drought limit biotic activity, which could potentially bias the interpretation of results. Subsequent monitoring can be based on the expected rates of change at the site and as determined in this protocol. The planned interval for each non-route is evaluated and documented in the short-term monitoring results and planning, to assist long term planning. 


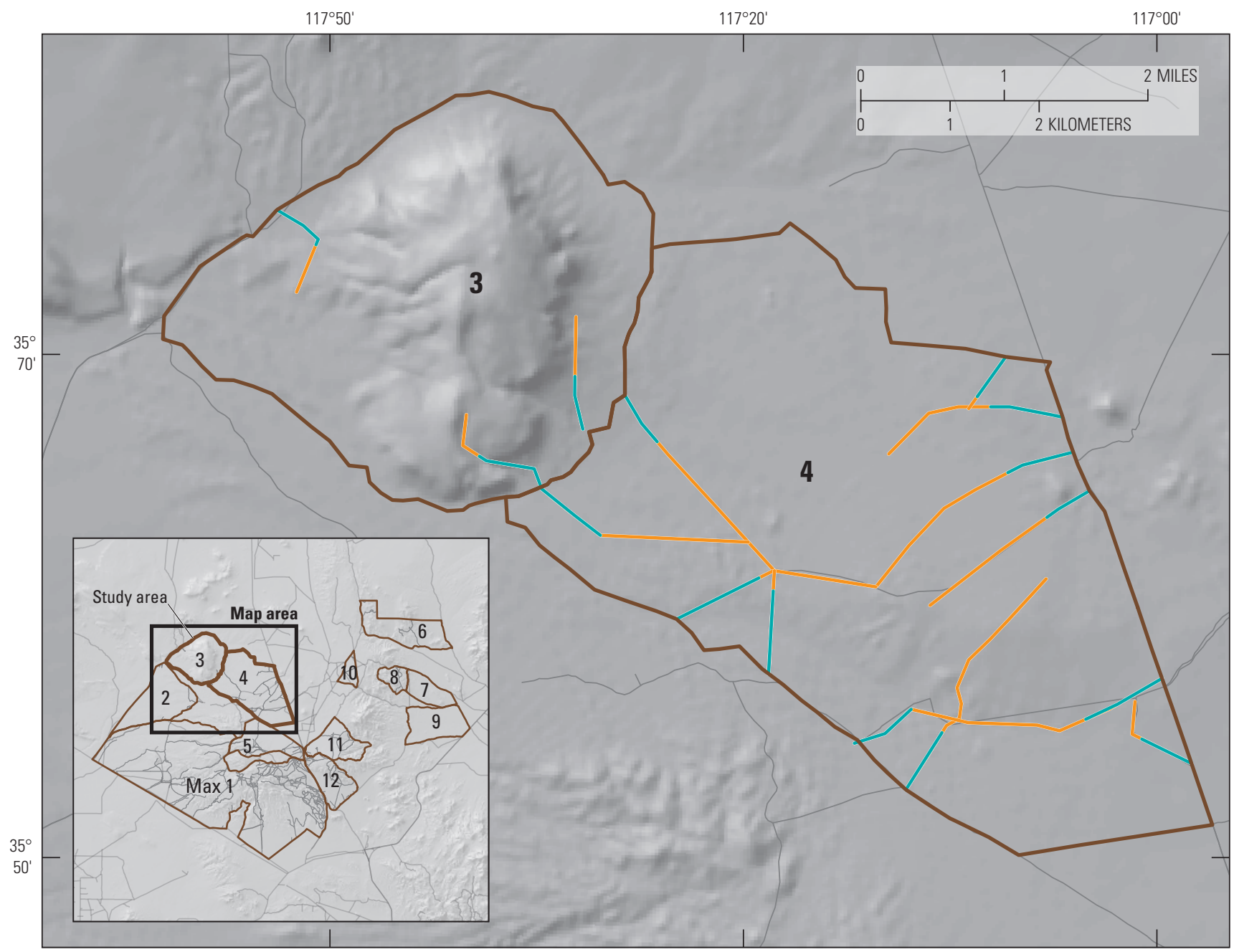

Base from U.S. Geological Survey and other Federal and State digital data, various scales:

Universal Transverse Mercator, zone 11; North American Datum of 1983

Adapted from Woods (2017)

\section{EXPLANATION}
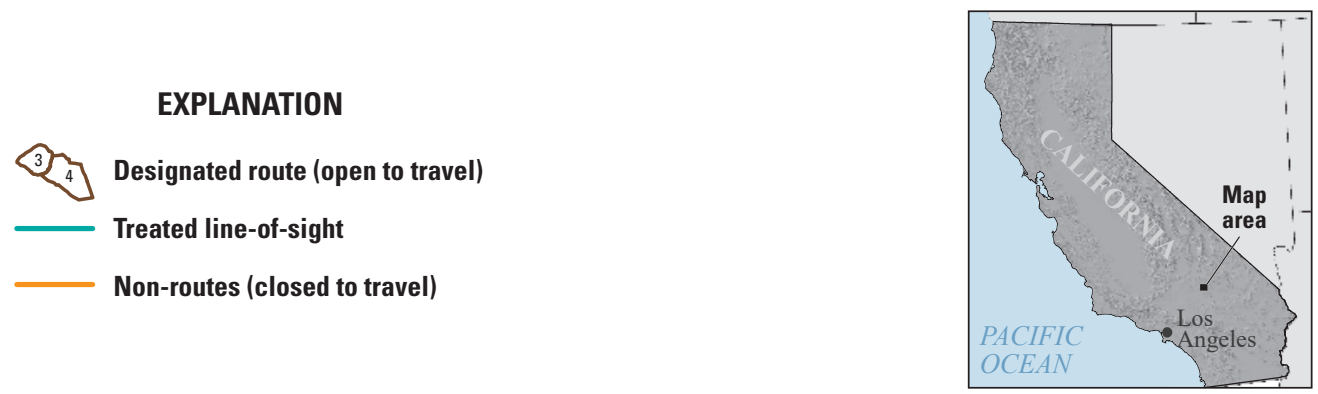

Figure 2. Monitoring design. The goal is to establish large polygons of areas that are stabilized and restored to eliminate trespass. In this example, the brown lines on the right illustrate designated routes that bound two adjacent restoration polygons (polygons 3 and 4). The gold lines represent roads under natural restoration that is facilitated by active restoration activities at all access points in the polygon (green). The roadheads and the non-routes within line-of-sight are all treated and monitored by using methods described herein (adapted from Woods, 2017). 
Table 1. Ecosystem indicators and monitoring methods for restoration of non-routes.

[Methods that use Assessment, Inventory, and Monitoring Strategy (AIM) protocols (Herrick and others, 2017) are indicated as such (AIM): $\mathrm{S}$, short-term monitoring frequency; L, long-term monitoring frequency]

\begin{tabular}{|c|c|c|}
\hline Ecosystem indicators & Measurement method(s) & Monitoring frequency \\
\hline \multicolumn{3}{|c|}{ Biotic } \\
\hline \multicolumn{3}{|c|}{ Core indicators } \\
\hline Ground cover & Line-point intercept (AIM) & Annually (S), biennially (L) \\
\hline Vegetation cover & Line-point intercept (AIM) & Annually (S), biennially (L) \\
\hline Vegetation composition & Plot-level species inventory & Annually (S), biennially (L) \\
\hline \multicolumn{3}{|c|}{ Supplemental indicators } \\
\hline Rodent mounds and burrows, ant nests, lagomorph scat & Ocular counting & Annually (S), biennially (L) \\
\hline \multicolumn{3}{|c|}{ Soil } \\
\hline \multicolumn{3}{|c|}{ Core indicators } \\
\hline Bare ground & Gap intercept (AIM) & Annually (S), biennially (L) \\
\hline Soil bulk density/ compaction & Soil core method or excavation method & Biennially (S), every 5 years (L) \\
\hline Soil aggregate stability & Soil stability test (AIM) & Biennially (S), biennially (L) \\
\hline \multicolumn{3}{|c|}{ Supplemental indicators } \\
\hline \multirow[t]{2}{*}{ Soil texture } & Texture by feel (AIM) & Once $(\mathrm{S})$, every $5-10$ years $(\mathrm{L})$ \\
\hline & Hydrometer method & Once $(\mathrm{S})$, every $5-10$ years $(\mathrm{L})$ \\
\hline \multicolumn{3}{|c|}{ Hydrologic } \\
\hline \multicolumn{3}{|c|}{ Core indicators } \\
\hline Erosion & Gap intercept (AIM); visual & Annually (S), biennially (L) \\
\hline \multicolumn{3}{|c|}{ Supplemental indicators } \\
\hline Infiltration & Infiltrometer (supplemental) & Biennially (S), every 5 years (L) \\
\hline
\end{tabular}

Monitoring intervals are treatment dependent and determined as needed by each BLM FO and their respective management objectives. For example, if the objective is to relieve soil compaction compared to the reference site without resorting to active decompaction methods, such as harrowing or ripping, then longer monitoring intervals for soil compaction could be considered rather than short term intervals so resources are not wasted, because soil properties take much longer (decades) to recover (Webb, 2002) without intervention. Treatments that result in rapid responses may require more frequent monitoring to capture the effects of the treatments through time, such as revegetation survival.

Short term monitoring (up to 2 years after restoration implementation) reveals rapid changes or effects from environmental or disturbance factors (for example, seasonal flooding event, or continued vehicle trespass); however, short term monitoring cannot determine project success alone because ecosystem function and plants could take much longer to recover and establish.

Long term monitoring ( 3 or more years after restoration implementation) captures the effects of restoration and environmental factors over time and may reveal trends in the recovery of the plot and upwards to the scale of the polygon. Long-term monitoring plans are more effective because long-term patterns or slow-acting processes may not be captured by short term monitoring. Additionally, short term monitoring may only capture a temporary status of a site, which could give a "false positive" of successful restoration or vice versa. 


\section{Project Timeline}

This project timeline outlines the sequence of site selection, treatments, implementation monitoring, ecological monitoring, and restoration evaluations. This timeline requires up to 2 years to account for short-term monitoring, depending on FO decisions, and at least 3 years to account for long-term monitoring (table 2). Both short- and long-term monitoring consist of the same monitoring techniques, but interpretation of restoration results will be dependent on the duration of monitoring. Long-term monitoring of greater than 3 years is preferred for determining restoration success because many ecosystem processes, such as vegetation recovery and soil structural changes, take multiple years for recovery (Webb, 2002). Severely degraded sites will take longer to show improvements than sites with few incursions (Webb, 2002); therefore, we suggest prioritizing routes or areas that have experienced heavy vehicle usage for long-term monitoring. The timeline incorporates a staggered start design for monitoring across years; for example, new polygons (and the non-routes within) are targeted for restoration every 2 years (1 year if funding and resources allow), whereas the previous years' polygon(s) continue to be monitored.

\section{Data Management—Data Input, Quality Assurance, Quality Control, Archiving, and Storage}

This project will generate natural resource data collected in a robust study design for analyzing landscape scale restoration success. These data are a valuable resource, and the best way to protect them is by using a sound data collection and management platform. Using this protocol, all data will be entered using the Survey 123 electronic survey forms (in testing phase; survey123.arcgis.com, accessed July 15, 2021) in coordination with the BLM. Paper datasheets that are in a compatible format with Survey 123 will accompany data collection as a paper backup in the case of electronic database failure (see appendix 1). The data management program will be designed to assist fieldworkers in collecting information accurately, and to specifications, in a relational database with standardized data formats. Managing data input is equally important, and this program requires that the input stage of data management be held to the highest standards of quality assurance/quality control (QA/QC). Archival procedures, including scanning paper data sheets for the permanent record, are imperative for data $\mathrm{QA} / \mathrm{QC}$ and reference; therefore, multiple data backup systems are essential.

When non-routes are identified, spatial data should be cross-referenced in the Surface Disturbance Analysis Reclamation Tracking Tool (SDARTT). This tool was created by the BLM and the USGS and can be used to track disturbance and reclamation spatial data (location, area) within the BLM's DRECP LUPA. If a non-route has not been previously recorded in SDARTT, relevant data can be entered into the system. More information regarding SDARTT start-up and data entry tutorials can be found at https://blm.sciencebase.gov/landing.html. A significant component of quality assurance is consistent and standardized training. Bureau of Land Management AIM training and calibration protocols ensure that data are accepted into the BLM's terrestrial monitoring database, TerrADat. To maximize success using this protocol, one crew member will have attended a BLM National AIM training within the past 3 years. However, it is preferred that all crew members attend AIM training annually. Crew calibration on core methods is another critical component of quality assurance. Calibration on the core methods before data collection begins each season is crucial. Calibration also is required monthly or when a crew enters a new ecological community (grassland, shrubland, or savannah). The detailed calibration protocol can be found on the aim.landscapetoolbox.org website (https://aim.landscapetoolbox.org/data-management-projectevaluation) within the annual data management protocol (BLM, 2020).

Table 2. Timeline for route restoration.

[This timeline is intended to stagger the start dates for monitoring so that many sites are already established at least partially representing each phase of restoration. Abbreviations: +, plus; y, year; >, greater than; QA/QC, quality assurance/quality control]

\begin{tabular}{llc}
\hline \multicolumn{1}{c}{ Year 1 } & \multicolumn{1}{c}{ Year 2 } & Actions \\
\hline & \multicolumn{1}{c}{ Years 3+ } \\
\hline Develop management goals. & Perform closure monitoring. & Continue ecological monitoring. \\
Determine short term $(2$ y) or long & Perform implementation monitoring. & Routinely perform data QA/ \\
term $(>3$ y) monitoring plan. & Perform ecological monitoring. & QC all data sets. \\
Select treatment and reference sites. & Compare with previous monitoring forms and reference & Determine project outcome \\
Determine and document restoration & site for evaluation. & based on checklist. \\
actions. & Maintain restoration structures as needed. & \\
Implement route closures. & Reimplement or adjust treatments or monitoring if & \\
Perform closure monitoring. & necessary, in response to vehicular activity levels. & \\
\hline
\end{tabular}




\section{Route Restoration Protocol}

Restoration project goals can be met using five steps: (1) select study plots, (2) gather baseline data, (3) determine and implement restoration treatments, (4) measure and evaluate treatment effectiveness, and (5) determine project outcome. Each step is critical to developing a coherent program for monitoring route restoration among BLM FOs and allowing for statistical comparison and interpretation of route restoration on the landscape.

\section{Step 1. Study Plot Selection}

The selection of the plots is determined through consultation with BLM Field Office personnel, and by evaluating Remotely Sensed Imagery (RSI), such as the National Agriculture Imagery Program (NAIP). Known locations and coordinates provided by the BLM can be used or non-routes can be identified through RSI. Boundaries for each polygon are determined and a unique identifier is assigned in the project database.

\section{Step 1. A. Identify Target Polygon}

The target polygon is identified by reviewing the SDARTT database for restoration using existing coordinates of non-routes found there or by locating new non-routes using NAIP or other updated RSI with a 1:10,000 scale. Linear disturbances that appear to originate from vehicle travel rather than natural disturbances (in other words, washes or other water erosional features; field verification is required) are targeted.

\section{Step 1. B. Identify All Roadheads}

All roadheads (coordinates and unique identification number) and the treated non-routes that intersect the polygon perimeter (geographic information system [GIS] layer with cross-references) are identified by using the Study Plot Selection Form (appendix 1) to record the following information:

1. Determine route type for each plot. Routes are classified as single-track or double-track, depending on the number of tire treads present on the route. Distinguishing between single track and double-track using remote sensing is difficult (J.J. Smith, BLM, oral commun., 2020) and should be field validated.

2. Record coordinates for the proximal and distal ends of the plot, with respect to the access road. A plot is $77 \mathrm{~m}$ in length (starting from the roadhead) and $2 \mathrm{~m}$ in width to accommodate monitoring measurements. Plot shape can vary depending on the shape of the non-route disturbance.

\section{Step 1. C. Identify a Paired Reference Plot}

A paired reference plot is identified; it is located within a 50-m distance for each restoration plot and matches vegetation community, landform, aspect, and slope. Record route characteristics on corresponding field data sheet (Study Plot Selection Form for Ecological Monitoring, appendix 1):

1. Record coordinates for the proximal and distal ends of the plot, with respect to the access road. Reference plots must be $77 \mathrm{~m}$ in length, with a matching width as the project route $(2 \mathrm{~m})$ and must be in undisturbed or considerably less-disturbed conditions. Reference plots should be straight in one direction with no curvature.

\section{Step 2. Gather Baseline Data}

Initial baseline data are collected by using the Treatment Monitoring and Ecological Monitoring forms (appendix figs. 1.4 and 1.5, respectively). These data will be used for (1) comparison between target restoration plots and reference plots, including observations of recent vehicle activity and initial ecological monitoring data and (2) comparison among pre-restoration treatment and post-restoration treatments and tracking reference plot changes over time. Study plot changes that are detected among these assessments will contribute to interpretation of project outcomes. All overlapping information between the office and field assessments will be verified for consistency (for example, office form states that the plot is on a single-track, but if it is a double-track, then the forms must be corrected). Use the corresponding Ecological Monitoring form and method-associated forms to record information. See the "Monitoring Methods" section for further instruction on assessment methods.

\section{Step 2. A. Ecological Monitoring Assessment}

The initial ecological monitoring will occur during the first field site visit. Use the following details to help complete the Ecological Monitoring form (appendix 1).

1. Confirm the plot start and end coordinates by using a Global Positioning System to record the latitude and longitude of the start of the route plot (such as the roadhead, where the route or non-route meets or intersects an authorized route) and end of the route plot. Plot length total should be $77 \mathrm{~m}$ to accommodate three 25-m transects and two 1-m buffers between transects. 

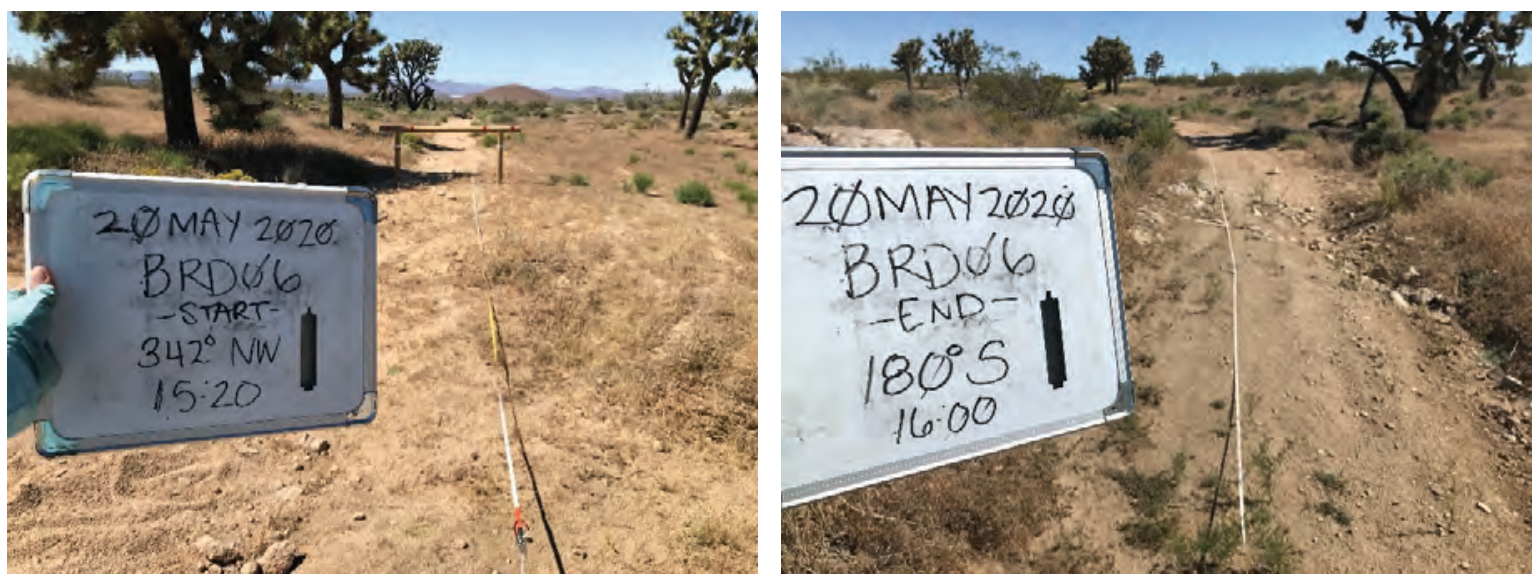

Figure 3. Examples of photo board and monitoring site condition photographs recorded on a route restoration plot. Note date, plot identification, plot position (start versus end), aspect at which the photograph was recorded, and time of day the photograph was recorded on the photo board. Inclusion of long term or permanent landmarks in the frame facilitates future success in rephotographing the site for analysis. Photographs taken by the Western Ecological Resource Center Road Restoration Team, U.S. Geological Survey, May 20, 2020.

2. Note travel time and directions on the Travel Log form (appendix 1).

3. Confirm other plot characteristics: road type (such as, single or double-track), elevation at roadhead, road plot azimuth, percent road slope, dominant surrounding vegetation, and landform.

4. Select the plot photo points and photograph by using a photo board. Minimum of two photographs: One photograph at each end of the plot and centered on the disturbance (single-track, or double-track, see fig. 3). Note the date using the format described on the forms (for example, 06MAY2020), direction the camera is facing (degrees, accounting for declination), time of day in military-style (for example, 6:00 a.m. and 6:00 p.m., will be noted as 0600 and 1800 hours; respectively), and plot identification on photo board (for example, REF01; RD01). Ensure the photo board is present in the corner of the photograph and not blocking important landmarks. The photograph should include landmarks on the horizon, which are especially useful to find the plot in subsequent years (Turner and others, 2010). Good landmarks include distinctive permanent features, power poles, cell towers, and roadbeds (Webb and others, 2010). Record photo point coordinates.

5. Record all relevant disturbances on the plot by using the Ecological Monitoring form (appendix fig. 1.5) by circling all applicable disturbances and their track types. If new disturbances (for example, since the last assessment) are present, indicate so on the form.
6. Record the visibility and erosion classification of the plot on the Ecological Monitoring form as low, moderate, or high. "Visibility" is how visible the linear disturbance is within the surrounding environment from the vantage point of the roadhead. Erosion can be caused by water (sheet, rills, gullies, alluvial deposition) or wind (aeolian deposits, blowout areas), and classification is dependent on the estimated percent cover of erosional features on a plot (tables 3-4).

7. Record relevant erosional features according to the monitoring form. Determine if the erosional feature represents a "natural feature" that is congruent with surrounding landscape or if feature is a product of the road disturbance, and then indicate the type of erosional feature according to the data sheet.

8. Record biological crust data. If present, identify crust type by using the Biological Soil Crust (BSC) ID guide (appendix 1). Note any damage to BSCs (for example, vehicle tracks on crust).

9. Record any observations of habitat use by wildlife. Indicate any sign of wildlife, including scat and bioturbation, according to the Ecological Monitoring form. Examples include burrows, dust baths, excavations, scat, tracks, carcasses, and seed caches.

10. Follow the instructions in the "Monitoring Methods" section to complete the following forms: Ecological Monitoring, Line-Point-Intercept (AIM), Belt Transect, Basal Gap, Canopy Gap (AIM), and Soil Stability (AIM; forms found in appendix 1). 
Table 3. Descriptions for assigning a visibility classification to a plot.

[Visibility should be evaluated from the roadhead of the disturbance]

\begin{tabular}{|c|c|c|}
\hline $\begin{array}{c}\text { Visibility classifi- } \\
\text { cation }\end{array}$ & Description & Example \\
\hline Low & $\begin{array}{l}\text { Linear disturbance is nearly or completely } \\
\text { camouflaged with the surrounding undisturbed } \\
\text { habitat. Characterized by vegetation matching } \\
\text { surrounding habitat in cover, limited (or } \\
\text { recovered) soil disturbance, presence of soil } \\
\text { crusts (if applicable), and presence of restoration } \\
\text { features that aid in visual disguise. Note: } \\
\text { reference plots should always be considered } \\
\text { "Low" visibility. }\end{array}$ & 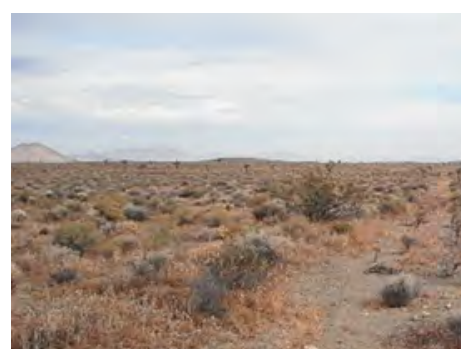 \\
\hline Moderate & $\begin{array}{l}\text { Linear disturbance is visible in the surrounding } \\
\text { undisturbed habitat, but may also have } \\
\text { characteristics of the surrounding habitat, such } \\
\text { as species presence and cover. Disturbance } \\
\text { may be characterized by less vegetative cover } \\
\text { than the surrounding habitat, noticeable soil } \\
\text { disturbance that may or may not be recent, lack } \\
\text { of or disturbed soil crusts (if applicable), and } \\
\text { presence of restoration features that aid in visual } \\
\text { disguise (for example, vertical mulch, rock } \\
\text { scatter, raking). }\end{array}$ & \\
\hline High & $\begin{array}{l}\text { Linear disturbance is strikingly visible from the } \\
\text { surrounding undisturbed habitat when viewed } \\
\text { from roadhead. Disturbance may have little to } \\
\text { no vegetation present, high soil disturbance that } \\
\text { may or may not be recent, little to no soil crusts } \\
\text { (if applicable), and excessive widening of the } \\
\text { disturbance from multiple uses. }\end{array}$ & \\
\hline
\end{tabular}


Table 4. Descriptions for assigning an erosion classification to a plot.

[Plot in this case is defined as the area 50 meters $(\mathrm{m})$ to the left and right of the disturbance and extends to the $77 \mathrm{~m}$ length of the disturbance. Abbreviation: \%, percent]

\begin{tabular}{l}
$\begin{array}{c}\text { Erosion classifica- } \\
\text { tion }\end{array}$ \\
\hline Low
\end{tabular}

Moderate

High
Erosion characterizes $25-50 \%$ of the site in the form of sheet flow, rills, aeolian/alluvial deposition, and blowout areas.

Erosion characterizes $0-25 \%$ of the site in the form of sheet flow, rills, aeolian/alluvial deposition, and blowout areas.

Erosion characterizes more than $50 \%$ of the site in the form of sheet flow, rills, gullies, aeolian/ alluvial deposition, and blowout areas. This classification is used if gullies are present on the site and the disturbance is present in a wash.
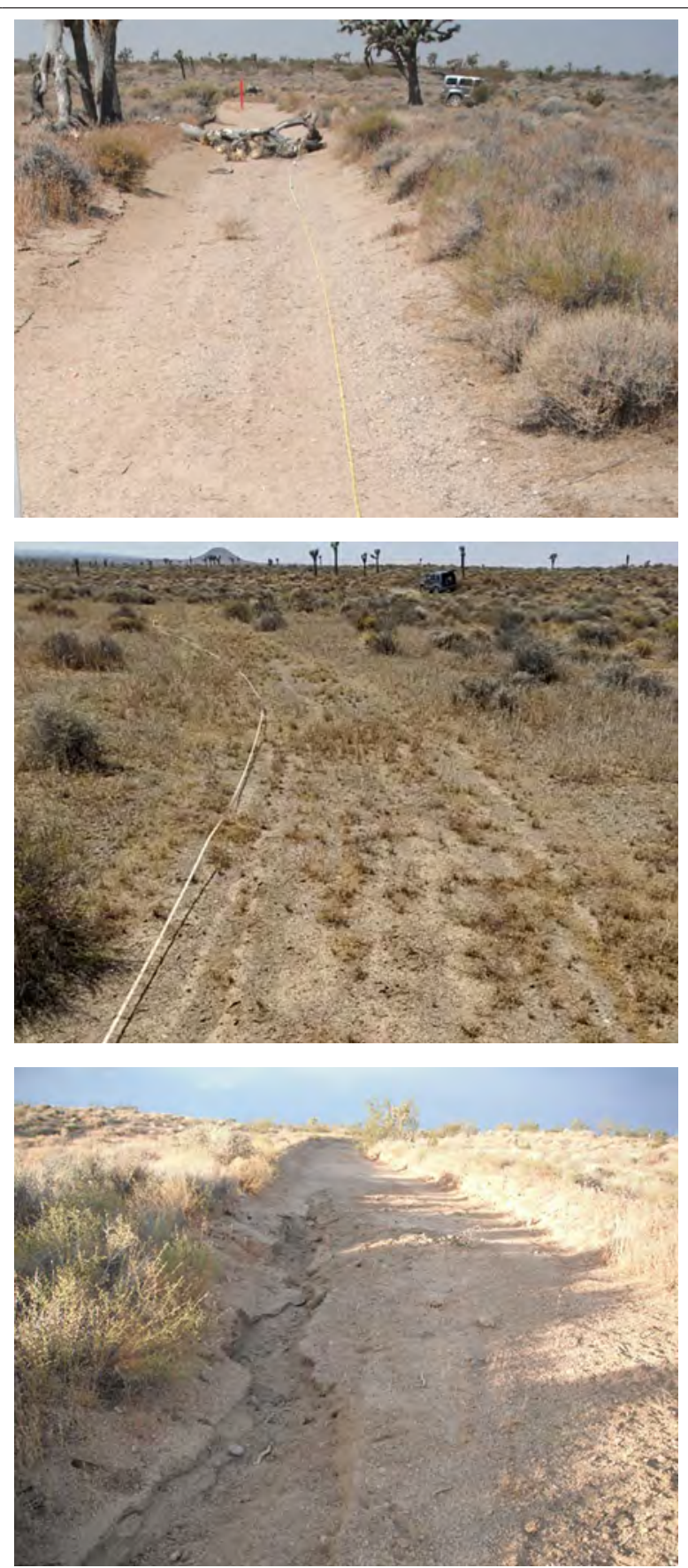


\section{Step 2. B. Monitoring Methods}

The following are step-by-step instructions to monitor the progress of ecological recovery. These methods are used in the Treatment Monitoring and in Ecological Monitoring assessments.

1. Perform a plant species inventory-Use the Species Inventory Method described in pages 55-57 of Herrick and others, 2017. Do not follow 1.3 optional size for compliance with the Natural Resources Conservation Service-Natural Resources Inventory Program (NRCS-NRI) compatibility. Instead, sample the plants (at least 50-percent rooted within the plot) within the treated and reference plot boundaries, which are $77 \mathrm{~m}$ in length and $2 \mathrm{~m}$ in width. Sampling will account for any plant species not encountered on the transect lines. To perform this method, please do the following:

a. If a species is unknown, take detailed notes, collect vouchers (preferably not from the plot), and photograph plants (leaves, flowers, and fruits, as well as a whole plant photograph). Vouchers ideally include fresh leaves and stems, flowers, and fruits. Coin envelopes can be used to collect representative seeds or fruits that may not stay attached to herbarium specimens.

b. Refer to plant keys and herbaria (online or through in-person visits) for identifications. Senior personnel should validate vouchers and identifications weekly.

2. Perform the line-point-intercept (LPI) method-Use the Line Point Intercept Method described in pages 27-31 of Herrick and others (2017). The line-point-intercept method is an efficient and accurate method for quantifying soil cover and documenting changes in vegetation on a site over time. Transect readings should be measured on the same side of the tape to ensure consistency and avoid bias. Three $25-\mathrm{m}$ transects with 1-m buffer between each transect will be used for each site. Transects should be placed in the middle of the tread, while following the curvature of the non-route (use additional pins to align transect with curvature if needed; fig. 4).

a. If the plot will undergo long-term monitoring, the use of permanent plot markers and transect markers (for example, rebar) is recommended. This step will minimize user error during plot monitoring setup in future site visits.

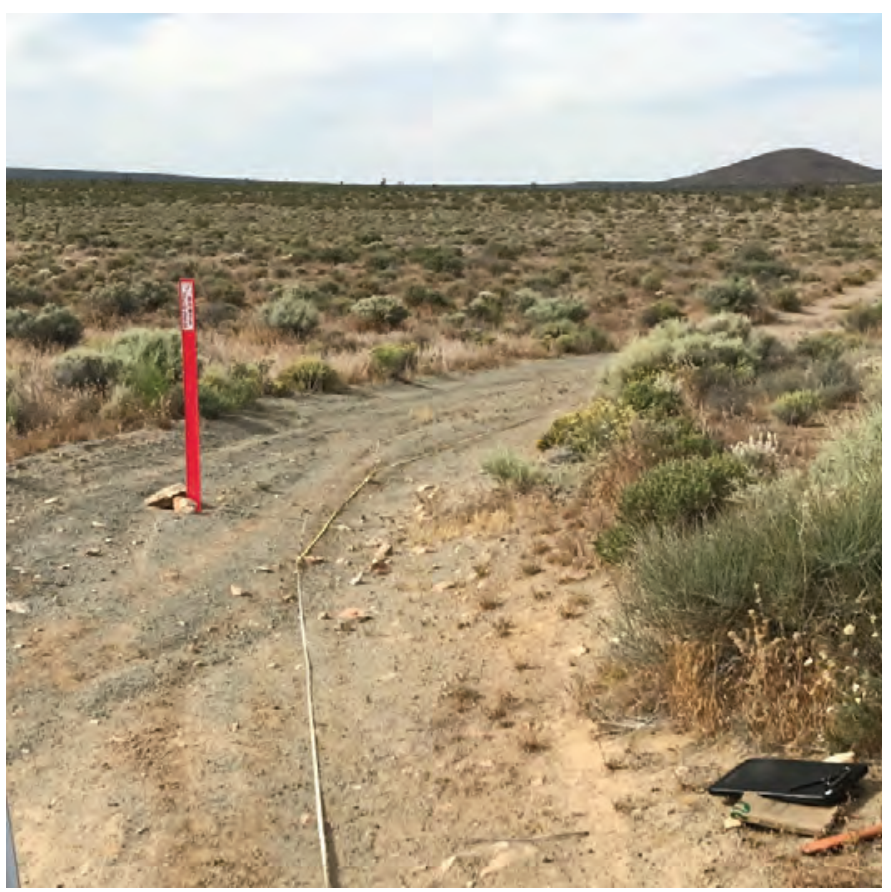

Figure 4. The line-point-intercept transects start at the closed route/non-route roadhead, are centered on the most-disturbed tread, and maintain that functional position, in line with the non-route curvature. Photograph taken by the Western Ecological Research Center Road Restoration Team, U.S. Geological Survey, spring 2020.

b. Place a 25-m transect tape down the middle of the main, most impacted tread (single-track) or down the middle of the tread with most disturbance present (double-track), aligning the beginning of the tape (zero end) with the proximal end of the plot. After rolling out the tape, secure both ends of the tape with chaining pins, with the metric side facing upward. Staying aligned with the first transect, measure $1 \mathrm{~m}$ from the proximal end of the first transect and pin the beginning of the second transect down. Measure out $25 \mathrm{~m}$ of the second transect and repeat steps to place the third (final) transect.

c. Start at the beginning of each transect line (zero centimeters $[\mathrm{cm}]$ ) and drop the pin flag or rod to touch the ground. Record each plant species or substrate matter that the pin flag or rod intercepts, according to the line-point-intercept datasheet (fig. 5). If bare ground is intercepted, substrate grain size classifications will be used to characterize the soil surface (table 5). Repeat at 10-cm intervals along the transect for the entire length of the transect line, starting at $10 \mathrm{~cm}$. 


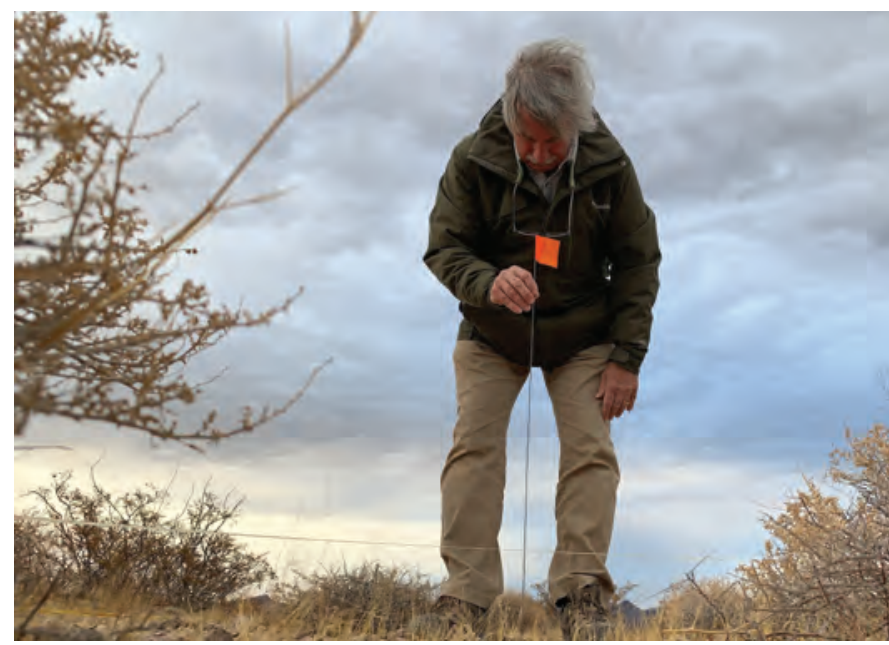

Figure 5. While performing the line-point-intercept transect to measure vegetation cover, hold the pin flag perpendicular to each meter mark along the transect tape and record the vegetation or surface substrate that is intercepted by the flag. Photograph taken by the Western Ecological Research Center Road Restoration Team, U.S. Geological Survey, spring 2020.

Table 5. Surface substrate grain size classifications.

[This table defines and illustrates grain size classifications for bare ground on the line-point-intercept transects. Abbreviations: $\mathrm{cm}$, centimeter; $<$, less than; mm, millimeter; >, greater than]

\begin{tabular}{|c|c|c|}
\hline $\begin{array}{l}\text { Substrate grain size classification } \\
\text { (Code) }\end{array}$ & $\begin{array}{l}\text { Grain size } \\
\text { (cm) }\end{array}$ & Example \\
\hline Clay (CL) & $<0.5 \mathrm{~mm}$ & \\
\hline
\end{tabular}


Table 5. Surface substrate grain size classifications.-Continued

[This table defines and illustrates grain size classifications for bare ground on the line-point-intercept transects. Abbreviations: cm, centimeter; $<$, less than; mm, millimeter; >, greater than]

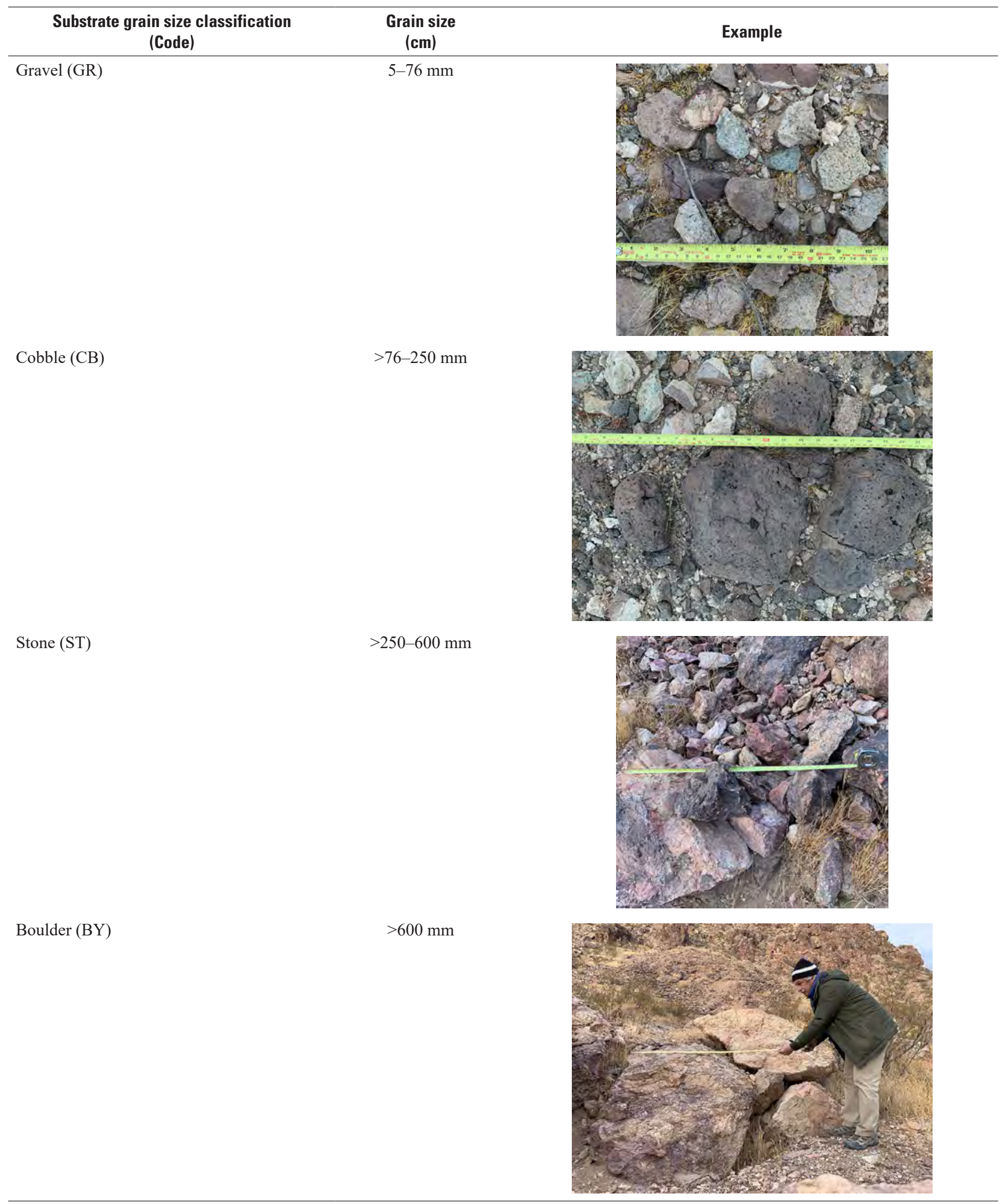



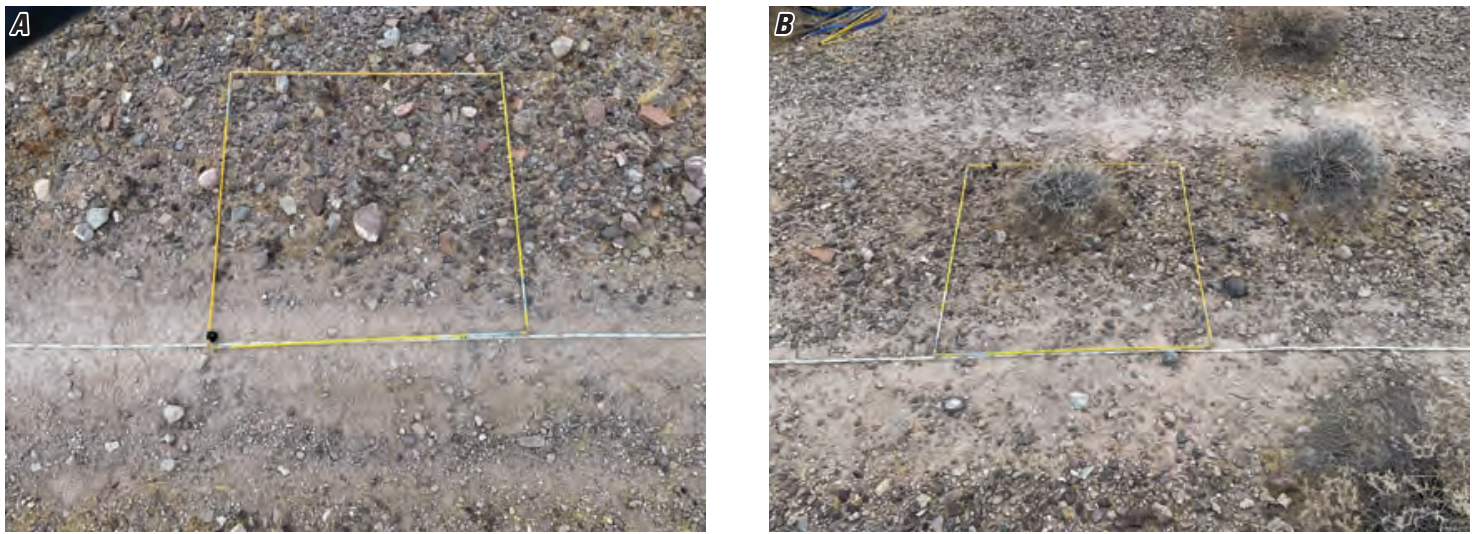

Figure 6. Example of a belt transect on a single-track disturbance $A$, centered on the tread and perpendicular to the line-point-intercept transect and; $B$, centered on the most damaged tread of a double track road, with the quadrat tape extending from one tread toward the median of the road. Photographs taken by the Western Ecological Research Center Road Restoration Team, U.S. Geological Survey, spring 2020.

3. Perform the belt transect method-The belt transect configuration for the single track will be the same as that described for the double track below. The belt transect can capture rare occurrences of plant species by providing density estimates and frequency distributions for all species found on the transect. Such data may be underrepresented with line-point-intercept methods in patchy desert environments (Schmutz and others, 1982; Herrick and others, 2009), and restoration sites are particularly patchy.

Belt transects on the paired reference plots should be set up in the same manner as the restoration plots. Each of the three segments of the total belt transect for the plot consists of 241 - by $1-m$ consecutive quadrats that are aligned parallel and contiguous with the line-point-intercept transect forming one side of the belt transect (recall, that the line-point intercept is established in the center of the most disturbed tread [fig. 6A]). Each 1- by 1-m cell can be delineated by placing a fiberglass quadrat or a measuring tape perpendicular to the base line (figs. $6 A, B$ ).

Density is recorded for perennial species but not annual species. Seedling perennials can be numerous, yet important to document the restoration process. When there are many young plants, they can be binned as $25-50,50-100$, and so on in 50 individual incremental bins as needed to represent your observations.

Frequency is quantified for perennial and annual species for each cell on the belt (please see the following information).

- Starting at $0 \mathrm{~m}$, place a $1-\mathrm{m}^{2}$ quadrat perpendicular to the line-point-intercept transect tape. The quadrat should be oriented to extend toward the interior of the road (fig. 6A).

- Start at the cell that ranges from 0 to $1 \mathrm{~m}$. For density estimations, count all perennial plants that have more than 50 percent of their stems rooted within the boundaries of the quadrat by species and enter them into the data sheet. For those on the line, the observer will have to make the judgement call.

- Using the same cell (in other words, $0-1 \mathrm{~m}$ ) as discussed in the "Montoring Methods" section on how to perform the line-point intercept, document presence (1) or absence (0) for each species of perennial or annual; this translates into species frequency. The frequency will range from 0 to 24 per belt and will be summed for all three belts to range from 0 to 72 . Plant species frequency provides important information about the spatial variability of species on the restoration project, and this is especially valuable for invasive species and documenting recruitment patterns.

- When all species are accounted for by using density and frequency estimation in the first cell, then move the $1-\mathrm{m}^{2}$ quadrat from the zero position on the baseline to the 4-m position and measure the 1- by 1-m cell at the 1 to $2 \mathrm{~m}$ position as described earlier.

4. Perform the basal gap intercept and canopy gap intercept methods (Herrick and others, 2017)—These methods provide information on the proportion of gaps in the vegetation along the transect line (fig. 7). Use the Basal and Canopy Gap Intercept Forms (appendix 1) to record information. Perform these methods to measure gaps on the three segments of the plot by using the same transect line as the line-point intercept.

Perform these methods by using the same three transect lines as the line-point-intercept, resulting in three basal gap transects and three canopy gap transects for each plot starting at $0 \mathrm{~cm}$. 
5. Determine soil texture-Texture is a static fundamental property of soil that can affect soil stability as well as infiltration rates above and below the ground surface. Methods include field (manual texture methods) and laboratory techniques (hydrometer methods, appendix 2). The difference between the two methods will be compared during the 2021 field season to inform future years. a. Perform manual soil texture. To measure soil texture manually ("texture by feel;" Thien, 1979), gather a soil sample from the top 25 millimeters $(\mathrm{mm})$ of soil, sieve it to remove large rocks using a \#3 soil sieve, and place approximately 5 grams $(\mathrm{g})$ of soil into the palm of the hand (fig. 8). Add distilled water, drop by drop, and knead the soil to break down all aggregates. The soil will reach proper consistency when it is malleable and moldable, like putty. Follow the flow chart to identify texture (fig. 9; National Soil Survey Center, 2009).

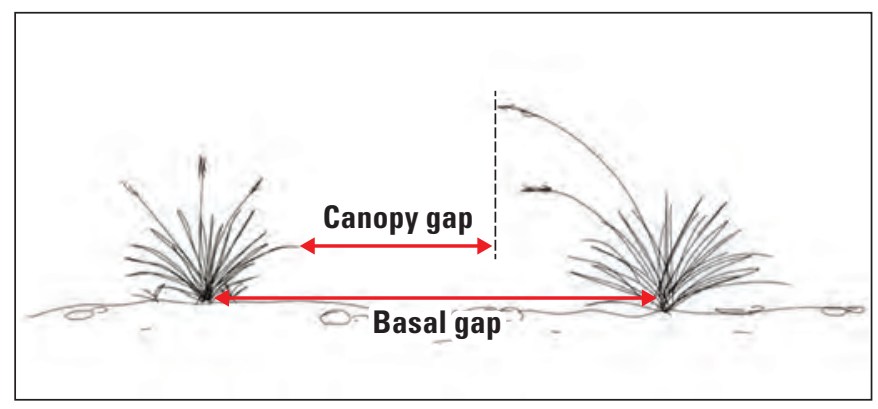

Figure 7. Canopy gap that is performed by recording the beginning and end of where a plant intercepts or touches the line along the transect and covers more than 50 percent of 3 centimeters consecutively. Basal gap is performed by recording only the basal stems of plants that touch or cross the transect line. The "gaps" between the canopy and bases must intercept at least 20 centimeters of transect to be considered a gap. Illustration by Kavoka Jackson, U.S. Geological Survey, 2020.
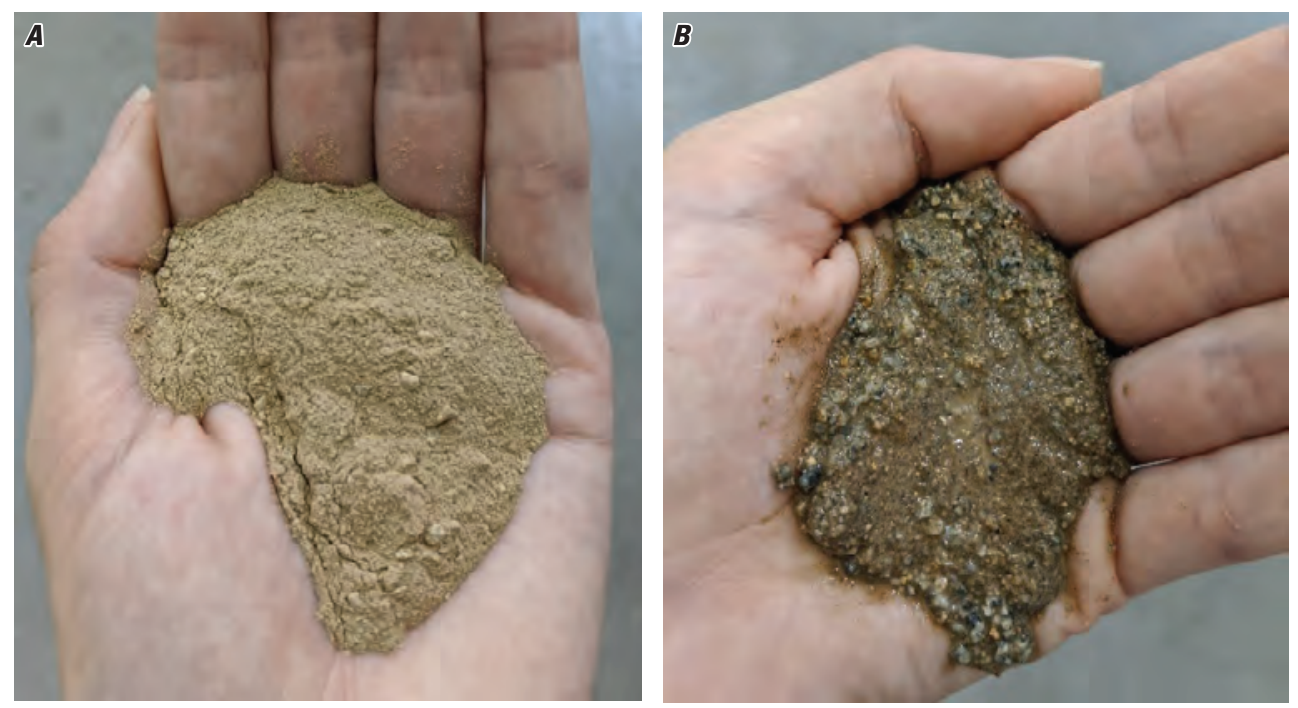

Figure 8. These photographs demonstrate the amount of soil used to perform the manual soil texture method. A, Add roughly 25 grams of soil to the palm of your hand; and $B$, Add water to break down soil aggregates and manipulate the soil to determine clay content. Photograph taken by Alexandrea Rice, U.S. Geological Survey, summer 2020. 


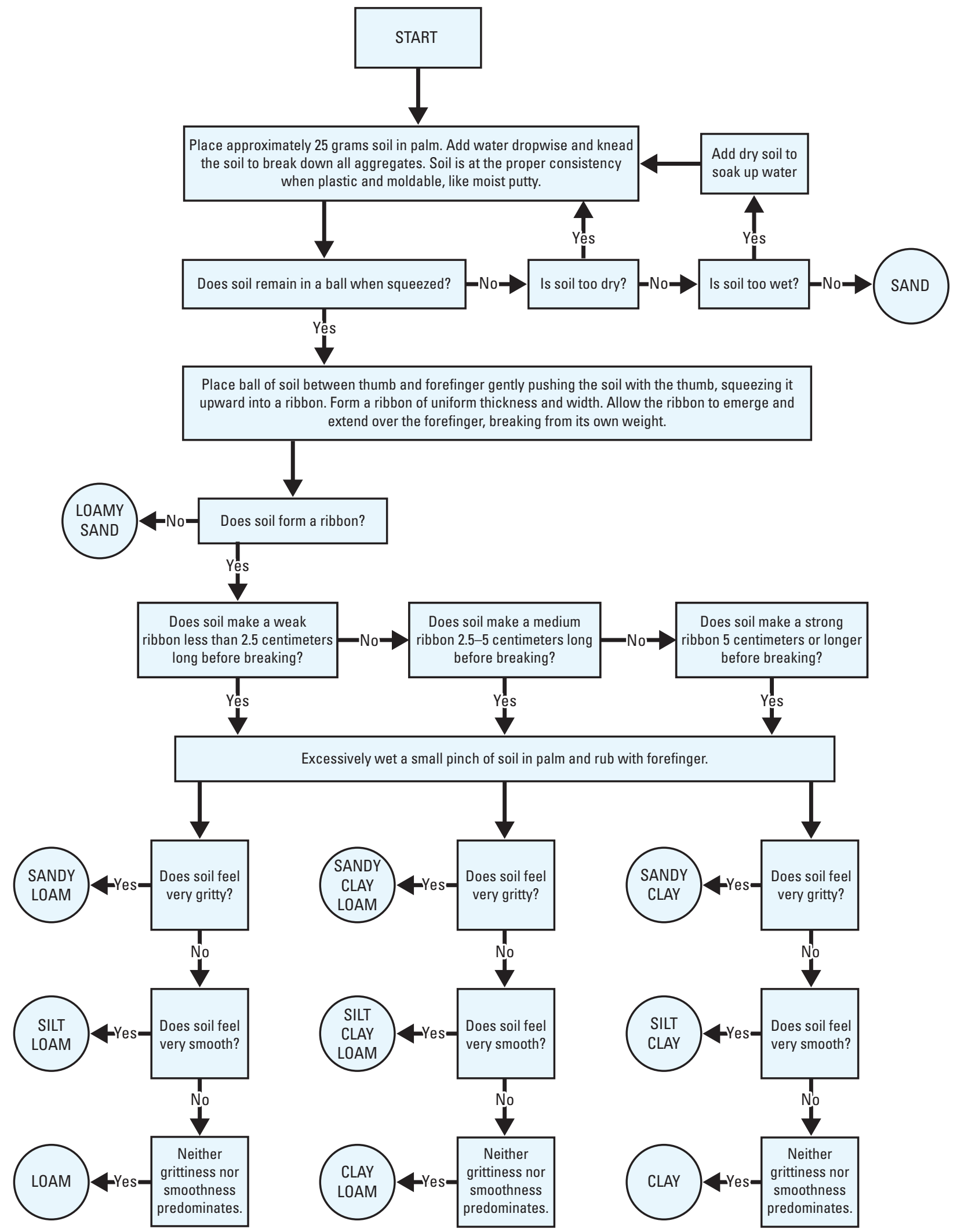

Figure 9. Manual soil texture determination (National Soil Survey Center, 2009). 
6. Determine bulk density—Soil bulk density is the dry mass $(\mathrm{g})$ per unit volume (cubic centimeter $\left[\mathrm{cm}^{3}\right]$ ) of soil and is often used to measure the compaction of soils in disturbed areas. Compacted soils can reduce the quality of a site by impeding plant growth through reduction of water-holding capacity and aeration/infiltration. Methods for measuring bulk density include soil coring and excavation of a known volume. After obtaining the soil sample in the field via coring or the pit excavation method (detailed below), the sample is dried in a drying oven and weighed for bulk density (grams per cubic centimeter $\left.\left[\mathrm{g} / \mathrm{cm}^{3}\right]\right)$.

a. Bulk Density Core Method. The bulk density coring method involves driving a metal cylinder of known volume into the ground to extract a sample of soil (National Soil Survey Center, 2009). However, soils with cobble or gravel could impede the depth to which the core can be driven, affecting the accuracy of measurements. Note: the cylinder is placed in the ground to extract the soil; no other implement, such as a spoon or scoop, should be used to place soil into the cylinder because the sampled volume must be intact for weighing.

- Select six sites on the plot for the core sampler (two per 25-m transect tape). Locations will be determined by using coordinates derived from a random numbers table. When there is a physical conflict with a sampling location (for example, a creosotebush in the way), use the next random number until an open spot is located.

- Clear away all foliage litter and debris so that the mineral soil is exposed.

- Push or gently hammer the sampler straight into the ground and capture the sample with as little disturbance as possible, so the soil is not compacted or disrupted.

- Excavate slightly around the sampler without disturbing it and carefully remove it from the soil profile to ensure the sample structure remains intact (fig. 10).

- Trim excess roots, rocks, and debris hanging from outside the sampler, then place the sample into a bag for transport.

- Dry the sample in a drying oven at 105 degrees Celsius $\left({ }^{\circ} \mathrm{C}\right)$ for $18-24$ hours until completely dry.

- Weigh the sample and calculate bulk density $\left(\mathrm{g} / \mathrm{cm}^{3}\right)$ by dividing the dry weight of the sample by the core volume. b. Bulk Density Pit Excavation Method. When soils are coarse with cobble and gravel, the pit excavation method may be more accurate to measure bulk density than the coring method.

- Dig a bowl-shaped soil pit that has a 13-cm diameter and 8-cm depth. Keep all excavated soil in a sample bag.

- Remove coarse fragments (those greater than or equal to $2 \mathrm{~mm}$ ) from the excavated soil with a $2 \mathrm{~mm}$ sieve. Place soil less than $2 \mathrm{~mm}$ in a plastic sample bag. If soil is too wet to sieve, skip this step.

- Line the soil pit with a plastic film, leaving excess film around the edge of the pit. To ensure the most accurate volume measurement, carefully place the coarse fragments in the bottom of the pit on top of the plastic.

- Fill the pit with water, using a 140-milliliter $(\mathrm{mL})$ syringe, until it is level with the surface soil. Record the volume $\left(1 \mathrm{~mL}=1 \mathrm{~cm}^{3}\right)$ of water required to fill the pit (round to nearest whole number). This volume represents the volume of soil removed.

- In the lab, weigh the sample with less than $2 \mathrm{~mm}$ soil (round to the hundredths place) and record the value. Then dry the sample in a drying oven at $105^{\circ} \mathrm{C}$ for $18-24$ hours until completely dry.

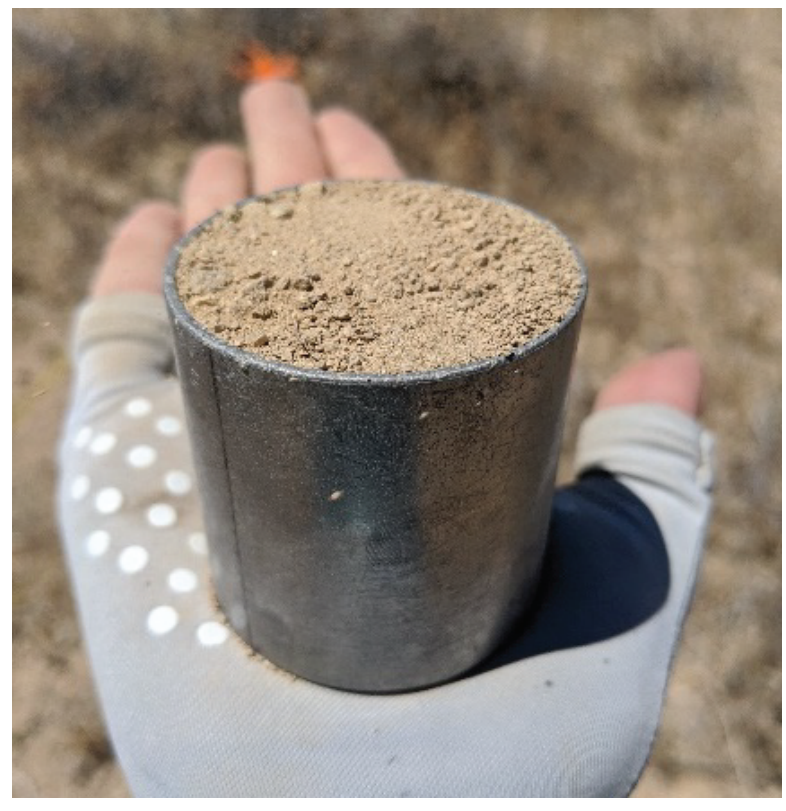

Figure 10. Bulk density pit excavation method. Be careful to keep as much of the soil intact while removing the soil core and scrape the excess soil off the top to make it level. Photograph taken by Alexandrea Rice, U.S. Geological Survey, summer 2020. 
- Weigh and record the dry sample. Save sample for soil texture analyses.

- Calculate bulk density $\left(\mathrm{g} / \mathrm{cm}^{3}\right)$ by dividing the dry weight of the sample by the volume of water added to the pit.

7. Perform the Soil Stability Test-This test provides information on the degree of soil structural development. Refer to the Soil Stability Test method. Do not collect optional subsurface samples. This test provides information on the degree of soil, structural development, and its resistance to erosion by testing the soil's stability when rapidly exposed to wetting. Soil

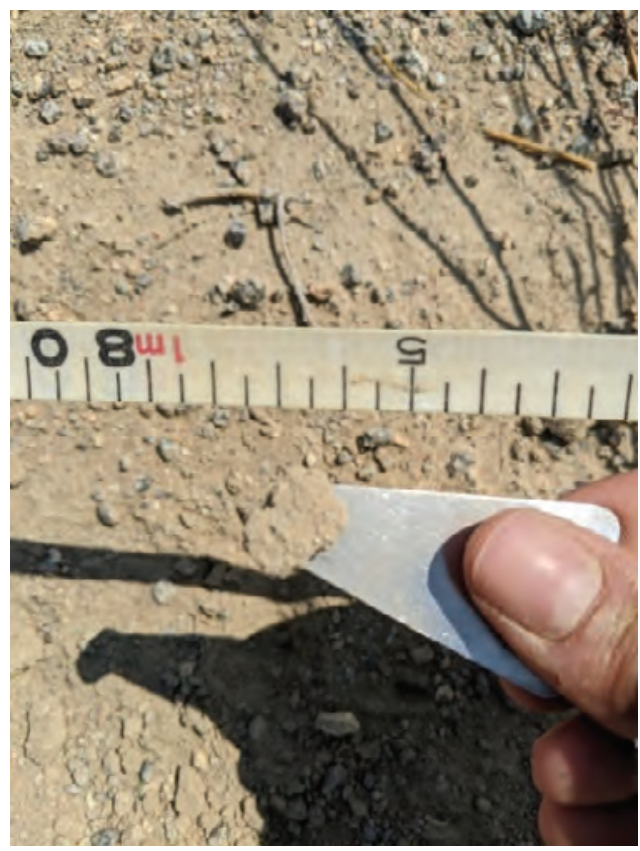

Figure 11. Carefully dig a small dimple in the soil and excavate a small soil fragment roughly the same size as the tip of the scoop (at least $2 \mathrm{~mm}$ thick and $6 \mathrm{~mm}$ diameter). Photograph taken by Kavoka Jackson, U.S. Geological Survey, summer 2020. stability is affected by soil structure, which is directly related to soil texture, so comparisons should be made among similar textures. Carefully dig a small dimple in the soil and excavate a small soil fragment roughly the same size as the tip of the scoop (at least $2 \mathrm{~mm}$ thick and 6-mm diameter (fig. 11). Perform the Soil Stability Test by using the soil stability test kit (AIM methods, Herrick and others, 2017; kit available from Synergy Resource Solution; http://www.countgrass.com; fig. 12). Stability class ranges from 1 to 6 (table 6). Site average values of 5.5 or higher generally are resistant to erosion, especially if there are low amounts of bare soil and high plant canopy cover.

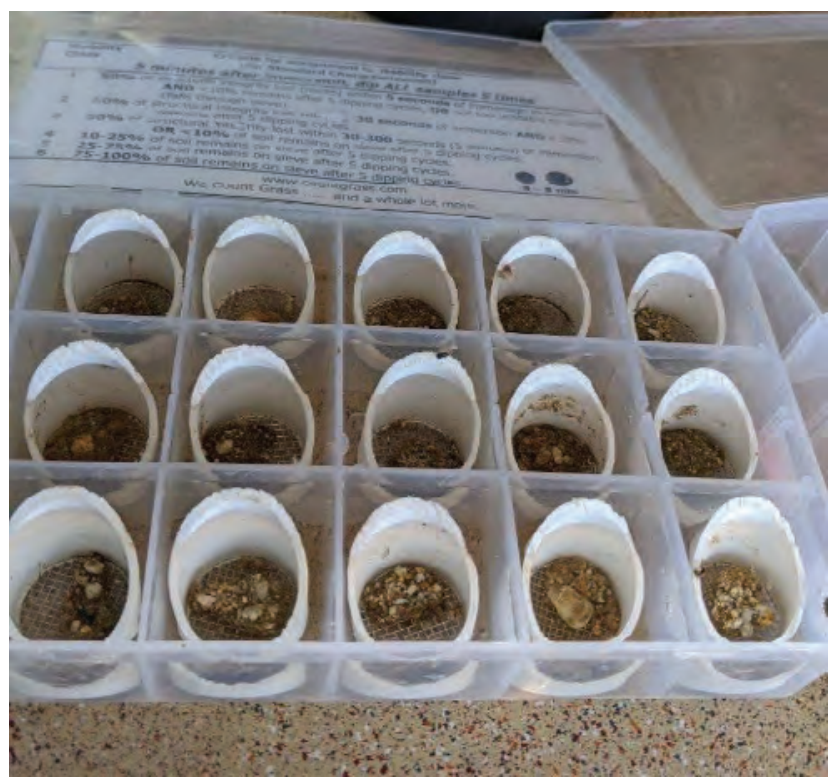

Figure 12. Perform the Soil Stability Test by using the soil stability test kit (AIM methods, Herrick and others, 2017; kit available from Synergy Resource Solution [http://www.countgrass.com]). This test provides information on the degree of soil structural development. Photograph taken by the Western Ecological Research Center Road Restoration Team, U.S. Geological Survey, spring 2020. 
Table 6. Stability class ratings for the soil stability test (adapted from Herrick and others, 2017).

$[\%$, percent; $<$, less than $]$

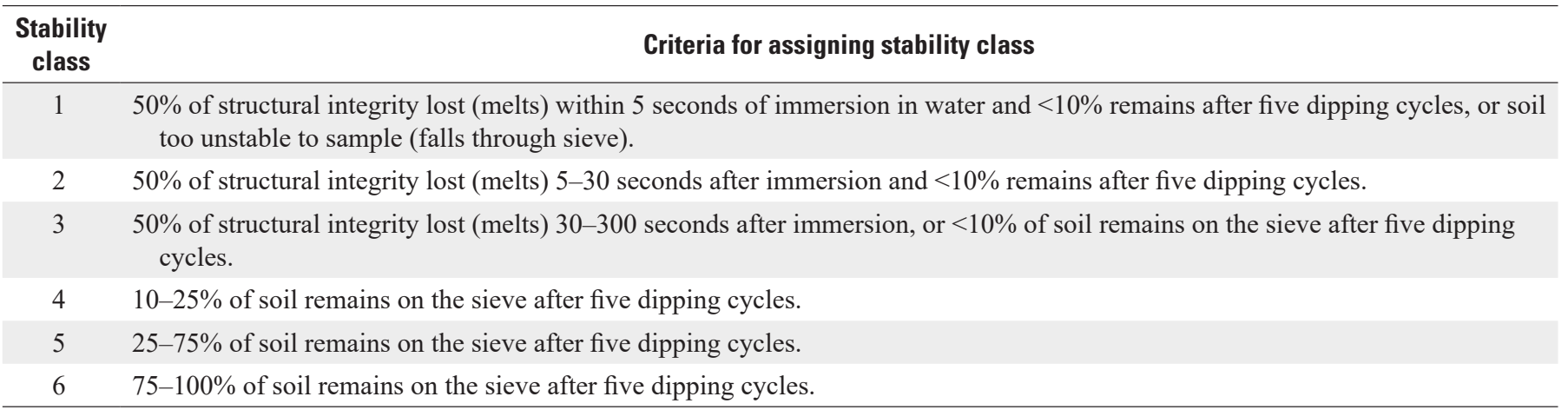

\section{Step 3. Determine and Implement Restoration Treatments}

Route restoration treatments are separated into two categories: vehicle-use deterrence and ecological restoration.

1. Vehicle-use deterrence treatments are implemented during route closure to deter vehicle operators from using non-routes. These treatments are applied to each roadhead within a polygon as determined by the Restoration Action Decision Tree (table 7). Initiating restoration treatments is best delayed until vehicle use is absent for at least 1 year after non-route and restoration action designation; this increases the likelihood that trespass does not interfere with the integrity of restoration treatments.

2. Ecological restoration is comprised of treatments such as decompaction and planting. After roadheads are successfully closed, as determined by cessation of vehicle use for at least 1 year, ecological restoration treatments can be implemented as determined by the Restoration Action Decision Tree (table 7) and Erosion Control Decision Tree (table 8). Restoration actions should ideally be implemented during an appropriate timeframe or season for the selected restoration methods (for example, planting). Use the Action Implementation Form (appendix 1) to record all restoration actions.

The following section describes the purpose and methods of the various restoration treatments in tables 7 and 8 , which are comprised of vehicle deterrence, ecological restoration, and erosion control methods.
Table 7. Restoration Action Decision Tree.

[Use the Visibility Classification Descriptions (table 3) to guide initial restoration decisions in addition to consultations with the BLM Field Offices. Abbreviations: BSC, biological soil crust; VM, vertical mulch (described later); LE, law enforcement]

\begin{tabular}{lll}
\hline $\begin{array}{c}\text { Visibility } \\
\text { from road }\end{array}$ & \multicolumn{1}{c}{ Actions } & $\begin{array}{c}\text { Elevated actions } \\
\text { (incursion, or no prog- } \\
\text { ress made) }\end{array}$ \\
\hline Low & $\begin{array}{c}\text { Passive restoration, raking } \\
\text { (if BSC present, then VM) }\end{array}$ & $\begin{array}{c}\text { Signs, VM/Rock scatter } \\
\text { Moderate }\end{array}$ \\
$\begin{array}{c}\text { Signs, VM/rock scatter, } \\
\text { barriers }\end{array}$ & Seeding \\
High & $\begin{array}{c}\text { Barrier, signs, VM/rock scat- } \\
\text { ter, ripping, seeding }\end{array}$ & $\begin{array}{c}\text { Fencing, LE, planting } \\
\text { (with aftercare) }\end{array}$ \\
\hline
\end{tabular}

Table 8. Erosion Control Decision Tree.

[Use the Erosion Classification Descriptions (table 4) to guide restoration decisions regarding erosion control on a plot.]

\begin{tabular}{ll}
\hline Erosion severity & \multicolumn{1}{c}{ Erosion control actions } \\
\hline Low & None \\
Moderate & Vertical/horizontal mulch, erosion control fabric \\
High & Landscape alteration, wattles \\
\hline
\end{tabular}




\section{Step 3. A. Vehicle-use Deterrence}

The approach that BLM has adopted to accomplish the restoration of routes is called "creating a defensible space." Desert restoration cannot be successful on lands where vehicular disturbance is recurrent. Therefore, prevention of vehicular disturbances is critical.

To remove vehicular activity, the landscape is first classified into polygons that are bounded by legal open routes on their perimeters. Perimeters also may be bounded by dirt tracks, paved roads, or fenced boundaries of non-BLM lands. Within the polygon, all tracks and trails are designated closed. All roadheads on the perimeter of a polygon require various forms of vehicle deterrence. Roadhead closures combined with visual erasure to line-of-sight are designed to eliminate vehicle incursions, and if successful, result in a unit of land that can be incorporated into defensible space as restored property. These defensible spaces may require enhanced outreach and law enforcement to increase awareness of the management guidelines for the area. When a defensible space is created with one polygon, nearby polygons are treated. Once recovered, they are merged into a larger defensible space to create large undisturbed habitat areas in compliance with the guidelines in the DRECP (BLM, 2016).

To deter further vehicle activity, enhanced techniques to block access to decommissioned routes may be required beyond visual erasure. Deterrence methods could include signage, fences, post and cable, gates, or disguising the entrance to the road using rocks, live plants, or vertical mulch (Egan, 2000). The following actions are currently employed by the BLM to deter vehicle activity as well as additional suggested road closure actions.

1. Vertical mulch-Vertical mulch (VM) is the placement of dead plant material (such as creosote bush and cholla) with stems buried vertically into the soil to resemble standing dead plants and visually disguise roadheads (fig. 13). Plant material is collected outside of the plot or salvaged from cleared vegetation on developed areas on public lands. Dead plant material can be harvested from the basal branches of perennial shrubs or cacti. Vertical mulching requires digging holes for placement of the branches near the roadhead; holes are approximately $10 \mathrm{~cm}$ deep, if possible, and wide enough to fit 5-10 branches to simulate shrub structure. Rocks can be used at the base of each structure to stabilize the branches. Vertical mulch structures should be placed to mimic the surrounding vegetation and staggered to avoid uniform patterns (if enough plant material is available).

2. Raking-Lightly raking the soil surface (for example, to eliminate vehicle tracks) can assist in disguising the disturbance. Raking must be done carefully because increased soil disturbance can facilitate plant invasions
(Winkel and others, 1994; Grantz and others, 1998). Rake from the roadhead to at least $70 \mathrm{~m}$ down the route (taking care to accommodate the study plots and avoid the edge of a restoration treatment) or to the line-of-sight and up to $4 \mathrm{~cm}$ deep, starting from the distal end (innermost) of the treatment area and working back to the junction with the access road.

3. Rock scatter-Scattering local rocks blends a closed road with the surrounding landscape and disguises it to deter further vehicle incursions (fig. 14). The added structure from the rocks captures detritus and seeds that blow onto the plot, reduces microsite run-off, and provides habitat structure for small animals.

4. Signage - Signs that clearly identify the status of routes (open versus closed) can be placed at the roadheads to inform recreationists and prevent vehicle use. Informational signs can be placed at the entrances to limited use or recreational areas along with maps that show open routes. However, signs can be damaged or removed after their deployment, which is a chronic problem in some areas (fig. 15). The BLM has data indicating that regular maintenance of signage networks is required.

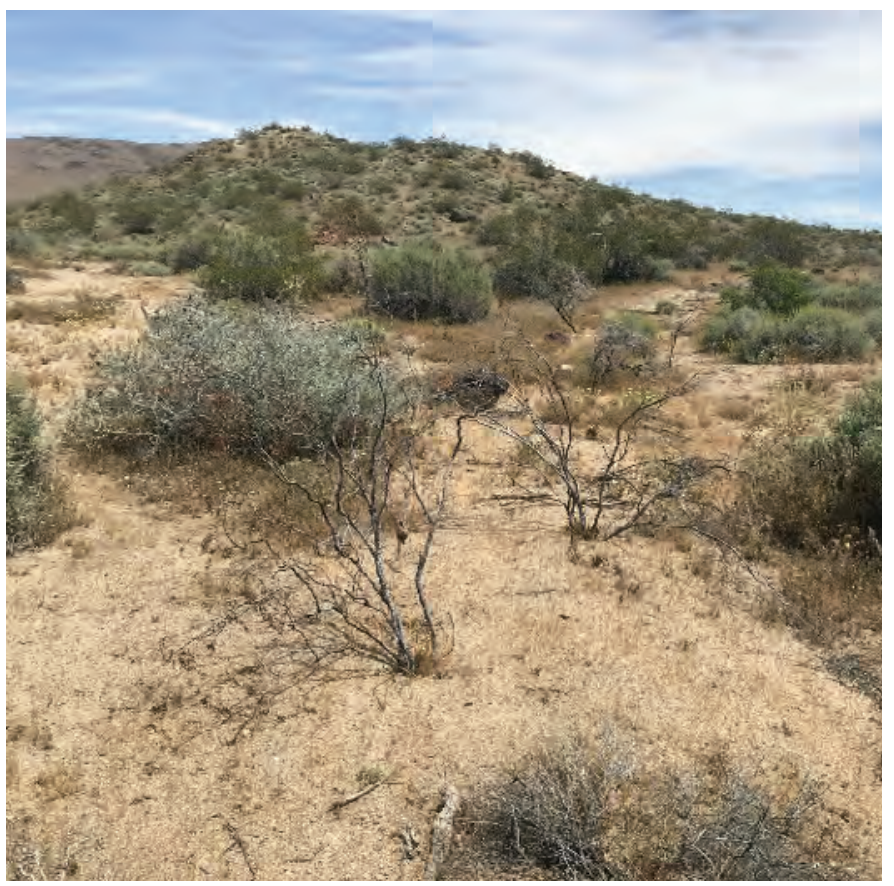

Figure 13. Dead branches and other native plant material can be used as vertical mulch to disguise linear disturbances and deter vehicle use. Photograph taken by the Western Ecological Resource Center Road Restoration Team, U.S. Geological Survey, spring 2020. 


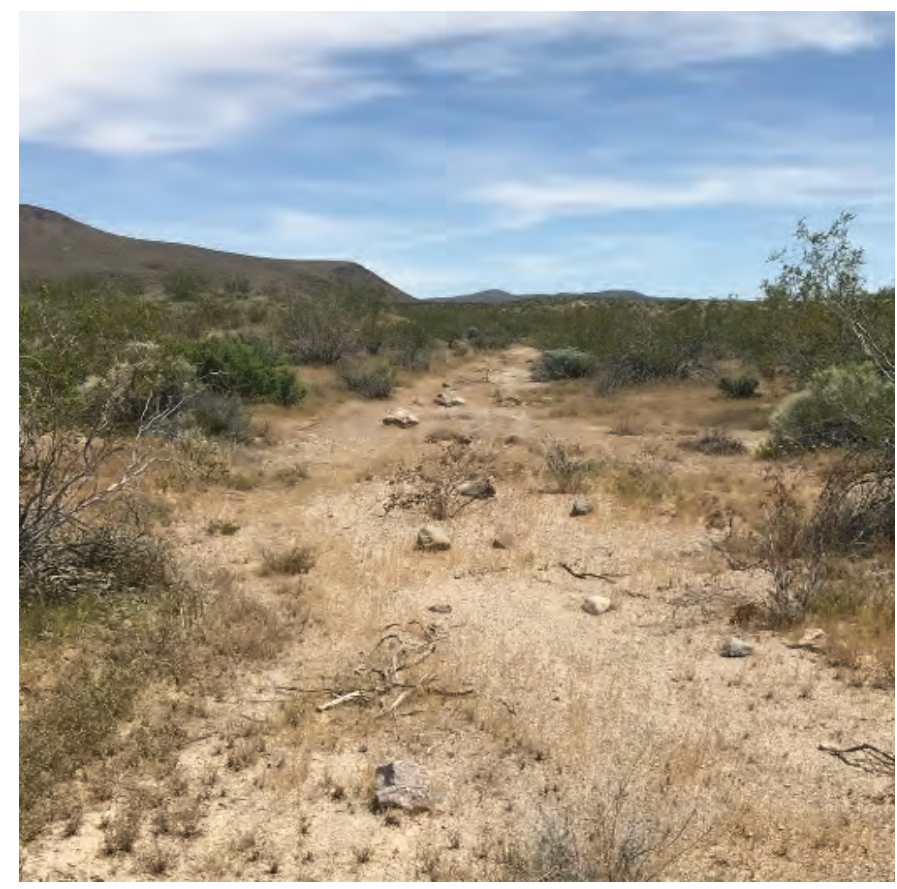

Figure 14. Rock scatter is a common restoration method used to disguise linear disturbances and deter vehicle use. Photograph taken by the Western Ecological Resource Center Road Restoration Team, U.S. Geological Survey, spring 2020.
5. Barriers-Barriers such as fences, gates, post and cable, ditches, and boulder placement can physically obstruct the non-route to prevent vehicle activity (fig. 16A, B). Artificial barriers used in conjunction with natural features reduce encroachment. However, artificial materials may increase the visibility of a site. Place barriers at roadheads perpendicular to the direction of travel with gaps that are narrow enough to restrict motorcycles.

6. Revegetation-Planting live plants or broadcast seeding at the roadhead eventually disguises the non-route. However, this method is more costly than vertical mulch and may not be enough to deter traffic. Revegetation may be most effective in combination with other road closure methods such as VM. Methods for revegetation can be found in the "Step 3. B. Road Closure Monitoring" section.

7. Public outreach-Public outreach that targets OHV user groups can inform recreationalists about route status within the BLM domain. Providing law enforcement and education presence at OHV recreation events, maps (physical and digital), interactive websites with downloadable maps and highlights about open routes, radio announcements, and general communication with the public may discourage and reduce vehicle use on closed routes but is difficult to quantify (Custer and others, 2017).
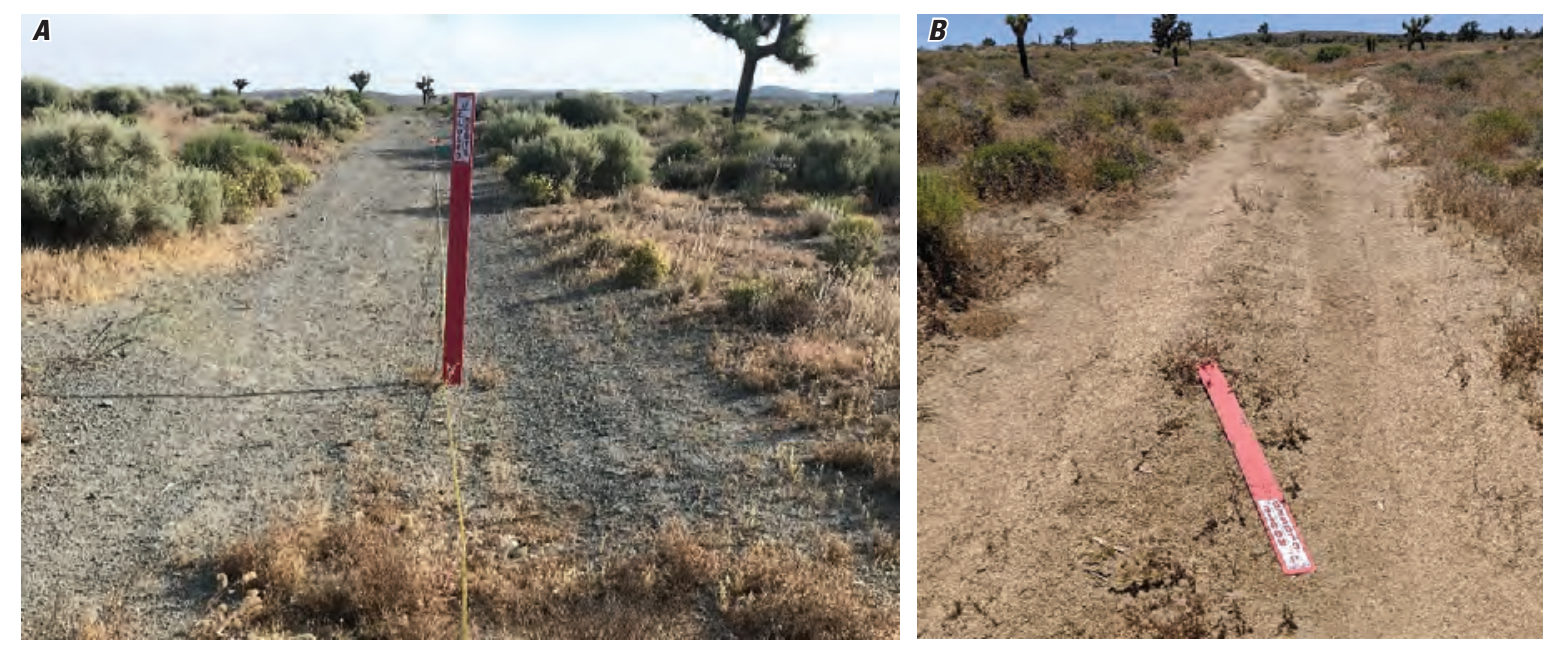

Figure 15. $A$, Red carsonite signs are used to indicate route closures; and $B$, red carsonite signs can be damaged or removed and are not always effective. Photographs taken by the Western Ecological Research Center Road Restoration Team, U.S. Geological Survey, spring 2020. 

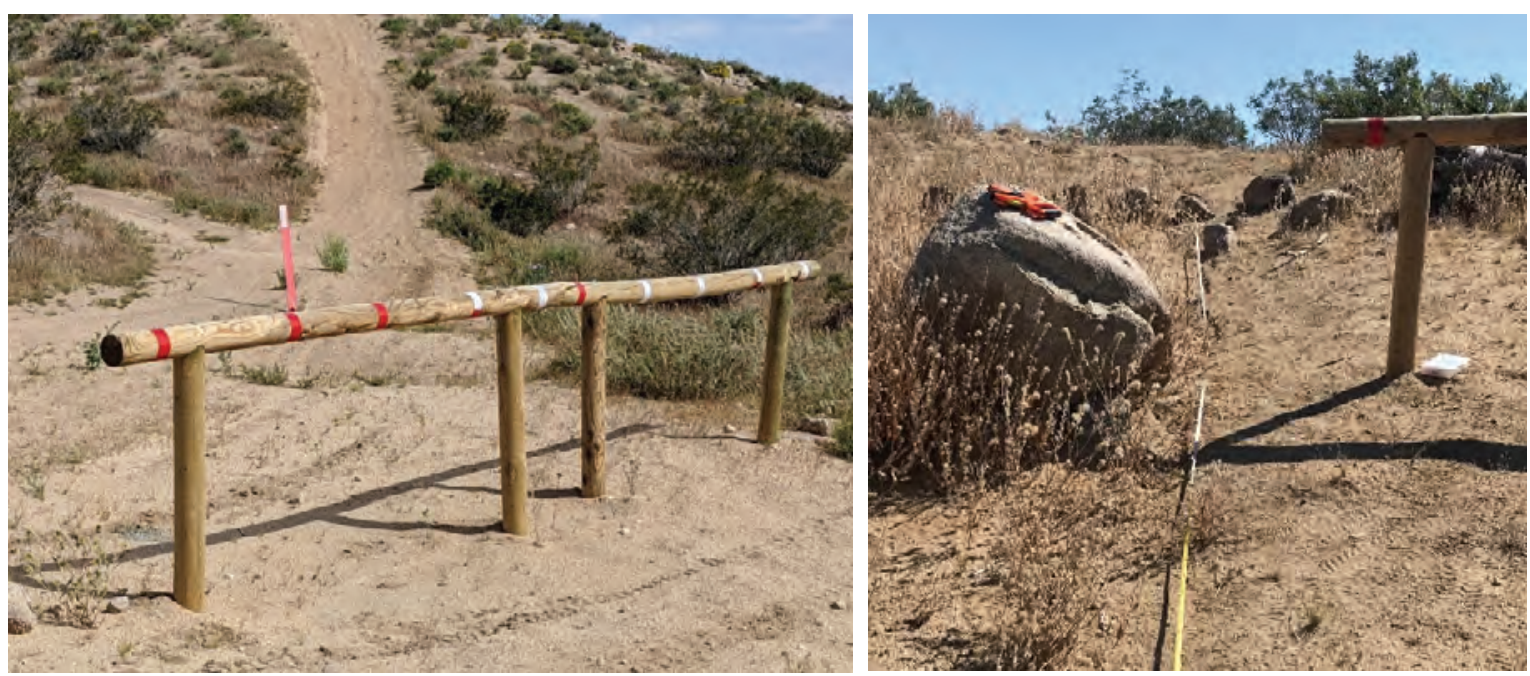

Figure 16. Barriers such as $A$, wooden gates; and $B$, boulders can be used to prevent vehicle access to restricted areas-possibly in combination. Photographs taken by the Western Ecological Research Center Road Restoration Team, U.S. Geological Survey, spring 2020.

8. Law enforcement-Law enforcement may be required to reduce vehicle activity. Focusing patrols in areas of high popularity and use, as well as timing patrols during high-use periods (for example, holidays), may provide the most protection (Custer and others, 2017).

9. Landscape alteration-Recontouring landscape surfaces using medium to heavy machinery can disguise roadheads and render them impassable in some areas, while sometimes restoring the natural slope and hydrological landscape features. Landscape alteration can include recontouring of berms, restoration of natural washes, backfill or recontouring of treads, rills, or gullies, among other actions. This is an aggressive treatment that can result in high site disturbance and longer ecological recovery; it is only suggested for extreme disturbance or for highly popular routes.

\section{Step 3. B. Road Closure Monitoring}

After closing non-routes, vehicle activity is monitored biannually for 2 years with efforts focused during the spring and fall seasons when vehicle users are most active. If vehicle incursions cease, further restoration treatments can begin. If incursions continue, more intensive road closure methods may be required, such as extra law enforcement in areas of frequent vehicle activity or during times of high activity. Following is a list of methods to monitor and quantify vehicle activity:
1. Raking - Raking can be used at roadheads to determine if a route has been used. Rake the roadhead to create a shallow (less than $4 \mathrm{~cm}$ deep) surface disturbance. Return after a pre-determined amount of time (for example, after a high vehicle activity period during a holiday weekend) to observe whether vehicle tracks are present at the raked roadhead. This method only documents the presence or absence of activity and does not quantify the number of vehicles that pass.

2. Pneumatic road tubes-Pneumatic road tubes are commonly used to quantify vehicle passes on a road. Place tubes on the ground surface at the roadhead, perpendicular to the direction of travel. The tubes release a burst of air pressure to a sensor when a vehicle passes over, and the number of passes is recorded in the nearby datalogger. The data logger associated with the pneumatic tube can be placed out of sight to prevent theft and damage. This method is simple, but tubes are sensitive to punctures and holes; such damage reduces traffic count accuracy and can be costly.

3. Motion-sensor cameras-Well-anchored and protected motion-sensor cameras, such as game or trail cameras, can quantify motor vehicle incursions, including number of vehicles and license plate numbers of vehicles. These cameras can be left in place for weeks to months but are subject to theft and damage. 


\section{Step 3. C. Ecological Restoration Treatments}

When vehicle activity stops on non-routes, then non-routes can undergo intensive restoration treatments or be left to recover naturally (with route closure methods in place) as determined by the Restoration Action Decision Tree (table 7):

1. Decompaction-Because vehicles can increase soil compaction in deserts (Webb and Wilshire, 1983), decompaction measures may be the first step to restore ecosystem function. Soil can be decompacted quickly with medium to heavy machinery or slowly by outplanting seedlings to increase bioturbation and encourage wildlife to use the area. Animals, including invertebrates, can be important factors in bioturbation. The burrowing activity of many invertebrates can occur in highly compacted roadbeds. For example, harvester ants and wind scorpions (in the Solifugae) regularly burrow into compacted roadbeds (fig. 17A, $B$ ). When compaction is severe, outplantings may not survive unless the surrounding soil is loosened. These methods will initially be implemented at the roadheads, and it is likely that additional treatments will be experimentally implemented in the polygon centers.

2. Imprinting-Machinery or hand tools create shallow depressions that relieve shallow soil compaction and provide microtopography for seed capture and pooling of precipitation, reduce wind erosion and seed removal, and increase contact between seeds and soil, which is important for germination of many plant species.

3. Harrowing - A heavy frame instrumented with several rows of teeth or tines is dragged along the ground to break up soil clods and roughen the ground surface to a depth determined by the tines and the weight of the frame. This method creates shallow linear furrows for the distance that the tines are in contact with the soil. Harrowing is a moderate-disturbance method that can facilitate the spread and density of invasive plants (Winkel and others, 1994) and is only used on highly compacted soils and is followed up with appropriate measures to reduce invasive species.

4. Spiked drum aerator - A heavy cylindrical drum with protruding spikes or tines that can penetrate the soil is dragged or pulled along the soil surface to decompact and aerate the soil surface up to more than $6 \mathrm{~cm}$ (2.5 inches [in.]) deep.

5. Ripping-A subsoiler or rock ripper submerges a heavy-duty tine in the soil and drags it, decompacting the soil $15-20 \mathrm{~cm}(6-8 \mathrm{in})$ or deeper. This method is used for severely compacted soils. Care must be taken when using this method because deeper soil disturbances can facilitate invasive plants (Grantz and others, 1998; Walker and Powell, 1999; Montalvo and others, 2002). If native soil structure exists on a site, this method can destroy it.
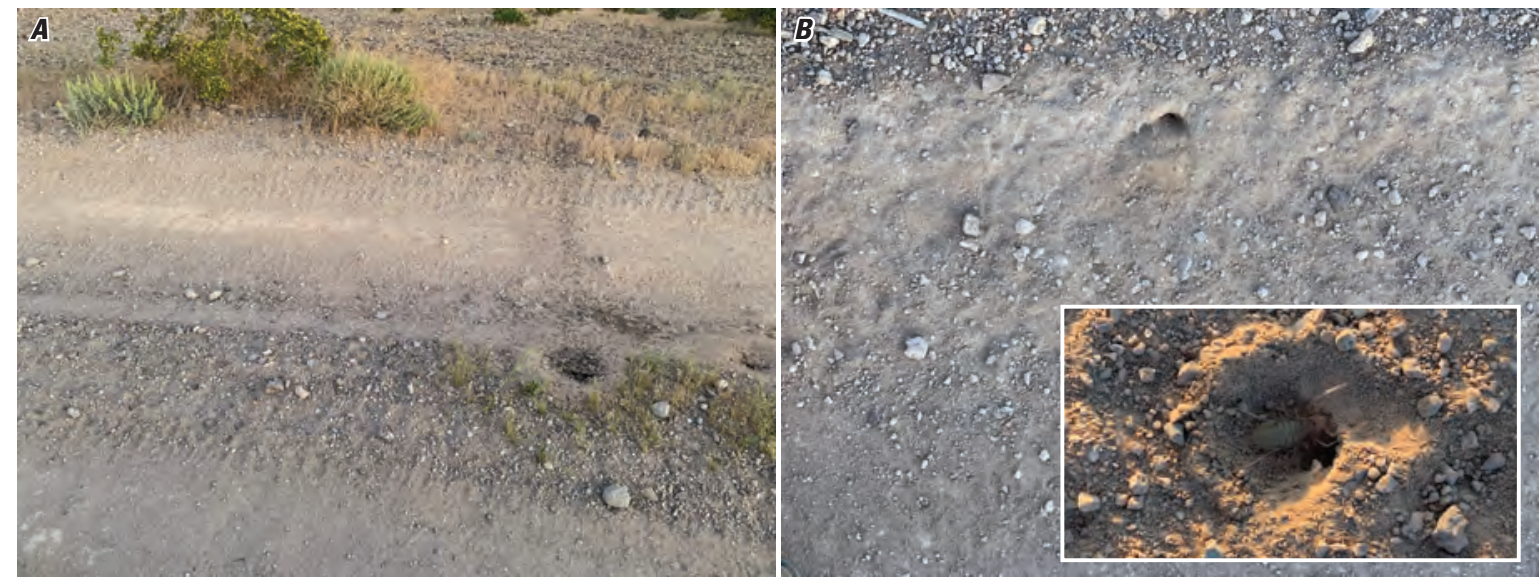

Figure 17. A, Harvester ants (Veromessor pergandei) burrowing in compacted roadbed and trailing to collect seed; and $B$, Invertebrates regularly burrow into the tread of compacted roadbeds such as this wind scorpion (in the Solifugae). Photographs taken by Todd Esque, U.S. Geological Survey, fall 2020. 
6. Passive restoration-Total non-route closure around the perimeter of a polygon provides 'defensible space' for recovery of linear disturbances inside the polygon with reduced risk of subsequent incursion. With vehicle activity abated within the boundaries of the defensible space, passive restoration is expected to develop with little additional intervention (active restoration) for disturbances of low severity or limited geographic area such as the diffuse network of linear disturbances found widely across California's deserts. In the Mojave Desert, this process may require decades to centuries, depending on the severity of disturbance (Johnson and others, 1975; Lovich and Bainbridge, 1999; Webb, 2002). High perimeter-to-area ratio and narrow widths of non-routes allow seeds from adjacent intact vegetation to disperse over short distances to recolonize linear disturbances and recruit new seedlings, if suitable microsites are available. Linear disturbances also benefit from increased bioturbation by burrowing animals in the surrounding community. Cessation of disturbances by vehicle activity is vital to promote passive restoration:

a. Implement road closure methods to discourage further vehicle activity that is detrimental to passive restoration.

b. Allow the site to recover slowly from human disturbances with little to no active restoration activity.

c. Record if passive restoration is implemented on the corresponding field data sheet.

d. Monitor for vehicle activity (see the "Road Closure Monitoring" section). Active restoration is implemented if no progress toward recovery is made or if the site is further disturbed (see Restoration Action Decision Tree).

7. Erosion control-Routes are prone to soil erosion by fugitive dust losses or by decreased infiltration and increased velocity of water movement that causes rills and gullies. Erosion control and returning native soil characteristics to a site can be definitive for restoration success. Several methods for controlling erosion are in the Erosion Control Decision Tree (table 5), and additional methods can be found in appendix 2 .

a. Vertical and horizontal mulch-In addition to disguising road closures, vertical and horizontal mulch reduce the velocity of wind and water movement of soils; this reduces erosion, increases infiltration, and eventually captures and builds organic surface matter deposits. See the description of "Vertical mulch" above for further instructions on use of vertical mulch.

b. Erosion control fabrics - Organic materials or fabrics such as straw (loose or consolidated in bales, woven into mats, or dispersed in long cylindric wattles), coir (fibrous coconut by-products), or jute (fiber woven into twine and stitched into a loose, open grid) can be placed over an existing area of erosion to reduce wind and water erosion by raindrops and surface flows (Bainbridge, 1995). These biodegradable materials have been used with some success. Such natural fabrics also act as mulch and can contribute to higher seedling emergence (Bainbridge, 2007). However, straw can reduce or increase soil water content and soil temperatures depending on how it is applied; this can negatively or positively influence the germination of seed species (Ostler and Hansen, 2003; Caldwell and others, 2009).

c. Landscape surface alteration-Landscape surface alteration can restore natural slope and hydrological landscape features through recontouring berms, restoring natural washes, and backfilling or recontouring treads, rills, or gullies. This action is intended to modify unnatural erosional features but can result in further erosional problems. This aggressive treatment can result in initial site instability and is only implemented where there is extreme disturbance or highly popularty routes and when resources for follow-up are available.

8. Invasive species removal—Non-routes invaded by aggressive weedy species (for example, Russian thistle - Salsola spp.) recover more slowly and may not respond to restoration treatments until invasive plants are suppressed. Invasive plant removal is not a standard method used by the BLM during road restoration but can be considered under special circumstances. More information on removal methods is provided in appendix 2 .

9. Soil amendments - Addition of soil moisture or nutrients is intended to improve conditions for seed germination and plant growth, reduce soil temperature, increase safe sites for seed capture, reduce compaction, and minimize erosion (Chambers, 2000; Gebhardt and others, 2017); however, results have not been consistent in hot desert environments (T.C. Esque, unpub. data, 2020). Furthermore, these strategies can be expensive or difficult to implement and are best carefully considered. See appendix 2 for more information. 
10. Revegetation-Revegetation is a popular restoration technique for disturbed areas. Revegetation can stabilize soil, increase bioturbation to promote soil recovery, encourage wildlife, and restore critical ecosystem functions. Seeding, transplanting, and outplanting are the primary methods used for revegetation. Several factors can affect revegetation survival including plant material sources, species selection, preparation of plant materials during grow-out, timing of seeding or planting relative to phenology and seasonality (precipitation and temperature), protecting seeds from granivory, and protecting plants from herbivory.

a. Seeding - Seeding can be an efficient way to increase diversity of plant species over a large area and can be less expensive than other methods (for example, outplanting, transplanting). Because appropriate seed sourcing is important, the BLM's Mojave Desert Native Plant Program promotes the use of provisional seed transfer zones to identify and use appropriate seed and plant material sources for restoration sites throughout the southwestern United States (Shryock and others, 2017, 2018). Seeding should take place during or shortly before the appropriate rainy season for the target species, if possible, to promote seed germination and establishment (Beatley, 1974). Seeds are planted approximately 1 centimeter deep to optimize emergence, although certain species may have deeper or shallower requirements for germination; these requirements are generally directly related to seed size.

- Broadcast seeding - Broadcast seeding involves distributing seed across the site by hand, using automated land-based equipment, or by aircraft. Hand treatment methods are more efficient on smaller areas. Aerial seeding methods are not recommended for route restoration because targeting the linear disturbances can be difficult from the air. Broadcast seeding treatments of any type sometimes can result in uneven distribution of seeds. Seed distributed on the soil surface is vulnerable to granivores such as ants and rodents (DeFalco and others, 2009); mixing the seeds into the soil is preferable.

- Spot seeding - Spot seeding involves placing individual seeds into holes created in the soil surface using a "dibble stick." Dibble sticks can be as simple as a pointed stick pressed into the soil to create a depression for seeds or a pipe that is stabbed into the soil with seeds delivered to just below the soil surface; both techniques reduce the amount of bending over required to position seeds into depressions that hold seeds in place. Once placed, seeds are covered with soil.

- Drill seeding-Drill seeding uses machinery to sow seeds directly into the soil at a specified rate and depth. Conventional and no-till drill seeders are often used for drill seeding.

b. Planting - Introducing greenhouse, shade house, and nursery-raised plants can quickly increase plant cover on a site and circumvent the natural yet vulnerable process of seed germination and establishment. Plant species selection and preparation, as well as after care treatments of plantings, can contribute significantly to the survival success of plantings (Bainbridge and MacAller, 1995). This approach is much more costly than seeding.

- Translocation/salvage-Cuttings of stems (or joints for cactus) or whole live plants can be moved from an adjacent area directly into the restoration site, although little research reports on the success of this method in California deserts. Plant material is sourced sustainably from near the site or a similar ecoregion so as not to decimate or significantly affect existing plant populations. When a site planned for construction will result in loss of mature plants, plant materials can be salvaged and planted in nearby, comparable sites for later use in restoration.

- Outplanting - Outplanting refers to propagating plants in a greenhouse or nursery using seeds or tissues collected from areas near restoration sites until they are mature enough to be planted back into the restoration site. This method requires more resources than seeding, including (but not limited to) access to a greenhouse, shade house, or outdoor growing space, careful sourcing of plant material, personnel for cultivation, and a longer time frame to allow for grow-out. Propagation conditions typically maximize plant yield by providing ample water and nutrients under mild environmental conditions; however, resulting plants are not well acclimated to field conditions unless several weeks of limiting conditions are used to adjust their physiology and growth to match the restoration environment. Not only can the wind, sun, and drought conditions reduce the vigor of outplantings quickly, but they can attract herbivores that can cause outplanting failure. More work on preparing field-hardy outplantings should be considered (L. DeFalco and others, unpub. data, 2020). 
c. Species selection-The sources of plant materials and species selected for revegetation can affect the likelihood of success. Plants from the appropriate ecotype have a higher chance of survival than the same species sourced from outside the planting region because they are likely to be better adapted to localized conditions (for example, weather conditions, soil type, plant neighbors, and other stressors). Seed germination and establishment requirements vary among species, so treatments are best reviewed for compatibility before implementation (Abella and Newton, 2009). A variety of tools are available to assist restoration practitioners in the selection of plant materials for the Mojave Desert region. Priority species lists for restoring habitats in the Mojave Desert identify species that are particularly useful for restoring desert tortoise habitat or pollinator habitat (Esque and others, 2021).

d. Revegetation aftercare-Deserts can be harsh environments that make establishment and survival for plants difficult. Supplemental irrigation and structures that protect plants from external stressors (for example, wind, direct sunlight, herbivory) can greatly improve survival rates of plants, especially during the first 1-2 years of establishment (Bainbridge, 2007; Abella and Newton, 2009). Results can vary by species (Abella and Newton, 2009), and the season of implementation also can influence success.

e. Irrigation-Irrigation can be used to enhance the survival of plantings. The source of water for irrigation must be carefully planned because transportation and delivery can be costly and plant response can vary by species (Abella and Newton, 2009). Effects of irrigation also can depend on the amount and timing of precipitation; periods of high precipitation can dilute the effects of irrigation whereas drought could enhance the effects of irrigation.

- Run-off structure/rain catchments-Rain catchments can be built around plantings to enhance plant survival by concentrating or increasing capture and moisture retention. They may be the most cost-effective way to increase planting success on a small scale. Catchments can be big enough to hold several plants or can be tailored to individual plants (Edwards and others, 2000). Placement that considers landscape position can enhance effectiveness.
It is most effective to place catchments and plantings in natural run-on areas in swales and proximal to washes and to avoid ridgetops and other higher landscape positions (natural run-off areas; John Kellam, BLM, oral commun., 2019).

Alternatively, roadside berms can be recontoured to act as rain catchments (Johnson and others, 1975; Vasek and others, 1975).

- Hand watering-Hand watering can be labor and time intensive as well as costly. This method is more efficient on small-scale projects. Hiking distance, weight of water, and personnel capabilities must be taken into consideration when using this method.

f. Protection and Crypsis_-Protection from harsh elements and herbivory can increase the probability of survival for seedlings and transplants (Bainbridge and MacAller, 1995; Abella and Newton, 2009). Additionally, seed predation may be reduced by using diversionary seeding (Longland and Ostoja, 2013) but is only currently being tested in the Mojave Desert (L. DeFalco, USGS, oral commun., 2020).

- Cones/tree shelters - Tree shelters and solid plastic cones provide effective protection against herbivory and harsh elements such as wind and sandblast. These shelters are costly, however, and may have other effects such as increased temperatures (Oliet and Jacobs, 2007; Scoles-Sciulla and others, 2015) and temporarily altered growth (Bainbridge, 2007; Devine and Harrington, 2008). Cones and tree shelters work best for upright and tall plant growth forms.

- Natural material shelters-Rock mulch, cairns, and dead plant material can be strategically placed around a plant to provide a natural form of shelter. Although these shelters may degrade more quickly compared to artificial shelters, using materials gathered from on-site is less costly and can provide a natural look to the site. When constructed carefully, they can provide protection against herbivory and harsh elements.

- Cages - Wire cages can protect against herbivory and do not alter the temperatures like cones and tree shelters (Scoles-Sciulla and others, 2015). Metal mesh size of a quarter inch is sufficient to deter most of the abundant and problematic herbivores, except for ants. 
- Diversionary seeding-Diversionary seeding uses treated and sterile non-target seeds (such as millet, Panicum milliaceum) mixed in with target native seed species. Millet seed can be rendered sterile using heat treatments (L. DeFalco, unpub. data, 2020). Diversionary seeding decreases the chances for granivory of target seeds, thus increasing the chances of native seedling establishment and growth (Longland and Ostoja, 2013).

\section{Step 3. D. Structure Maintenance}

Maintenance of degraded restoration structures (for example, signs, vertical mulch, plant shelters and catchments) can reduce costs associated with completely reinstalling a structure. Restoration structures can be monitored on every visit to the project site. Maintenance and replacements can be performed as needed.

\section{Step 4. Measure and Evaluate Treatment Effectiveness}

Monitoring for treatment implementation integrity and ecological functions is used to evaluate treatment effectiveness.

1. Perform short-term treatment implementation monitoring using the Implementation Monitoring form. Repeated site visits document presence of vehicle tracks and integrity of restoration structures placed on plots. Implementation monitoring is completed seasonally (at least twice a year) for 2 years following initial treatment implementation.

2. Perform short-term or long-term ecological monitoring to capture ecological recovery according to the timeline and frequency determined during project planning (see "Step 2. A. Ecological Monitoring Assessment"; table 1). The decision to use short-term (2 years) versus long-term (3-plus years) is dependent on personnel and funding, and therefore, is decided by the individual FO during the project planning process. Use ecological monitoring methods to quantify treatment effectiveness and integrity over time. Adjust management or monitoring strategies if deemed necessary through monitoring observations.

3. Perform data quality assurance and quality control (QA/QC) on a bi-weekly schedule.
- If using paper datasheets, each paper datasheet is to be entered electronically, initialed in the lower right corner of the sheet by the technician entering data, and electronically scanned and stored in an online storage system.

- If possible, ensure that datasheet recorders cross-reference their own written sheets with what is input on the electronic database.

- Ensure metadata containing site names, waypoints, plant species lists, and so forth, are kept up to date on a bi-weekly basis.

4. If no positive progress is made at a site within the first 2 years of monitoring or every 5 years during long-term monitoring, management and restoration actions can be elevated by using the Restoration Action Decision Tree under the Elevated actions column (table 7). Frequency of monitoring may be altered when monitoring shows a trend in recovery requiring different frequencies. See the "Determine Project Outcome" section for examples.

\section{Step 5. Determine Project Outcome}

The DRECP requires that one of two criteria must be met before the BLM determines a disturbed area has recovered and is removed from the disturbance cap (BLM, 2016):

- Ground disturbance can no longer be seen at the $1: 10,000$ scale when using the best available aerial imagery, or

- Field verification that disturbed area(s) are dominated by the establishment of native shrubs, as appropriate for the site, and have demonstrated function of ecological processes comparable to reference conditions (including measures for soil stability).

\section{Step 5. A. Aerial Imagery Evaluation}

Aerial imagery can be used to determine the visibility of vehicle-related linear disturbances at the 1:10,000 scale, as guided by the DRECP (BLM, 2016; fig. 18A, B). Restoration actions and natural recovery can result in less visibility at this scale. If linear disturbances are still visible, the disturbances must demonstrate presence of native perennial shrubs and functioning ecological processes, which can be determined by following Steps 2-4 of this protocol. 


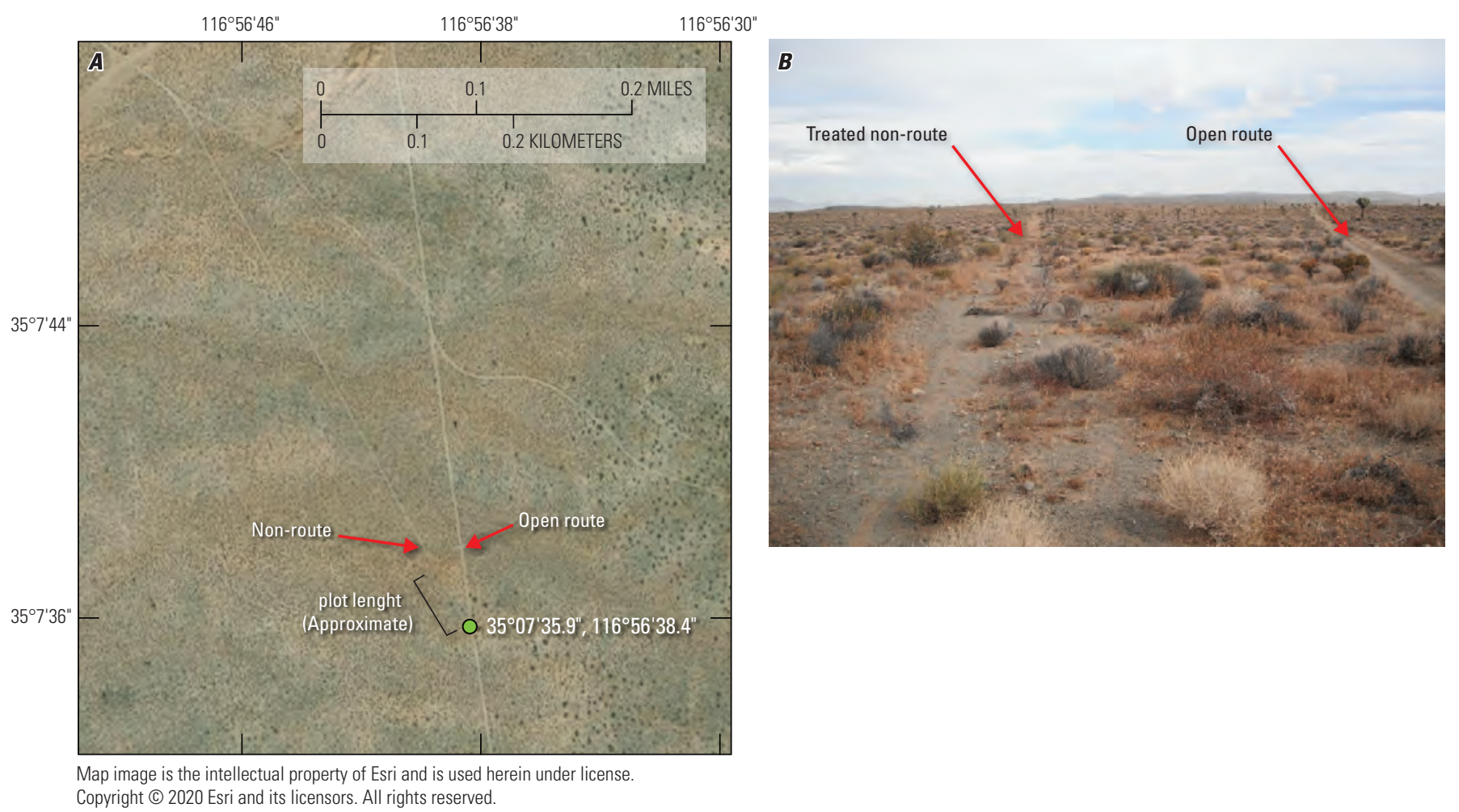

Figure 18. A, Comparison of National Agriculture Imagery Program (NAIP) imagery of a roadhead (green dot) for a treated and closed non-route in comparison with an open route at the 1:10,000 scale; and $B, A$ field photograph from the roadhead of the same closed and open routes. Note camouflage of closed route nearest the roadhead where treatment (vertical mulch) was implemented in NAIP image (A). Photograph taken by the Western Ecological Research Center Road Restoration Team, U.S. Geological Survey, spring 2020.

National Agriculture Imagery Program imagery, which is administered by the U.S. Department of Agriculture's Farm Service Agency, is gathered at mostly 1-m resolution and is made into digital ortho photography that is available to governmental agencies and the public. National Agriculture Imagery Program imagery collection began in 2003 and continues to be acquired during the agricultural growing seasons in the continental United States. National Agriculture Imagery Program imagery may have a 2-year delay for updates online; therefore, the date of imagery will need to be verified. This imagery is available for download at https://datagateway.nrcs.usda.gov/GDGHome DirectDownLoad.aspx.

If it is determined that a vehicle disturbance is still visible in NAIP imagery, the success or failure of a project is then determined by the cessation of further disturbance (from vehicles in particular) and recovery of ecosystem functions in comparison to a reference site. Data from site monitoring are used to quantify the degree of restoration success by evaluating the function of ecological processes. In addition to the ecosystem indicators in table 1, weather (precipitation and temperature) can influence the success of restoration (for example, survival of seedlings or plantings are heavily influenced by weather patterns).

\section{Step 5. B. Ecological Function Evaluation Guidelines}

When evaluating the function of ecological processes on a site, comparisons are made between the pre-treatment (initial) and final ecological monitoring assessment once closure and ecological monitoring have occurred for a minimum of 2 years for short-term monitoring and 3 or more years for long-term monitoring plans.

- Use the data collected from all valid monitoring efforts (for example, LPI, belt transect, basal and canopy gap). Separately, for each quantified monitoring method, plot the values recorded over time on a graph to visualize and quantify when changes in values occur. Then, calculate the percent change from the initial (first) ecological monitoring assessment and the final ecological monitoring assessment. Weather patterns and timing of implementation may influence change over time and will be incorporated into analyses when interpreting data.

- Once determination of a route status is made (restored or not restored), update the status in all relevant databases. 
The following are requirements to classify a route as successfully ecologically restored, as opposed to visually restored at the 1:10,000 scale, and are used in the restoration outcome criteria (table 9) to determine the project outcome for restored ecological functions. One hundred percent of roadheads within a polygon must be considered restored, according to the criteria, for the entire polygon to be considered ecologically restored. These criteria may be adapted as needed as more scientific data and information become available.

\section{Step 5. C. Project Successful}

Once a polygon is deemed successfully restored and all supporting databases are updated, closure monitoring is done at least once every 2-5 years, depending on the area's previous popularity, management requirements, and funding restrictions. To deem a polygon restored, all routes within a polygon must achieve the successfully restored status. Additional management and restoration actions may be triggered if vehicle activity reoccurs in an area.

\section{Step 5. D. Project Unsuccessful}

If a project fails to meet the restoration outcome criteria for polygons (table 9), actions are taken to reimplement restoration or continue ecological monitoring. Each criterion that was not met is carefully examined to:
- Ensure all data QA/QC has been done for the dataset

- Check for observations of new incursions or disturbances

- Plot the dataset over time and observe outliers or aberrations

- Cross-reference other datasets and determine if the outliers are in other datasets

- Cross-reference and compare with weather and climate variables, which influence ecological processes over time

If a reason criteria were not met can be pinpointed, such as user error, actions are planned to address the issue, continue monitoring, or reimplement restoration actions.

If a cause cannot be determined, or if it appears the site simply needs more time to recover, continue ecological and vehicle incursion monitoring for the site every $2-5$ years, depending on the area's previous popularity, management requirements, or funding restrictions. Reimplement or maintain any degraded, destroyed, or missing structures. Management and restoration actions may be triggered or escalated to more intensive methods by using the Restoration Action Decision Tree (table 7) if vehicle activity reoccurs in an area.

Table 9. Use these restoration outcome criteria to determine if a polygon meets the criteria to be considered successfully restored or on a positive trajectory toward success.

$[\%$, percent $]$

\section{Restoration outcome criteria for polygons}

\footnotetext{
If non-routes within the polygon are visible at the 1:10,000 scale, and

No is answered to one or more of the below statements, non-routes within the polygon are monitored at 5-year intervals and additional treatments applied according to the Restoration Decision Tree (table 7).

If non-routes within the polygon are no longer visible at the 1:10,000 scale, and all statements are Yes, the polygon is considered successfully restored.

1. Vehicle use is absent on non-routes during the first 2 years after closure.

Yes or No

2. Restoration structure applied to all non-routes, measured by frequency of vertical mulch and signs on belt transects Yes or No (excluding revegetation), declines no more than $30 \%$ during the first 2 years after treatment.

3. Average compaction for each non-route and each depth, measured by bulk density, is within 10\% of the reference plot Yes or No average.

4. Average soil aggregate stability for each non-route, measured by the soil stability test, is within one stability class of the Yes or No reference plot average.

5. Native perennial plant prevalence for each non-route, measured by frequency on belt transects, is not less than $40 \%$ of the Yes or No reference plot average.

6. Average basal and canopy gap for each non-route is no more than $40 \%$ of reference plot average.

Yes or No
} 


\section{Summary}

Field work completed in 2020 established the feasibility of quantifying the effectiveness of desert road restoration efforts and established a protocol to determine when a polygon of desert habitat has met specified restoration success criteria. The use of polygons for restoration success is an advance in the land management framework because it facilitates making estimations of the areal extent of restoration activities, a benefit over point source data for the interpretation of results.

This protocol to evaluate ecological restoration is the product of a synthesis of literature on desert road restoration methods, questionnaires, and interviews with the U.S. Department of the Interior, Bureau of Land Management (BLM) restoration practitioners across California's Desert District. Consultations also were conducted through webinars and field trips with resource managers from several government and non-government agencies.

As the project matured, it was clear that it would benefit the BLM most to use core methods from the BLMs national Assessment, Inventory, and Monitoring (AIM; Herrick and others, 2009, 2017) program in the protocol. After consultations with the BLM National Operations Center AIM staff, it was clear that supplementary methods could be incorporated into the protocol. Even novel methods could be added if properly evaluated and coordinated. More detailed discussions with AIM staff clarified that using the BLM's established data flow procedures and adopting the digital forms that were already created by the BLM would be most effective for archiving the data. Some of these goals were realized in fiscal year 2020, but data sheets and data flow procedures have been adopted during the 2021 field season.

Consultations with restoration practitioners across the California desert emphasized that, once established, the protection and stability of restoration sites is crucial to restoration success and that this goal is extremely challenging across the desert at this time. However, there have been successes with sufficient investment in restoration activity in conjunction with education and law enforcement.

\section{References Cited}

Abella, S.R., and Newton, A.C., 2009, A systematic review of species performance and treatment effectiveness for revegetation in the Mojave Desert: USA, Arid Environments and Wind Erosion, p. 45-74.

Bainbridge, D.A., 1995, Vertical mulch for site protection and revegetation: Restoration and Management Notes, v. 14, no. $72,6 \mathrm{p}$.

Bainbridge, D.A., 2007, A guide for desert and dryland restoration-New hope for arid lands: Washington D.C., Island Press, $416 \mathrm{p}$.

Bainbridge, D.A., and MacAller, R., 1995, Tree shelters improve desert planting success: Proceeding of the Tree Shelter Conference, GTR-NE-221, p. 57-59.

Beatley, J.C., 1974, Phenological events and their environmental triggers in Mojave Desert ecosystems: Ecology, v. 55, no. 4, p. 856-863, https://doi.org/10.2307/1934421.

Belnap, J., and Warren, S.D., 2002, Patton's tracks in the Mojave Desert, USA-An ecological legacy: Arid Land Research and Management, v. 16, no. 3, p. 245-258, https://doi.org/10.1080/153249802760284793.

Bureau of Land Management, 2016, Desert renewable energy conservation plan record of decision for the land use plan amendment to the California desert conservation area plan, Bishop resource management plan, and Bakersfield resource management plan-September 2016: Bureau of Land Management (BLM/CA/PL-2016/03+1793+8321), https://eplanning.blm.gov/public_projects/lup/66459/ 133460/163124/DRECP_BLM LUPA_ROD.pdf.

Bureau of Land Management, 2020, BLM's terrestrial assessment, inventory, and monitoring (AIM) - 2020 Field season-Data management protocol, version 4.2: Bureau of Land Management, 62 p., accessed December 30, 2020, at https://aim.landscapetoolbox.org/wp-content/uploads/2020/ 03/2020-Data-Management-Protocol-1-2.pdf. 
Bury, R.B., Luckenbach, R.A., and Busack, S.D., 1977, Effects of off-road vehicles on vertebrates in the California desert: U.S. Fish and Wildlife Service, Wildlife Research Report 8, 23 p.

Caldwell, T.G., McDonald, E.V., and Young, M.H., 2009, The seedbed microclimate and active revegetation of disturbed lands in the Mojave Desert: Journal of Arid Environments, v. 73, no. 4-5, p. 563-573, https://doi.org/10.1016/j.jaridenv.2008.12.008.

Chambers, J.C., 2000, Seed movements and seedling fates in disturbed sagebrush steppe ecosystems-Implications for restoration: Ecological Applications, v. 10, no. 5, p. 1400-1413, https://doi.org/10.1890/1051-0761(2000)010 [1400:SMASFI]2.0.CO;2.

Custer, N.A., DeFalco, L.A., Nussear, K.E., and Esque, T.C., 2017, Drawing a line in the sand-Effectiveness of off-highway vehicle management in California's Sonoran Desert: Journal of Environmental Management, v. 193, p. 448-457, https://doi.org/10.1016/j.jenvman.2017.02.033.

DeFalco, L.A., Esque, T.C., Kane, J.M., and Nicklas, M.B., 2009, Seed banks in a degraded desert shrubland-Influence of soil surface condition and harvester ant activity on seed abundance: Journal of Arid Environments, v. 73, no. 10, p. 885-893, https://doi.org/10.1016/j.jaridenv.2009.04.017.

DeFalco, L.A., and Scoles-Sciulla, S.J., 2013, Protocol for documenting disturbances, prioritizing restoration, and evaluating restoration effectiveness for vehicle disturbances in Mojave Desert Uplands-Report prepared in collaboration with Southern Nevada Restoration Team Interagency Partners, National Park Service, Bureau of Land Management, U.S. Fish and Wildlife Service, U.S. Forest Service.

Devine, W.D., and Harrington, C.A., 2008, Influence of four types of tree shelter types on microclimate and seedling performance in Oregon: U.S. Department of Agriculture Report no. PNW-RP-576.

Edwards, F.S., Bainbridge, D.A., Zink, T.A., and Allen, M.F., 2000, Rainfall catchments improve survival of container transplants at Mojave Desert site: Ecological Restoration, v. 18, no. 2, p. 100-103, https://doi.org/10.3368/er.18.2.100.

Egan, T.B., 2000, Restoration of unauthorized routes in sensitive species habitats: Denver, Colo., U.S. Bureau of Land Management, National Applied Resource Sciences Center, Resource notes no. 16, https://permanent.fdlp.gov/ gpo123068/BLMResourceNote16.pdf.

Esque, T.C., DeFalco, L.A., Tyree, G.L., Drake, K.K., Nussear, K.E., and Wilson, J.S., 2021, Priority species list to restore Desert tortoise and pollinator habitats in Mojave Desert shrublands: Natural Areas Journal, v. 41, no. 2 , p. 145-158, https://doi.org/10.3375/043.041.0209.
Gebhardt, M., Fehmi, J.S., Rasmussen, C., and Gallery, R.E., 2017, Soil amendments alter plant biomass and soil microbial activity in a semi-desert grassland: Plant and Soil, v. 419, nos. 1-2, p. 53-70, https://doi.org/10.1007/s11104-017-3327-5.

Grantz, D.A., Vaughn, D.L., Farber, R., Kim, B., Zeldin, M., VanCuren, T., and Campbell, R., 1998, Seeding native plants to restore desert farmland and mitigate fugitive dust and $\mathrm{PM}_{10}$ : Journal of Environmental Quality, v. 27, no. 5, p. 1209-1218, https://doi.org/10.2134/jeq1998.0 $0472425002700050028 x$.

Herrick, J.E., Van Zee, J.W., Havstad, K.M., Burkett, L.M., and Whitford, W.G., 2009, Monitoring manual for grassland, shrubland and Savanna ecosystems, volume IIDesign, supplementary methods and interpretation: Las Cruces, NM, U.S. Department of Agriculture, Agricultural Research Service, Jornada Experimental Range, 200 p.

Herrick, J.E., Van Zee, J.W., McCord, S.E., Courtright, E.M., Karl, J.W., and Burkett, L.M., 2017, Monitoring manual for grassland, shrubland, and Savanna ecosystemsVolume I-Core methods ( $2 \mathrm{~d}$ ed.): U.S. Department of Agriculture, Agricultural Research Service, Jornada Experimental Range, $77 \mathrm{p}$.

Johnson, H.B., Vasek, F.C., and Yonkers, T., 1975, Productivity, diversity and stability relationships in Mojave Desert roadside vegetation: Bulletin of the Torrey Botanical Club, v. 102, no. 3, p. 106-115, https://doi.org/10.2307/2484732.

Longland, W.S., and Ostoja, S.M., 2013, Ecosystem services from keystone species-Diversionary seeding and seed-caching desert rodents can enhance indian ricegrass seedling establishment: Restoration Ecology, v. 21, no. 2, p. 285-291, https://doi.org/10.1111/j.1526-100X.2012.00895.x.

Lovich, J.E., and Bainbridge, D., 1999, Anthropogenic degradation of the southern California desert ecosystem and prospects for natural recovery and restoration: Environmental Management, v. 24, no. 3, p. 309-326, https://doi.org/10.1007/s002679900235.

Montalvo, A.M., McMillan, P.A., and Allen, E.B., 2002, The relative importance of seeding method, soil ripping, and soil variables on seeding success: Restoration Ecology, v. 10, no. 1, p. 52-67, https://doi.org/10.1046/j.1526-100X.2002.10106.x.

National Soil Survey Center, 2009, Soil survey field and laboratory methods manual: Soil Survey Investigations Report No. 51, version 1.0, Burt, R., compiler and editor: Lincoln, Nebraska, National Soil Survey Center, Natural Resources Conservation Service, U.S. Department of Agriculture, $435 \mathrm{p}$. 
Oliet, J.A., and Jacobs, D.F., 2007, Microclimatic conditions and plant morpho-physiological development within a tree shelter environment during establishment of Quercus ilex seedlings: Agricultural and Forest Meteorology, v. 144, nos. 1-2, p. 58-72, https://doi.org/10.1016/j.agrformet.2007.01.012.

Ostler, W.K., and Hansen, D.J., 2003, Diagnostic tools and reclamation technologies for mitigating impacts of $\mathrm{DoD} /$ DOE activities in arid areas: Las Vegas, Nev., Department of Energy, Nevada Operations Office, Final Report, SERDP Project no. CS-1131, 55 p.

Ouren, D.S., Haas, C., Melcher, C.P., Stewart, S.C., Ponds, P.D., Sexton, N.R., Burris, L., Fancher, T.S., and Bowen, Z.H., 2007, Environmental effects of off-highway vehicles on Bureau of Land Management lands-A literature synthesis, annotated bibliographies, extensive bibliographies, and internet resources: U.S. Geological Survey, Open-File Report 2007-1353, 225 p., https://doi.org/10.3133/ofr20071353.

Schmutz, E.M., Reese, M.E., Freeman, B.N., and Weaver, L.C., 1982, Metric belt transect system for measuring cover, composition, and production of plants: Rangelands, v. 4, no. 4, p. 162-164.

Scoles-Sciulla, S.J., DeFalco, L.A., and Esque, T.C., 2015, Contrasting long-term survival of two outplanted Mojave Desert perennials for post-fire revegetation: Arid Land Research and Management, v. 29, no. 1, p. 110-124, https://doi.org/10.1080/15324982.2014.901994.

Society for Ecological Restoration International, 2004, The SER international primer on ecological restoration: Tucson, Arizona, Society for Ecological Restoration International, accessed July 16, 2021, at www.ser.org.

Shryock, D.F., Havrilla, C.A., DeFalco, L.A., Esque, T.C., Custer, N.A., and Wood, T.E., 2017, Landscape genetic approaches to guide native plant restoration in the Mojave Desert: Ecological Applications, v. 27, no. 2, p. 429-445, https://doi.org/10.1002/eap.1447.

Shryock, D.F., DeFalco, L.A., and Esque, T.C., 2018, Spatial decision-support tools to guide restoration and seedsourcing in the Desert Southwest: Ecosphere, v. 9, no. 10, 19 p., https://doi.org/10.1002/ecs2.2453.

Thien, S.J., 1979, A flow diagram for teaching texture-by-feel analysis: Journal of Agronomic Education, v. 8, no. 1, p. 54-55, https://doi.org/10.2134/jae.1979.0054.
Toevs, G.R., Taylor, J.J., Spurrier, C.S., MacKinnon, W.C., and Bobo, M.R., 2011, Bureau of Land Management assessment, inventory, and monitoring strategy-For integrated renewable resources management: Denver, Colo., Bureau of Land Management, National Operations Center, $34 \mathrm{p}$.

Turner, R.M., Webb, R.H., Esque, T.C., and Rogers, G.F., 2010, Repeat photography and low-elevation fire responses in the southwestern United States, chap. 17 of Webb, R.H., Boyer, D.E., and Turner, R.M., eds., Repeat photographyMethods and Applications in the Natural Sciences: Washington, D.C., Island Press, p. 223-244.

Vasek, F.C., Johnson, H.B., and Brum, G.D., 1975, Effects of power transmission lines on vegetation of the Mojave Desert: Madrono, v. 23, p. 114-130.

Walker, L.R., and Powell, E.A., 1999, Effects of seeding on road revegetation in the Mojave Desert, southern Nevada: Ecological Restoration, v. 17, no. 3, p. 150-155, https://doi.org/10.3368/er.17.3.150.

Webb, R.H., 2002, Recovery of severely compacted soils in the Mojave Desert, California, USA: Arid Land Research and Management, v. 16, no. 3, p. 291-305, https://doi.org/10.1080/153249802760284829.

Webb, R.H., Boyer, D.E., and Turner, R.M., eds., 2010, Repeat photography-Methods and applications in the natural sciences: Washington, D.C., Island Press, 392 p.

Webb, R.H., and Wilshire, H.G., eds., 1983, Environmental effects of off-road vehicles: New York, New York, USA, Springer, p. 279-302, https://www.springer.com/gp/book/9781461254560.

Winkel, V.K., Ostler, W.K., Gabbert, W.D., and Lyon, G.E., 1994, Effects of seedbed preparation, irrigation and water harvesting on seedling emergence at the Nevada test site, in Roundy, B.A., McArthur, E.D., Haley, J.S., and Mann, D.K., Proceedings-Wildland shrub and arid land restoration symposium, Las Vegas, NV, October 19-21, 1993: General Technical Report INT-GTR-315, U.S. Department of Agriculture Forest Service, Intermountain Research Station, Ogden, Utah, USA, p. 135-141.

Woods, Caroline S., 2017, Off-highway vehicles (OHV) Rehabilitation-Presentation at the Mojave Desert Ecoregion, Native Plant Materials Development and Restoration Symposium, November 17-19, Barstow, California. 



\section{Glossary}

Aeolian deposit Deposits of sediment grains by wind transportation.

Alluvial deposit Materials, such as clay, sand, gravel, and organic matter, that are deposited by the flow of water or precipitation over the soil surface.

Alluvial fan An accumulation of sediments in the shape of a fan, typically at the base of canyons or mountains, deposited by the interaction of flowing water and mountains, hills, or steep canyons.

Arroyo A steeply, eroded gully formed by fast-moving water, such as flash floods, in an arid or semi-arid region

Aspect Direction of slope (fall linedownslope) in degrees.

Azimuth Compass bearing in direction away from roadhead in degrees based on $\mathrm{N}$ at 0 degrees $\left({ }^{\circ}\right)$.

Bedrock The solid rock buried below soil or other unconsolidated materials.

Blowout erosion Sandy depressions in dune ecosystems caused by the removal of sediments by wind.

Defensible space A restoration method that involves protecting the perimeter of a target restoration area or polygon from further disturbance and vehicle access, allowing the processes of active and passive ecological restoration to proceed. Adjacent restoration areas or polygons can be grouped together to expand the defensible space and increase the area to perimeter ratio of restoration area.

Desert bench or flat $A$ desert landscape that has a low to flat general slope that may or may not be bounded by significantly steeper slopes above and below.

Desert pavement A desert soil surface covered with firmly packed and interlocked rock fragments of gravel and cobble, forming a pavement-like surface.

Ecological restoration The process of halting or minimizing future degradation from use as a route while simultaneously assisting the recovery of ecosystem function and community composition in relation to reference sites.
Elevation Meters above mean sea level.

Grain size The diameter of the individual grains of sediment in soils. Examples include sand, gravel, cobble, and boulder.

Grassland A large open area dominated by grasses.

Gully A channel or ravine in the ground greater than $10 \mathrm{~cm}$ deep that is developed by the erosive action of overland water flow.

Hill/Mountain slope A naturally raised area of land forming a hill or a steep mountain.

Landform Type of geographic feature where a plot occurs (for example, bajada).

Land use/ disturbance history Any known land use history $(\mathrm{OHV}$, military training, hiking, camping, grazing, historic town site, construction history, fire).

Location Name or identifier of land parcel.

Non-route A linear disturbance that is not authorized by BLM for motor vehicle use.

Percent slope Dominant topographic slope in degrees.

Pinyon forest A landscape dominated by pinyon pine trees, sometimes co-dominated by juniper trees.

Plant alliance Predominant plant community present-top number of species based on ocular survey of cover, including one to two visual dominants (for exampl., Larrea tridentata-Ambrosia dumosa).

Playa The flat and lowest part of an interior desert basin that typically has dry conditions but is periodically flooded by water that slowly infiltrates and evaporates, leaving sediment deposits. Playas are characterized by little to no vegetation, sediment or salt crusts, soil cracks (often in clay), and aeolian processes such as dust storms.

Plot type The status of the plot in question: untreated, treated, or reference.

Polygon The target restoration area that is bordered by open access routes.

Polygon ID Unique polygon identifier within each field office. 
Rill A shallow channel less than $10 \mathrm{~cm}$ deep on the soil surface that is developed by the erosive action of overland water flow.

Riparian area An area or habitat that interfaces between land and a river or stream, such as riverbanks. Riparian areas are typically characterized by vegetation with higher water use.

Roadhead The start of a route or non-route at the junction of where a route or non-route meets with the access route.

Rock outcrop An exposed protrusion of rock or rock formation from underneath the soil surface that extends outward.

Route A road, trail, or other route that is authorized for motor vehicle use.

Sand dune A large mass of sand deposits formed by aeolian processes or the flow of water.
Sheet erosion Sheet erosion occurs when large amounts of water or precipitation flow across the land surface, resulting in the removal of surface soil and matter.

Site A single non-route that is being targeted for restoration and monitoring, or a reference area with little to no disturbance that is being targeted for monitoring.

Site ID Unique site identifier.

Undulating desert flat A desert landscape with very low hills that average out to a low to flat (zero degree) slope.

Wash A narrow flat bottom of a canyon or drainage that usually lacks water at or near the surface but is subject to periodic severe flooding events. Typically characterized by the scouring and erosion of the ground and alluvial sediment deposits. 


\section{Appendix 1. Data Sheets}

Table 1.1. Ecological Monitoring Team Supply List.

$\left[\mathrm{m}\right.$, meter; $\mathrm{m}^{2}$, square meter]

\begin{tabular}{|c|c|c|}
\hline Method & Item & Quantity \\
\hline \multirow[t]{4}{*}{ Record taking } & Electronic tablet & 1 \\
\hline & Clip board & 1 \\
\hline & Pen/pencil & 2 \\
\hline & Datasheets & $\begin{array}{c}\text { Number of plots, } \\
\text { plus extras }\end{array}$ \\
\hline UTMs, elevation & Global Positioning System & 1 \\
\hline Aspect, azimuth & Compass & 1 \\
\hline Slope & Clinometer & 1 \\
\hline \multirow[t]{3}{*}{ Photos } & Camera & 1 \\
\hline & Photo ID board & 1 \\
\hline & Dry erase marker & \\
\hline \multirow[t]{3}{*}{ Line-point intercept } & 25-m transect tapes & 3 \\
\hline & Chaining pins (for transect tape) & 6 \\
\hline & Pin flag (for measurement) & 1 \\
\hline \multirow[t]{2}{*}{ Gap intercept } & 25-m transect tapes & 3 \\
\hline & Pin flag (for measurement) & 1 \\
\hline Belt transect & 25-m transect tape, meter sticks, or $1-\mathrm{m}^{2}$ quadrats & 2 \\
\hline \multirow[t]{3}{*}{ Soil stability test } & Soil stability kit & 1 \\
\hline & Stop-watch & 1 \\
\hline & Water & 1 liter \\
\hline \multirow[t]{4}{*}{ Bulk density } & Bags & 6 \\
\hline & Bulk density liner & 1 \\
\hline & Rubber hammer/mallet & \\
\hline & \#3 Soil sieve & \\
\hline
\end{tabular}


Table 1.2. Biological Soil Crust ID.

\begin{tabular}{|c|c|}
\hline Crust type & Description \\
\hline Soil crust & $\begin{array}{l}\text { Soil crusts, either biological or physical, hold surface soils in place. Where plant cover is sparse, crusts are important for } \\
\text { minimizing wind and water erosion. }\end{array}$ \\
\hline Alkali crust & $\begin{array}{l}\text { Any one of various soils found in arid and semiarid regions, containing an unusual amount of soluble mineral salts that } \\
\text { effloresce in the form of a hardened physical crust (usually white). }\end{array}$ \\
\hline $\begin{array}{l}\text { Cyanobacteria - } \\
\text { patchy }\end{array}$ & $\begin{array}{l}\text { Patchy cyanobacteria coverage over the area. Soils with low cyanobacterial biomass can be difficult to distinguish from } \\
\text { soils with no cyanobacteria. If the soil surface looks bare, tap it lightly with a pin flag. If you do not penetrate the soil } \\
\text { surface, or if the pin flag goes through the surface leaving a distinct hole, you have either a physical or biological soil } \\
\text { crust. Pick up a small piece of surface soil and look for hanging fibers; these are cyanobacteria. }\end{array}$ \\
\hline $\begin{array}{l}\text { Cyanobacteria - } \\
\text { continuous }\end{array}$ & $\begin{array}{l}\text { A continuous coverage of cyanobacterial crust over the area. In high densities, cyanobacteria make the surface soil appear } \\
\text { darker than underlying soils. The soil appears slightly roughened, but no lichens or mosses are visible. }\end{array}$ \\
\hline Lichen-patchy & The coverage of lichen crust occurs in patches with intervening areas of bare soil or cyanobacterial crust. \\
\hline
\end{tabular}

\section{Site Selection for Ecological Monitoring Checklist (V2)}

Implementation monitoring, performed over 3 years following restoration implementation, is designed to monitor public closure, treatment integrity, and initial recovery trajectories.

To determine if the disturbance is suitable to enter the Ecological Monitoring stage, designed to monitor recovery of ecosystem function, complete Table 1 . The disturbance is considered suitable if all questions are answered in the affirmative.

Table 1: Suitability for Ecological Monitoring

\begin{tabular}{|c|c|c|}
\hline Questions & & Answer \\
\hline Is the disturbance linear? & Yes $\square$ & No $\square$ \\
\hline $\begin{array}{l}\text { Is the disturbance equal or greater than }(\geq) 77 \text { meters }(m) \text { in } \\
\text { length? }\end{array}$ & Yes $\square$ & No $\square$ \\
\hline Has vehicular activity ceased? & Yes $\square$ & No $\square$ \\
\hline Are treatment structures still intact? & Yes $\square$ & No $\square$ \\
\hline $\begin{array}{l}\text { Is there a suitable tract of land for use as a reference? (1) } \geq 77 \mathrm{~m} \\
\text { in length by } 2 \mathrm{~m} \text { in width in one direction with no curvature, } \\
\text { (2) undisturbed or considerably less disturbed condition, } \\
\text { (3) within } 50 \mathrm{~m} \text { of the restoration plot }\end{array}$ & Yes $\square$ & No $\square$ \\
\hline
\end{tabular}

Is the disturbance suitable for ecological monitoring?

Yes $\square \quad$ No $\square$

Figure 1.1. Study Plot Selection Form for Ecological Monitoring 
Travel Log Form

\begin{tabular}{|l|l|}
\hline Plot ID: & Date: \\
\hline Location/polygon ID: & Recorder: \\
& Driver: \\
\hline Start mileage: & Start time: \\
\hline End mileage: & End time: \\
\hline 1st road junction: & \\
Direction traveled: & \\
\hline 2nd road junction: \\
Direction traveled: \\
\hline 3rd road junction: \\
Direction traveled: \\
\hline 4th road junction: \\
Direction traveled: \\
\hline 5th road junction: \\
Direction traveled: \\
\hline 6th road junction: \\
Direction traveled: \\
\hline Total miles: \\
\hline Notal time: \\
\hline
\end{tabular}

Notes:

Figure 1.2. Travel Log Form. 


\section{Action Implementation Form}

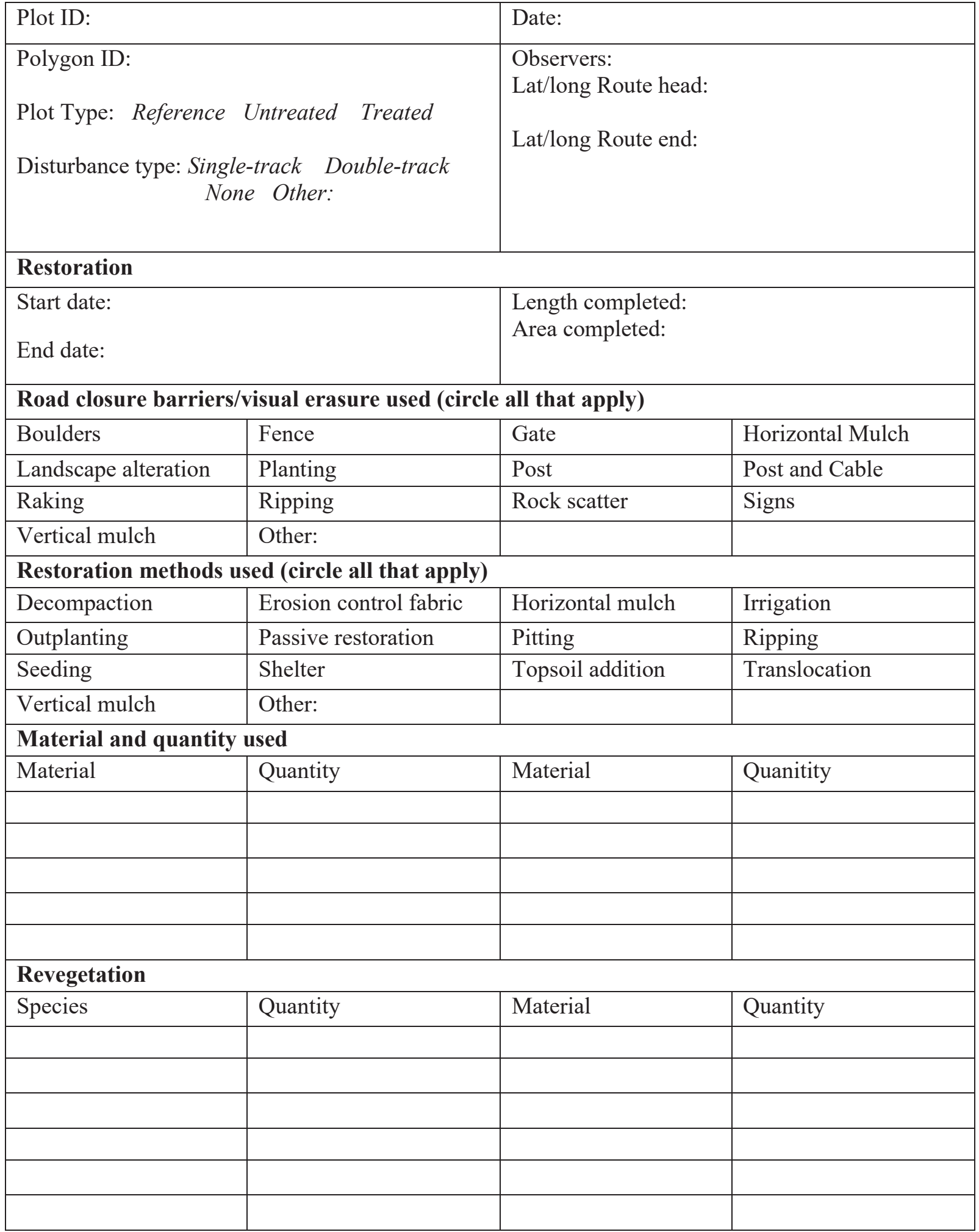

Figure 1.3. Action Implementation Form. 
Closure Monitoring Form

\begin{tabular}{|c|c|}
\hline Plot ID: & Date: \\
\hline Polygon ID: & Observers: \\
\hline Plot Type: Reference Untreated Treated & Lat/long Route head: \\
\hline \multirow[t]{2}{*}{$\begin{array}{l}\text { Disturbance type: Single-track Double-track } \\
\text { None Other: }\end{array}$} & Lat/long Route end: \\
\hline & Dominant plant alliance: \\
\hline Treatment used: Red sign Gate Post-cable & Landform: \\
\hline Vertical mulch Rock-scatter Revegetation N/A & Elevation: \\
\hline Other: & Azimuth: \\
\hline Photo file numbers: & Slope percent: \\
\hline Notes: & \\
\hline \multicolumn{2}{|c|}{ Closure monitoring method used: Raking Pneumatic tubes Photo cameras Other: } \\
\hline \multicolumn{2}{|l|}{ Date range of closure monitoring: } \\
\hline New incursions present? Yes No & $\begin{array}{l}\text { If Yes, source: OHV Hiking Biking Grazing } \\
\text { Other: }\end{array}$ \\
\hline
\end{tabular}

Figure 1.4. Closure Monitoring Form. 
Treatment Monitoring Form

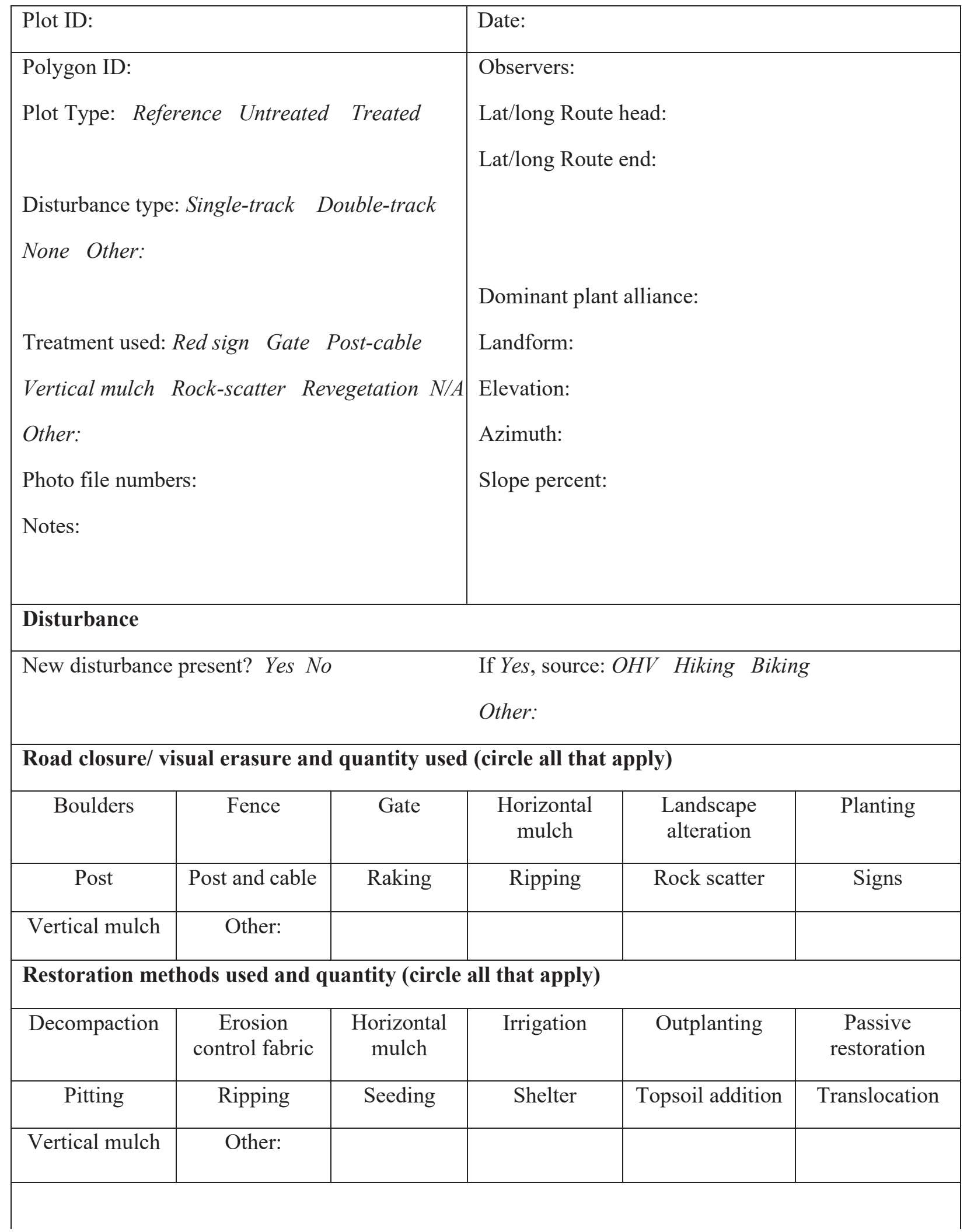

Figure 1.5. Treatment Monitoring Form. 
Number of structures initially implemented:

Previous restoration status: Good Fair Poor Decimated

Number of structures affected, and how:

Recommend retreatment? Yes No

If Yes, recommended treatment(s):

Figure 1.5.-Continued 
Ecological Monitoring Form

\begin{tabular}{|c|c|}
\hline Plot ID: & Date: \\
\hline Polygon ID: & Observers: \\
\hline Plot Type: Reference Untreated Treated & Lat/long Route head: \\
\hline $\begin{array}{l}\text { Disturbance type: Single-track Double-track } \\
\text { None Other: }\end{array}$ & Lat/long Route end: \\
\hline & Dominant plant alliance: \\
\hline Treatment used: Red sign Gate Post-cable & Landform: \\
\hline Vertical mulch Rock-scatter Revegetation N/A & Elevation: \\
\hline Other: & Azimuth: \\
\hline Photo file numbers: & \\
\hline Notes: & Slope percent: \\
\hline \multicolumn{2}{|l|}{ Disturbance } \\
\hline New incursions/recent use present? Yes No & Visibility: None Low Moderate High \\
\hline $\begin{array}{l}\text { If Yes, source: OHV Hiking Grazing } \\
\text { Construction Other: }\end{array}$ & \\
\hline \multicolumn{2}{|l|}{ Biological soil crusts (BSC) } \\
\hline Present? Yes No & BSC classification (circle all that apply): \\
\hline If Yes, BSC damage present? Yes No & $\begin{array}{l}\text { No crust Alkali Cyano-patchy Cyano-continuous } \\
\text { Lichen-patchy Lichen-continuous }\end{array}$ \\
\hline \multicolumn{2}{|l|}{ Erosion } \\
\hline $\begin{array}{l}\text { Erosion classification: } \\
\text { None Low Moderate High }\end{array}$ & $\begin{array}{l}\text { Erosion type: N/A Rills Gullies Sheet erosion } \\
\text { Aeolian deposits Alluvial deposits Fugitive dust } \\
\text { Other: }\end{array}$ \\
\hline \multicolumn{2}{|l|}{ Habitat use } \\
\hline Bioturbation present? Yes No & Wildlife observations/ID: \\
\hline $\begin{array}{l}\text { Bioturbation type: Mound Den Tunnel } \\
\text { Other }\end{array}$ & \\
\hline
\end{tabular}

Figure 1.6. Ecological Monitoring Form. 
Plant Species Inventory (Use AIM form in 2021)

\begin{tabular}{|c|c|c|c|}
\hline \multicolumn{2}{|l|}{ Plot ID: } & \multicolumn{2}{|l|}{ Date: } \\
\hline Species Name & $\begin{array}{l}\text { Native or } \\
\text { Exotic? }\end{array}$ & Species Name & $\begin{array}{l}\text { Native or } \\
\text { Exotic? }\end{array}$ \\
\hline & & & \\
\hline & & & \\
\hline & & & \\
\hline & & & \\
\hline & & & \\
\hline & & & \\
\hline & & & \\
\hline & & & \\
\hline & & & \\
\hline & & & \\
\hline & & & \\
\hline & & & \\
\hline & & & \\
\hline & & & \\
\hline & & & \\
\hline & & & \\
\hline & & & \\
\hline & & & \\
\hline & & & \\
\hline & & & \\
\hline & & & \\
\hline & & & \\
\hline & & & \\
\hline & & & \\
\hline & & & \\
\hline & & & \\
\hline & & & \\
\hline 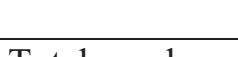 & & & \\
\hline
\end{tabular}

Figure 1.7. Plant Species Inventory 


\section{Line-Point Intercept Form}

Plot ID:

Polygon ID:
Date:

Plot type: Reference Untreated Treated

$\mathrm{POL}=$ Point on Line (for example, $1 \mathrm{~m}$ ). Point codes: $\mathrm{BSC}=$ Biology soil crust, $\mathrm{L}=$ Plant litter, $\mathrm{T}=\mathrm{Trash}$, $\mathrm{RS}=$ Restoration structure, $\mathrm{F}=$ Fine soil $(<0.006 \mathrm{~cm}), \mathrm{S}=$ Sand $(0.006-0.2 \mathrm{~cm}), \mathrm{G}=$ Gravel $(0.2-6 \mathrm{~cm})$, $\mathrm{C}=$ Cobble $(6-20 \mathrm{~cm}), \mathrm{B}=$ Boulder $(>20 \mathrm{~cm}), \mathrm{ER}=$ Rill, $\mathrm{EG}=$ Gully, EA = Aeolian deposit,

$\mathrm{ES}=$ Sheet erosion, $\mathrm{ED}=$ Alluvial deposit, $\mathrm{BT}=$ Bioturbation, $\mathrm{VT}=$ Vehicle track, $\mathrm{W}=$ Woody debris

\begin{tabular}{|c|c||c|c||c|c|}
\hline \multicolumn{2}{|c||}{ Transect 1 } & \multicolumn{2}{|c|}{ Transect 2 } & \multicolumn{2}{|c|}{ Transect 3 } \\
\hline POL & Point/Species code & POL & Point/Species code & POL & Point/Species code \\
\hline
\end{tabular}

\begin{tabular}{|l|l|l|l|l|l|}
\hline & & & & & \\
\hline & & & & & \\
\hline & & & & & \\
\hline & & & & & \\
\hline & & & & & \\
\hline & & & & & \\
\hline & & & & & \\
\hline
\end{tabular}

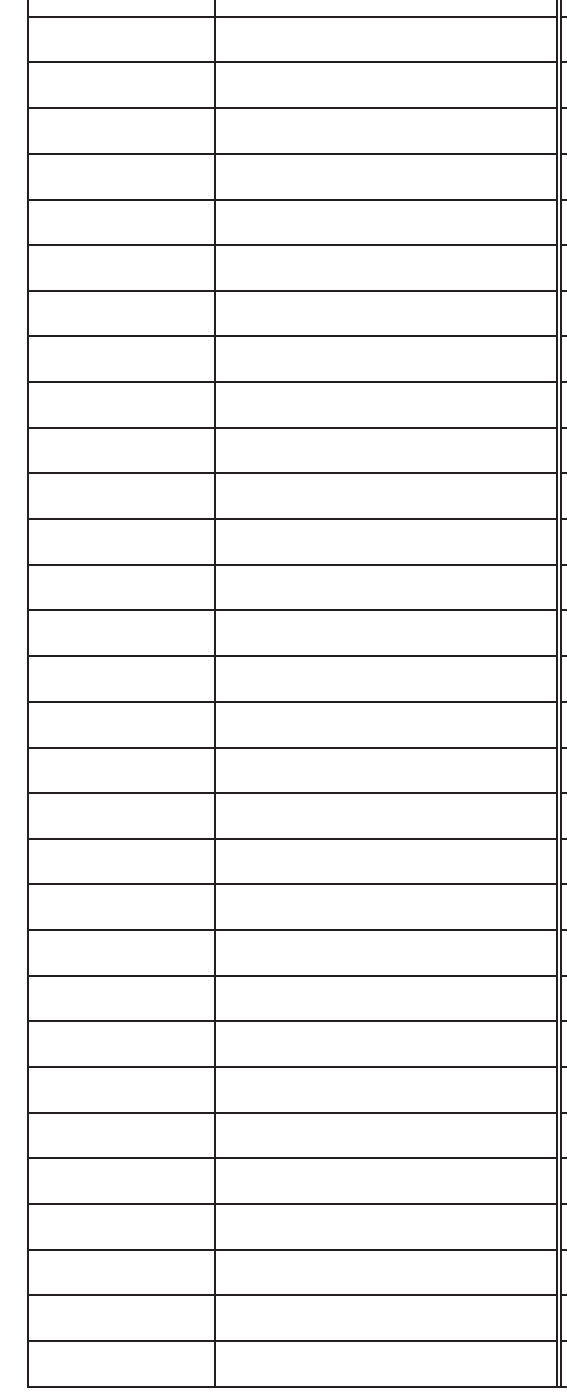

\begin{tabular}{|l|l|}
\hline & \\
\hline & \\
\hline & \\
\hline & \\
\hline & \\
\hline & \\
\hline & \\
\hline & \\
\hline & \\
\hline & \\
\hline & \\
\hline
\end{tabular}

\section{Observers:}

\begin{tabular}{|l|l|}
\hline & \\
\hline & \\
\hline & \\
\hline
\end{tabular}

Figure 1.8. Line-Point Intercept Form. 


\begin{tabular}{|c|c|c|c|c|c|}
\hline \multicolumn{2}{|r|}{ Transect 1} & \multicolumn{2}{|r|}{ Transect 2} & \multicolumn{2}{|r|}{ Transect 3} \\
\hline POL & Point/Species code & POL & Point/Species code & POL & Point/Species code \\
\hline & & & & & \\
\hline & & & & & \\
\hline & & & & & \\
\hline & & & & & \\
\hline & & & & & \\
\hline & & & & & \\
\hline & & & & & \\
\hline & & & & & \\
\hline & & & & & \\
\hline & & & & & \\
\hline & & & & & \\
\hline & & & & & \\
\hline & & & & & \\
\hline & & & & & \\
\hline & & & & & \\
\hline & & & & & \\
\hline & & & & & \\
\hline & & & & & \\
\hline & & & & & \\
\hline & & & & & \\
\hline & & & & & \\
\hline & & & & & \\
\hline & & & & & \\
\hline & & & & & \\
\hline & & & & & \\
\hline & & & & & \\
\hline & & & & & \\
\hline & & & & & \\
\hline & & & & & \\
\hline & & & & & \\
\hline & & & & & \\
\hline & & & & & \\
\hline & & & & & \\
\hline & & & & & \\
\hline & & & & & \\
\hline & & & & & \\
\hline & & & & & \\
\hline & & & & & \\
\hline & & & & & \\
\hline & & & & & \\
\hline & & & & & \\
\hline & & & & & \\
\hline & & & & & \\
\hline & & & & & \\
\hline & & & & & \\
\hline
\end{tabular}

Figure 1.8.-Continued 
Belt Transect Form

Plot ID:

Location/Polygon ID:
Date:

Plot type: Reference Untreated Treated
Observers:

$\mathrm{POL}=$ Point on Line (for example, 0-2 m). Plant type key: NA = Native Annual, NNA = Non-native annual, $\mathrm{PH}=$ Perennial Herb, $\mathrm{PG}=$ Perennial Grass, $\mathrm{WP}=$ Woody Perennial, $\mathrm{SP}=$ Succulent Perennial.

\begin{tabular}{|c|c|c|c|c|c|c|c|c|c|c|c|}
\hline \multicolumn{4}{|c|}{ Transect 1} & \multicolumn{4}{|c|}{ Transect 2} & \multicolumn{4}{|c|}{ Transect 3} \\
\hline POL & $\begin{array}{c}\text { Species } \\
\text { code }\end{array}$ & $\begin{array}{c}\text { Density } \\
\text { count }\end{array}$ & Frequency & POL & $\begin{array}{c}\text { Species } \\
\text { code }\end{array}$ & $\begin{array}{c}\text { Density } \\
\text { count }\end{array}$ & Frequency & POL & $\begin{array}{c}\text { Species } \\
\text { code }\end{array}$ & $\begin{array}{c}\text { Density } \\
\text { count }\end{array}$ & Frequency \\
\hline & & & & & & & & & & & \\
\hline & & & & & & & & & & & \\
\hline & & & & & & & & & & & \\
\hline & & & & & & & & & & & \\
\hline & & & & & & & & & & & \\
\hline & & & & & & & & & & & \\
\hline & & & & & & & & & & & \\
\hline & & & & & & & & & & & \\
\hline & & & & & & & & & & & \\
\hline & & & & & & & & & & & \\
\hline & & & & & & & & & & & \\
\hline & & & & & & & & & & & \\
\hline & & & & & & & & & & & \\
\hline & & & & & & & & & & & \\
\hline & & & & & & & & & & & \\
\hline & & & & & & & & & & & \\
\hline & & & & & & & & & & & \\
\hline & & & & & & & & & & & \\
\hline & & & & & & & & & & & \\
\hline & & & & & & & & & & & \\
\hline & & & & & & & & & & & \\
\hline & & & & & & & & & & & \\
\hline & & & & & & & & & & & \\
\hline & & & & & & & & & & & \\
\hline & & & & & & & & & & & \\
\hline & & & & & & & & & & & \\
\hline & & & & & & & & & & & \\
\hline & & & & & & & & & & & \\
\hline & & & & & & & & & & & \\
\hline & & & & & & & & & & & \\
\hline & & & & & & & & & & & \\
\hline & & & & & & & & & & & \\
\hline & & & & & & & & & & & \\
\hline & & & & & & & & & & & \\
\hline & & & & & & & & & & & \\
\hline & & & & & & & & & & & \\
\hline & & & & & & & & & & & \\
\hline & & & & & & & & & & & \\
\hline & & & & & & & & & & & \\
\hline
\end{tabular}

Figure 1.9. Belt Transect Form. 


\begin{tabular}{|c|c|c|c|c|c|c|c|c|c|c|c|}
\hline \multicolumn{4}{|c|}{ Transect 1} & \multicolumn{4}{|c|}{ Transect 2} & \multicolumn{4}{|c|}{ Transect 3} \\
\hline POL & $\begin{array}{c}\text { Species } \\
\text { code }\end{array}$ & \begin{tabular}{|c|} 
Density \\
count
\end{tabular} & Frequency & POL & $\begin{array}{c}\text { Species } \\
\text { code }\end{array}$ & \begin{tabular}{|c|} 
Density \\
count
\end{tabular} & Frequency & POL & $\begin{array}{c}\text { Species } \\
\text { code }\end{array}$ & \begin{tabular}{|c|} 
Density \\
count
\end{tabular} & Frequency \\
\hline & & & & & & & & & & & \\
\hline & & & & & & & & & & & \\
\hline & & & & & & & & & & & \\
\hline & & & & & & & & & & & \\
\hline & & & & & & & & & & & \\
\hline & & & & & & & & & & & \\
\hline & & & & & & & & & & & \\
\hline & & & & & & & & & & & \\
\hline & & & & & & & & & & & \\
\hline & & & & & & & & & & & \\
\hline & & & & & & & & & & & \\
\hline & & & & & & & & & & & \\
\hline & & & & & & & & & & & \\
\hline & & & & & & & & & & & \\
\hline & & & & & & & & & & & \\
\hline & & & & & & & & & & & \\
\hline & & & & & & & & & & & \\
\hline & & & & & & & & & & & \\
\hline & & & & & & & & & & & \\
\hline & & & & & & & & & & & \\
\hline & & & & & & & & & & & \\
\hline & & & & & & & & & & & \\
\hline & & & & & & & & & & & \\
\hline & & & & & & & & & & & \\
\hline & & & & & & & & & & & \\
\hline & & & & & & & & & & & \\
\hline & & & & & & & & & & & \\
\hline & & & & & & & & & & & \\
\hline & & & & & & & & & & & \\
\hline & & & & & & & & & & & \\
\hline & & & & & & & & & & & \\
\hline & & & & & & & & & & & \\
\hline & & & & & & & & & & & \\
\hline & & & & & & & & & & & \\
\hline & & & & & & & & & & & \\
\hline & & & & & & & & & & & \\
\hline & & & & & & & & & & & \\
\hline & & & & & & & & & & & \\
\hline & & & & & & & & & & & \\
\hline & & & & & & & & & & & \\
\hline & & & & & & & & & & & \\
\hline & & & & & & & & & & & \\
\hline & & & & & & & & & & & \\
\hline & & & & & & & & & & & \\
\hline & & & & & & & & & & & \\
\hline
\end{tabular}

Figure 1.9.-Continued 
Basal Gap Intercept Form

Plot ID:

Location/Polygon ID:

Date:

Plot type: Reference

Untreated Treated

Observers:

Basal Gap ( $\geq 20$ centimeters $(\mathrm{cm})$ continuous gap only; min. basal stem diameter $=1$ millimeter $(\mathrm{mm})$

\begin{tabular}{|c|c|c|c|c|c|c|c|c|}
\hline \multicolumn{3}{|c|}{ Transect 1} & \multicolumn{3}{|c|}{ Transect 2} & \multicolumn{3}{|c|}{ Transect 3} \\
\hline Start & End & Gap size & Start & End & Gap size & Start & End & Gap size \\
\hline & & & & & & & & \\
\hline & & & & & & & & \\
\hline & & & & & & & & \\
\hline & & & & & & & & \\
\hline & & & & & & & & \\
\hline & & & & & & & & \\
\hline & & & & & & & & \\
\hline & & & & & & & & \\
\hline & & & & & & & & \\
\hline & & & & & & & & \\
\hline & & & & & & & & \\
\hline & & & & & & & & \\
\hline & & & & & & & & \\
\hline & & & & & & & & \\
\hline & & & & & & & & \\
\hline & & & & & & & & \\
\hline & & & & & & & & \\
\hline & & & & & & & & \\
\hline & & & & & & & & \\
\hline & & & & & & & & \\
\hline & & & & & & & & \\
\hline & & & & & & & & \\
\hline & & & & & & & & \\
\hline & & & & & & & & \\
\hline & & & & & & & & \\
\hline & & & & & & & & \\
\hline & & & & & & & & \\
\hline & & & & & & & & \\
\hline & & & & & & & & \\
\hline & & & & & & & & \\
\hline & & & & & & & & \\
\hline & & & & & & & & \\
\hline & & & & & & & & \\
\hline & & & & & & & & \\
\hline & & & & & & & & \\
\hline & & & & & & & & \\
\hline & & & & & & & & \\
\hline & & & & & & & & \\
\hline & & & & & & & & \\
\hline & & & & & & & & \\
\hline & & & & & & & & \\
\hline
\end{tabular}

Figure 1.10. Basal Gap Intercept Form. 


\begin{tabular}{|c|c|c|c|c|c|c|c|c|}
\hline \multicolumn{3}{|c|}{ Transect 1} & \multicolumn{3}{|c|}{ Transect 2} & \multicolumn{3}{|c|}{ Transect 3} \\
\hline Start & End & Gap size & Start & End & Gap size & Start & End & Gap size \\
\hline & & & & & & & & \\
\hline & & & & & & & & \\
\hline & & & & & & & & \\
\hline & & & & & & & & \\
\hline & & & & & & & & \\
\hline & & & & & & & & \\
\hline & & & & & & & & \\
\hline & & & & & & & & \\
\hline & & & & & & & & \\
\hline & & & & & & & & \\
\hline & & & & & & & & \\
\hline & & & & & & & & \\
\hline & & & & & & & & \\
\hline & & & & & & & & \\
\hline & & & & & & & & \\
\hline & & & & & & & & \\
\hline & & & & & & & & \\
\hline & & & & & & & & \\
\hline & & & & & & & & \\
\hline & & & & & & & & \\
\hline & & & & & & & & \\
\hline & & & & & & & & \\
\hline & & & & & & & & \\
\hline & & & & & & & & \\
\hline & & & & & & & & \\
\hline & & & & & & & & \\
\hline & & & & & & & & \\
\hline & & & & & & & & \\
\hline & & & & & & & & \\
\hline & & & & & & & & \\
\hline & & & & & & & & \\
\hline & & & & & & & & \\
\hline & & & & & & & & \\
\hline & & & & & & & & \\
\hline & & & & & & & & \\
\hline & & & & & & & & \\
\hline & & & & & & & & \\
\hline & & & & & & & & \\
\hline & & & & & & & & \\
\hline & & & & & & & & \\
\hline & & & & & & & & \\
\hline & & & & & & & & \\
\hline & & & & & & & & \\
\hline
\end{tabular}




\section{Canopy Gap Intercept Form}

Plot ID:

Location/Polygon ID:
Date:

\begin{tabular}{l|l|l} 
Plot type: & Reference & Observers:
\end{tabular}

Canopy Gap ( $\geq 20$ centimeters $(\mathrm{cm})$ continuous gap only; must have $\geq 50$-percent cover of 3 centimeters $(\mathrm{cm})$

\begin{tabular}{|c|c|c|c|c|c|c|c|c|}
\hline \multicolumn{3}{|c|}{ Transect 1} & \multicolumn{3}{|c|}{ Transect 2} & \multicolumn{3}{|c|}{ Transect 3} \\
\hline Start & End & Gap size & Start & End & Gap size & Start & End & Gap size \\
\hline & & & & & & & & \\
\hline & & & & & & & & \\
\hline & & & & & & & & \\
\hline & & & & & & & & \\
\hline & & & & & & & & \\
\hline & & & & & & & & \\
\hline & & & & & & & & \\
\hline & & & & & & & & \\
\hline & & & & & & & & \\
\hline & & & & & & & & \\
\hline & & & & & & & & \\
\hline & & & & & & & & \\
\hline & & & & & & & & \\
\hline & & & & & & & & \\
\hline & & & & & & & & \\
\hline & & & & & & & & \\
\hline & & & & & & & & \\
\hline & & & & & & & & \\
\hline & & & & & & & & \\
\hline & & & & & & & & \\
\hline & & & & & & & & \\
\hline & & & & & & & & \\
\hline & & & & & & & & \\
\hline & & & & & & & & \\
\hline & & & & & & & & \\
\hline & & & & & & & & \\
\hline & & & & & & & & \\
\hline & & & & & & & & \\
\hline & & & & & & & & \\
\hline & & & & & & & & \\
\hline & & & & & & & & \\
\hline & & & & & & & & \\
\hline & & & & & & & & \\
\hline & & & & & & & & \\
\hline & & & & & & & & \\
\hline & & & & & & & & \\
\hline & & & & & & & & \\
\hline & & & & & & & & \\
\hline & & & & & & & & \\
\hline & & & & & & & & \\
\hline & & & & & & & & \\
\hline
\end{tabular}

Figure 1.11. Canopy Gap Intercept Form. 


\begin{tabular}{|c|c|c|c|c|c|c|c|c|}
\hline \multicolumn{3}{|c|}{ Transect 1} & \multicolumn{3}{|c|}{ Transect 2} & \multicolumn{3}{|c|}{ Transect 3} \\
\hline Start & End & Gap size & Start & End & Gap size & Start & End & Gap size \\
\hline & & & & & & & & \\
\hline & & & & & & & & \\
\hline & & & & & & & & \\
\hline & & & & & & & & \\
\hline & & & & & & & & \\
\hline & & & & & & & & \\
\hline & & & & & & & & \\
\hline & & & & & & & & \\
\hline & & & & & & & & \\
\hline & & & & & & & & \\
\hline & & & & & & & & \\
\hline & & & & & & & & \\
\hline & & & & & & & & \\
\hline & & & & & & & & \\
\hline & & & & & & & & \\
\hline & & & & & & & & \\
\hline & & & & & & & & \\
\hline & & & & & & & & \\
\hline & & & & & & & & \\
\hline & & & & & & & & \\
\hline & & & & & & & & \\
\hline & & & & & & & & \\
\hline & & & & & & & & \\
\hline & & & & & & & & \\
\hline & & & & & & & & \\
\hline & & & & & & & & \\
\hline & & & & & & & & \\
\hline & & & & & & & & \\
\hline & & & & & & & & \\
\hline & & & & & & & & \\
\hline & & & & & & & & \\
\hline & & & & & & & & \\
\hline & & & & & & & & \\
\hline & & & & & & & & \\
\hline & & & & & & & & \\
\hline & & & & & & & & \\
\hline & & & & & & & & \\
\hline & & & & & & & & \\
\hline & & & & & & & & \\
\hline & & & & & & & & \\
\hline & & & & & & & & \\
\hline & & & & & & & & \\
\hline & & & & & & & & \\
\hline & & & & & & & & \\
\hline & & & & & & & & \\
\hline & & & & & & & & \\
\hline
\end{tabular}

Figure 1.11.-Continued 
Soil Stability Form

\begin{tabular}{|c|c|c|c|c|c|c|c|c|c|c|}
\hline \multicolumn{6}{|c|}{ Plot ID: } & \multicolumn{5}{|c|}{ Date: } \\
\hline \multicolumn{4}{|c|}{ Location/Polygon ID: } & \multicolumn{3}{|c|}{$\begin{array}{c}\text { Plot type: Reference } \\
\text { Untreated } \quad \text { Treated }\end{array}$} & \multicolumn{4}{|c|}{ Observers: } \\
\hline \multicolumn{11}{|c|}{$\begin{array}{l}\text { Veg = NC (no perennial canopy); C (perennial cover); G (grass or grass/shrub mix), F (forb), S (shrub), } \\
\text { T (tree); M (root mat); Class = Stability value (1-6). Circle value if samples are hydrophobic. }\end{array}$} \\
\hline Tray & Position & Veg & In time & Dip time & Class & Position & Veg & In time & Dip time & Class \\
\hline \multirow[t]{3}{*}{1} & & & $0: 00$ & $5: 00$ & & & & $0: 45$ & $5: 45$ & \\
\hline & & & $0: 15$ & $5: 15$ & & & & $1: 00$ & $6: 00$ & \\
\hline & & & $0: 30$ & $5: 30$ & & & & $1: 15$ & $6: 15$ & \\
\hline \multirow[t]{3}{*}{2} & & & $1: 30$ & $6: 30$ & & & & $2: 15$ & $7: 15$ & \\
\hline & & & $1: 45$ & $6: 45$ & & & & $2: 30$ & $7: 30$ & \\
\hline & & & $2: 00$ & $7: 00$ & & & & $2: 45$ & $7: 45$ & \\
\hline \multirow[t]{3}{*}{3} & & & $3: 00$ & $8: 00$ & & & & $3: 45$ & $8: 45$ & \\
\hline & & & $3: 15$ & $8: 15$ & & & & $4: 00$ & 9:00 & \\
\hline & & & $3: 30$ & $8: 30$ & & & & $4: 15$ & $9: 15$ & \\
\hline
\end{tabular}

\begin{tabular}{|l|l|l|}
\hline Average Soil Stability $=$ Sum of Rankings/ Total Number of Samples Taken \\
\hline All samples & $\begin{array}{l}\text { Protected samples } \\
(\text { Veg }=\mathrm{C}, \mathrm{G}, \mathrm{F}, \mathrm{S}, \mathrm{T}, \mathrm{M})\end{array}$ & $\begin{array}{l}\text { Unprotected samples } \\
(\text { Veg = NC) }\end{array}$ \\
\hline & & \\
\hline
\end{tabular}

Notes:

Figure 1.12. Soil Stability Form. 


\begin{tabular}{|c|c|c|c|c|c|}
\hline \multicolumn{6}{|c|}{ Line-point intercept (Attach corresponding data sheet) } \\
\hline Transect number & \multicolumn{3}{|c|}{ Percent $(\%)$ total bare cover } & \multicolumn{2}{|c|}{$\%$ Total foliar cover } \\
\hline \multicolumn{6}{|c|}{ 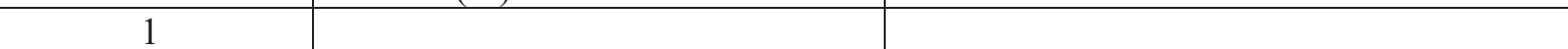 } \\
\hline \multicolumn{6}{|l|}{2} \\
\hline \multicolumn{6}{|l|}{3} \\
\hline \multicolumn{6}{|c|}{ Gap intercept (Attach corresponding data sheet) } \\
\hline Transect number & $\begin{array}{c}\% 25-50 \\
\text { centimeters }(\mathrm{cm})\end{array}$ & \multicolumn{2}{|c|}{$\begin{array}{c}\% 51-100 \\
\text { centimeters }(\mathrm{cm})\end{array}$} & $\begin{array}{c}\% 101-200 \\
\text { centimeters }(\mathrm{cm})\end{array}$ & $\begin{array}{c}\%>>200 \\
\text { centimeters }(\mathrm{cm})\end{array}$ \\
\hline \multicolumn{6}{|c|}{ 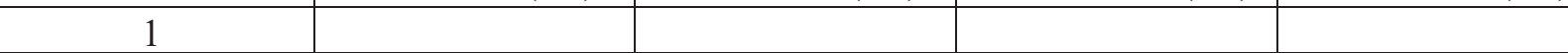 } \\
\hline \multicolumn{6}{|l|}{2} \\
\hline \multicolumn{6}{|l|}{3} \\
\hline \multicolumn{6}{|c|}{ Soil stability (use soil stability kit; Attach corresponding data sheet) } \\
\hline \multicolumn{3}{|c|}{\begin{tabular}{l|l} 
All samples average & Protected surface average \\
\end{tabular}} & \multicolumn{3}{|c|}{ Unprotected surface average } \\
\hline \multicolumn{6}{|c|}{ Soil texture (indicate if texture by feel method or hydrometer method) } \\
\hline \multicolumn{6}{|c|}{ Soil bulk density (indicate if core or excavation method; two samples/transect) } \\
\hline \multicolumn{6}{|c|}{\begin{tabular}{l|l} 
Transect 1 &
\end{tabular}} \\
\hline \multicolumn{6}{|l|}{ Transect 2} \\
\hline Transect 3 & & & & & \\
\hline
\end{tabular}

Figure 1.13. Calculations. 


\section{Appendix 2. Supplemental Methods}

The methods listed in appendix 2 are supplemental methods for restoration and site monitoring that are under consideration for use at the printing of this document. Additional work is being conducted in the 2021 field season to determine their inclusion or exclusion. Methods presented within the protocol should be explored first before adding supplemental methods.

1. Erosion control-Vehicles can cause significant changes to the erosion of a site, including exacerbating wind and water erosion. Most of the Supplemental Methods require further evaluation and more research before implementation, and therefore, are not discussed in more detail.

2. Organic or gravel mulch-Gravel or organic mulches, such as bark, jute, and straw can be used to provide safe sites and seed microsites that promote germination and soil moisture retention. Mulches can reduce erosion, increase soil stabilization, retain soil moisture and nutrients, and catch seeds. Mulches can also act as a visual disguise for roads. Both horizontally and vertically placed mulches of various materials can be used.

3. Invasive species removal-Invasive species can be facilitated by disturbances and have detrimental effects on ecosystems, such as altered fire regimes (Brown and Minnich, 1986; D'Antonio and Vitousek, 1992), altered nutrient cycling (D'Antonio and Vitousek, 1992; Esque and others, 2010), vegetation community shifts (Brooks, 2003), and decreased biodiversity (D'Antonio and Vitousek, 1992; Brooks and Pyke, 2001; Báez and Collins, 2008; Asner and others, 2008; Barrows and others, 2009; Hejda and others, 2009; Marshall and others, 2012).

- Herbicide-The use of herbicides is commonly used to control invasive species and can be implemented in several ways, including backpack sprayers and aerial applications. However, herbicide can negatively affect native plant populations and must be carefully applied to avoid contamination of non-target plants or soil, making backpack sprayers a preferred method. Herbicide mixtures and strengths used depend on target species and growth forms (grass versus herbaceous, annual versus perennial, and herbaceous versus woody) and should be selected based on the invasive species present.

- Manual removal-In areas with low densities and covers of invasive species, manual removal may be sufficient to control unwanted plants. This can be done through hand pulling, shovels, picks, and other hand tools. This method requires extensive manual labor and time compared to herbicide treatments and may be best suited for small scale restoration sites with few invasives present. Another consideration is that hand removal is most efficacious with large individual plants, such as perennial grasses, established tamarisk, or Sahara mustard. In the Mojave Desert the primary invasives are annual grasses that are not conducive to hand removal at a large scale.

- All-terrain vehicle (ATV) chain-drag-In some severe cases of invasions, chain-dragging (usually by means of ATV) may be used to remove surface vegetation. This method could cause significant soil disturbances and should only be implemented in severe cases.

3. Irrigation-Many forms of irrigation exist, with mixed positive and negative results. These methods are supplemental, and other methods provided in the protocol should be explored first.

- Time release water-Time release water packs,

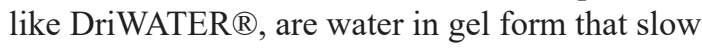
releases when it degrades in soil; they can provide a steady source of water to plants when placed in the soil at the plant base. This method may be especially useful in arid environments, such as the Mojave Desert, and during times of drought. Time release water packs can be time and labor saving and are relatively budget friendly but may not be suitable for all plant species.

- Water infiltration-The rate at which water infiltrates the soil can have a significant effect on plant growth and survival. One method to measure water infiltration is the use of a single-ring infiltrometer. A single-ring infiltrometer provides a relative indication of infiltration under saturated conditions and is comparable in efficacy to a double-ring infiltrometer. This method may not be suitable if the site contains a high amount (greater than 10 percent) of gravel and cobble (grain sizes greater than 2 millimeters [mm]), steep slopes, or areas with dense root mats at the surface. The single-ring infiltrometer method is not recommended as a core method.

4. Soil amendments - Soil amendments can be used to improve soil conditions and provide essential nutrients and biota to disturbed soils. However, these methods can be costly and require special circumstances and planning, and they may have negative effects. Therefore, these methods should be used sparingly. 
- Topsoil salvage-Salvaged topsoil from a construction or disturbance site can be used to amend the soil on restoration sites to relieve compaction and provide necessary nutrients and seeds to the disturbed soil. Most seeds in the Mojave Desert are found in the top 5 centimeters $(\mathrm{cm})$ of soil (Guo and others, 1998) and the upper layers of soil contain seedbank, organic matter, biocrust, and microbiota (Wallace and others, 1980). Thus, it is not recommended to gather topsoil from deeper than $5 \mathrm{~cm}$ to avoid seedbank dilution (Scoles-Sciulla and DeFalco, 2009). Soil should be sourced by targeting similar soil characteristics, and preferably using soil from a nearby site. Any plantings should take place after topsoil amendments for best chances of plant survival and to reduce erosion potential of the topsoil (Abella and Berry, 2016). Some considerations on use of topsoil are below.

- Shovels, draglines, excavators, scrapers, and dozers can be used to salvage topsoil.

- Salvaging topsoil at $5 \mathrm{~cm}$ requires trained equipment operators.

- Soil must be handled carefully to avoid degrading soil quality.

- Use salvaged topsoil immediately, though storing topsoil in piles can help extend the biological activity and quality if needed (Bainbridge, 2007).

- Mycorrhizal fungi-Mycorrhizal fungi such as vesicular arbuscular mycorrhizal fungi (VAM) can increase nutrient uptake in plants by colonizing roots and is found on most of the native Mojave Desert perennial plants (Titus and others, 2002). Focused application of VAM into planted or existing native plant species on a restoration site can greatly help their survival and growth (Bethlenfalvay and others, 1984). Some considerations are:

- Inoculation material is best obtained from nursery or field soils and roots underneath existing native plants (Bainbridge, 2007).

- Inoculated soil can be layered in planting holes or containers to accommodate germination requirements.

- Be aware that the use of native soil may risk spread of plant pathogens (Bainbridge, 2007).

- Biological soil crusts (BSCs) - BSCs can contribute significantly to soil stability, nutrient cycling, and hydrological processes in the deserts, especially where vegetative cover is limited. The inoculation of BSCs on appropriate sites can assist with the recovery of ecosystem functions (Chiquoine and others, 2016), while providing soil stability to help prevent further erosion.

5. Nutrient addition-Direct addition of nutrients can aid the establishment of vegetation by providing essential nutrients in a resource limited environment. However, the addition of nutrients has been shown to increase the prevalence of invasive plants on arid lands (McLendon and Redente, 1991; Brooks, 2003) and is therefore discouraged.

6. Soil moisture-To determine the soil moisture of a plot, a soil moisture sensor or a soil sample and the wet and oven-dry weight method can be used:

- Soil moisture sensor: The soil moisture sensor method is easiest. Measurement methods can vary by brand of sensor used; follow manufacturer instructions.

- Wet and oven-dry weight method:

- Take a fist-sized volume of soil from each of three random spots within the plot. Combine the samples together in an air-tight plastic bag or container for transport if needed.

- Using a scale, tare to zero an empty small tin container for the soil. As soon as possible, so as not to lose soil moisture, place a scoop of the mixed soil in the tin container and weigh. Record as wet weight.

- Place the tin with sample in a drying oven for 24 hours at 105 degrees Celsius $\left({ }^{\circ} \mathrm{C}\right)$. Weigh again once the sample is completely dry. Record as dry weight.

- Use the following equation to determine soil moisture percentage:

- $[($ wet weight)-(dry weight) $] /($ dry weight $)$ x100 percent

7. Soil texture by hydrometer-The hydrometer method is a laboratory method used to determine the textural class of a soil sample. Textural class is defined by the relative proportion of sand, silt, and clay in each sample. Soil texture of a site is important to plant establishment and recovery potential of disturbed sites.

- After obtaining bulk density information, sieve oven-dried soils (from bulk density core) to $2 \mathrm{~mm}$. Record weights of greater than or equal to $2 \mathrm{~mm}$ and less than 2-mm particles.

- Weigh out 40 grams of less than $2 \mathrm{~mm}$ oven-dried soil and place in a mixing cup. 
- Add 100 milliliters $(\mathrm{mL})$ of sodium hexametaphosphate solution (50 grams per liter $[\mathrm{g} / \mathrm{L}])$ to the soil in the cup.

- Add $100 \mathrm{~mL}$ of deionized water to the soil solution (total of $200 \mathrm{~mL}$ of solution is in the cup now).

- Attach the cup to the mixer and then plug it in. Mix for 5 minutes.

- After 5 minutes, empty the mixed soil solution into the $1000 \mathrm{~mL}$ glass sedimentation cylinder. Use deionized water to rinse all the soil from the cup and fill the cylinder to the $1000 \mathrm{~mL}$ line (labeled white line around the circumference of the cylinder near the top).

- Use a long-handled stir rod to resuspend particles that have settled to the bottom back into the water column. Stir in an up-and-down motion for 30 seconds.

- Start timer immediately after stirring ceases and insert hydrometer and thermometer.

- Record hydrometer and temperature readings at exactly 40 seconds.

- If a reading at exactly 40 seconds is missed, restart with step 7 .

- After taking the readings, remove the hydrometer and rinse it.

- Take an additional hydrometer and thermometer reading at 120 minutes. Reinsert the hydrometer 15 seconds before the reading

- It is important to be careful not to move or jostle the settling cylinder during this procedure. Any movement could resuspend fine particles that had already settled, which will provide inaccurate measurements.

8. Soil water-holding capacity-If water infiltrates the soil surface and penetrates subsurface layers, the next question is how much water that it is available for plant growth can be held by the soil. The water-holding capacity of a soil is directly related to soil texture and organic matter content. It can be defined as the water that is held against the force of gravity and is readily available to plants. The amount of water held has a direct relationship with soil texture. Sandier soils tend to have lower holding capacities because the large pores between the grains drain quickly (National Soil Survey Center, 2009). However, these dynamics are dependent on other factors such as the texture of the soil surface and the texture of deeper soil layers.

- The soil textural class determined from the hydrometer method described earlier can be used to estimate an index of soil water-holding capacity (table 2.1). However, highly compacted soils can behave differently from those used to develop this index. This method is being? vetted by the U.S. Geological Survey field team in 2021.

9. Surface topography - Surface topography for road and trail cross sections (fig. 2.1) within the study plot will have a specific visual characteristic depending on the soil type, the source of the disturbance, how long the disturbance has existed, and how much traffic uses the route. This method is designed to provide a quantitative measure of the intensity of soil disturbance as well as a permanent visual record of the disturbance (photos).

Table 2.1. Range of water holding capacity for a soil based on textural class.

$\left[\mathrm{H}_{2} \mathrm{O} / \mathrm{ft}\right.$, water per foot $]$

\begin{tabular}{lc}
\hline \multicolumn{1}{c}{ Textural class } & $\begin{array}{c}\text { Water holding capacity } \\
\text { (inches of } \mathbf{H}_{\mathbf{2}} \mathbf{O} / \mathrm{ft} \text { soil) }\end{array}$ \\
\hline Coarse sand & $0.25-0.75$ \\
Fine sand & $0.75-1.00$ \\
Loamy sand & $1.10-1.20$ \\
Sandy loam & $1.25-1.40$ \\
Fine sandy loam & $1.50-2.00$ \\
Silt loam & $2.00-2.50$ \\
Silty clay loam & $1.80-2.00$ \\
Silty clay & $1.50-1.70$ \\
Clay & $1.20-1.50$ \\
\hline
\end{tabular}




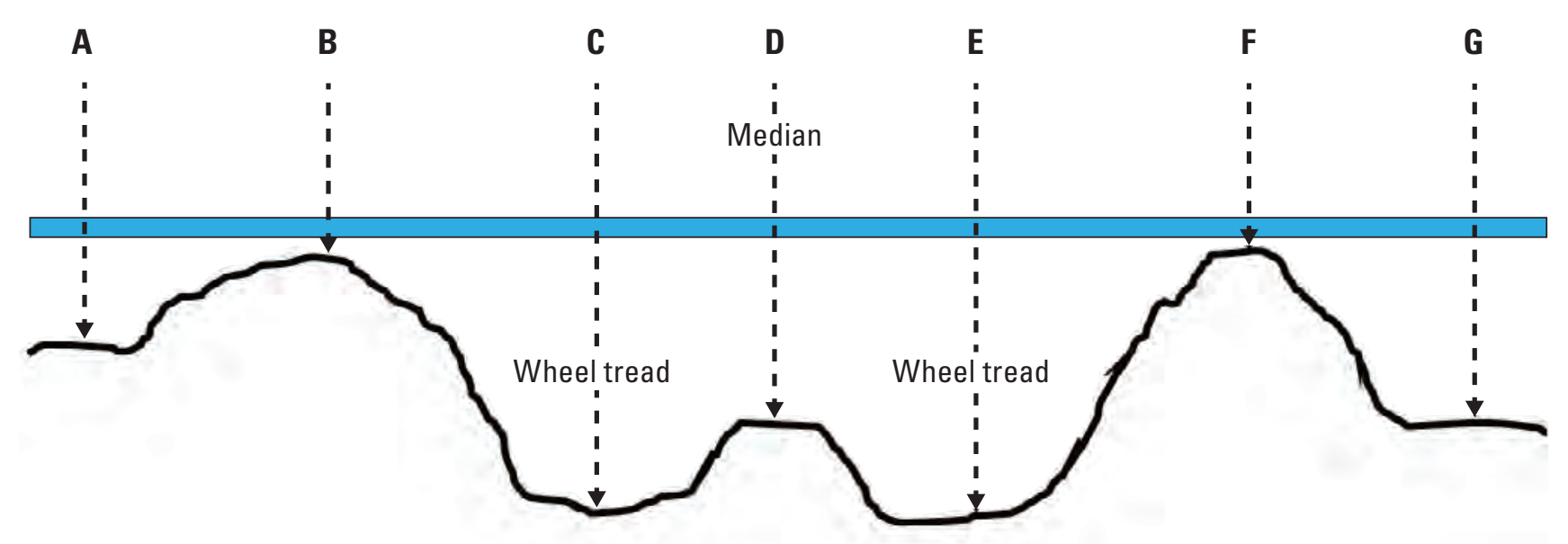

EXPLANATION

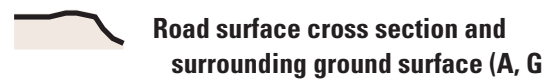

$\square$ Road berm peak (B, F)

surrounding ground surface (A, G)

Figure 2.1. Illustration of method to identify road or trail cross section. A pole (blue line in figure) is placed across the roadperpendicular to the tread (measure the slope of the pole by placing an inclinometer on top of it and indicate direction of slope using compass azimuth). The pole may be lying on the landscape level elevation ( $A, G)$, on the berm of the road ( $B, F)$, or a combination of the two on variable surfaces. Make measurements vertically to quantify the difference between the pole and the surrounding landscape (points $A$ and $G$; may be ' 0 '), the highest point on each berm of the road or trail (B and $F$ ), the lowest part of the each tread on the trail ( $C$ and $E$ ), and the highest part of the median ( $D$; may not be different from the treads). An index of soil displacement can be calculated by adding the vertical distances from the pole to the soil surface at each of the measurement points. 


\section{References Cited}

Abella, S.R., and Berry, K.H., 2016, Enhancing and restoring habitat for the desert tortoise: Journal of Fish and Wildlife Management v. 7, no. 1, p. 255-279, https://doi.org/10.3996/052015-JFWM-046.

Asner, G.P., Hughes, R.F., Vitousek, P.M., Knapp, D.E., Kennedy-Bowdoin, T., Boardman, J., Martin, R.E., Eastwood, M., and Green, R.O., 2008, Invasive plants transform the three-dimensional structure of rain forests: Proceedings of the National Academy of Sciences of the United States of America, v. 105, no. 11, p. 4519-4523, https://doi.org/10.1073/pnas.0710811105.

Báez, S., and Collins, S.L., 2008, Shrub invasion decreases diversity and alters community stability in northern Chihuahuan Desert plant communities: PLoS One, v. 3, no. 6, 8 p., https://doi.org/10.1371/journal.pone.0002332.

Bainbridge, D.A., 2007, A guide for desert and dryland restoration-New hope for arid lands: Washington D.C., Island Press, 416 p.

Barrows, C.W., Allen, E.B., Brooks, M.L., and Allen, M.F., 2009 , Effects of an invasive plant on a desert sand dune landscape: Biological Invasions, v. 11, no. 3, p. 673-686, https://doi.org/10.1007/s10530-008-9282-6.

Bethlenfalvay, G.J., Dakessian, S., and Pacovsky, R.S., 1984, Mycorrhizae in a southern California desert-Ecological implications: Canadian Journal of Botany, v. 62, no. 3, p. 519-524, https://doi.org/10.1139/b84-077.

Brooks, M.L., 2003, Effects of increased soil nitrogen on the dominance of alien annual plants in the Mojave Desert: Journal of Applied Ecology, v. 40, no. 2, p. 344-353, https://doi.org/10.1046/j.1365-2664.2003.00789.x.

Brooks, M.L., and Pyke, D.A., 2001, Invasive plants and fire in the deserts of North America, in Galley, K.E.M., and Wilson, T.P., eds., Proceedings of the invasive species workshop-The role of fire in the spread and control of invasive species: Fire Conference 2000, The First National Congress on Fire Ecology, Prevention, and Management: Tallahassee, FL, Tall Timbers Research Station, Miscellaneous Publication No. 11, p. 1-14.

Brown, D.A., and Minnich, R.A., 1986, Fire and changes in creosote bush shrub of the western Sonoran Desert, California: American Midland Naturalist, v. 116, no. 2, p. 411-422, https://doi.org/10.2307/2425750.

Chiquoine, L.P., Abella, S.R., Bowker, M.A., 2016, Rapidly restoring biological soil crusts and ecosystem functions in a severely disturbed desert ecosystem: Ecological Applications, v. 26, no. 4, p. 1260-1272, https://doi.org/10.1002/15-0973.
D’Antonio, C.M., and Vitousek, P.M., 1992,

Biological invasions by alien grasses, the grass/ fire cycle and global change: Annual Review of Ecology and Systematics, v. 23, no. 1, p. 63-87, https://doi.org/10.1146/annurev.es.23.110192.000431.

Esque, T.C., Kaye, J.P., Eckert, S.E., DeFalco, L.A., and Tracy, C.R., 2010, Short-term soil inorganic $\mathrm{N}$ pulse after experimental fire alters invasive and native annual plant production in a Mojave Desert shrubland: Oecologia, v. 164, no. 1, p. 253-263, https://doi.org/10.1007/s00442-010-1617-1.

Guo, Q., Rundel, P.W., and Goodall, D.W., 1998, Horizontal and vertical distribution of desert seed banks - Patterns, causes, and implications: Journal of Arid Environments, v. 38, no. 3, p. 465-478, https://doi.org/10.1006/jare.1997.0353.

Hejda, M., Pyšek, P., and Jarošík, V., 2009, Impact of invasive plants on the species richness, diversity and composition of invaded communities: Journal of Ecology, v. 97, no. 3, p. 393-403, https://doi.org/10.1111/j.1365-2745.2009.01480.x.

Marshall, V.M., Lewis, M.M., and Ostendorf, B., 2012, Buffel grass (Cenchrus ciliaris) as an invader and threat to biodiversity in arid environments - A review: Journal of Arid Environments, v. 78, p. 1-12, https://doi.org/10.1016/j.jaridenv.2011.11.005.

McLendon, T., and Redente, E.F., 1991, Nitrogen and phosphorus effects on secondary succession dynamics on a semi-arid sagebrush site: Ecology, v. 72, no. 6, p. 2016-2024, https://doi.org/10.2307/1941556.

National Soil Survey Center, 2009, Soil survey field and laboratory methods manual, Soil Survey Investigations Report No. 51, version 1.0, Burt, R., comp. and ed., National Soil Survey Center, Natural Resources Conservation Service, U.S. Department of Agriculture, Lincoln, Nebraska, 435 p.

Scoles-Sciulla, S.J., and DeFalco, L.A., 2009, Seed reserves diluted during surface soil reclamation in eastern Mojave Desert: Arid Land Research and Management v. 23, p. 1-13.

Titus, J.H., Titus, P.J., Nowak, R.S., and Smith, S.D., 2002, Arbuscular mycorrhizae of Mojave Desert plants: Western North American Naturalist, v. 62, no. 3, p. 327-334.

Wallace, A., Romney, E.M., and Hunter, R.B., 1980, The challenge of a desert-Revegetation of disturbed desert lands: Great Basin Naturalist Memoirs, v. 4, no. 31, p. 216-225. 
For more information concerning the research in this report, contact the

Director, Western Ecological Research Center

U.S. Geological Survey

3020 State University Drive East

Sacramento, California 95819

https://www.usgs.gov/centers/werc

Publishing support provided by the U.S. Geological Survey

Science Publishing Network, Sacramento Publishing Service Center 


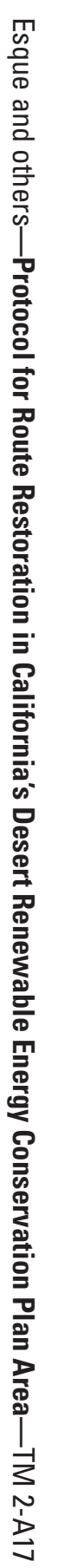

